Possible Influences of Circadian Melatonin on the Function of Neurosecretory Neurons and Serotonin-Modulated Behavior on Crayfish.

Dissertation zur Erlangung des mathematisch-naturwissenschaftlichen Doktorgrades

"Doctor rerum naturalium" der Georg-August-Universität Göttingen

Vorgelegt von

Abud José Farca Luna

Aus Mexiko Stadt (Mexiko)

Göttingen 2008 
Anleiter: Dr. Ralf Heinrich

Referent: Dr. Rüdiger Hardeland

Korreferent: Dr. Thomas Reischig

Tag der mündlichen Prüfung: 17.Oktober.2008 


\section{STATEMENT OF ORIGINALITY:}

I declare that this thesis is my own work and contains nothing which is the outcome of work done in collaboration with others, except as a specified in the text and Acknowledgements.

The thesis submitted has been written independently with no other sources and aids than quoted, and never been submitted for a degree or other qualification at any other University. 


\section{ACKNOWLEDGEMENTS}

I would like to express my sincere gratitude to Dr. Ralf Heinrich for giving me the opportunity of working in his laboratory and having accepted me as a $\mathrm{PhD}$ student. Thanks for your patience, your support and your advice. I am also very grateful to Prof. Dr. Hardeland and Dr. Reischig who have been very supportive during the working process of my thesis and who offered me guidance whenever I needed it.

Thanks also to Prof. Dr. Elsner, Dr. Grass, Dr. Stumpner. and Dr. Poeggeler, to my colleagues and the technicians: Margaret Winkler, Patricia Sprysch and Mathias Schink thanks for the friendly working atmosphere. Also, thanks to Joaquin Hurtado Zavala for his help in aggression experiments. It was a pleasure to work with all of you..

I would also like to express my special thanks to Deutsche Akademische Austauschdienst (DAAD) for having giving me the opportunity of getting to know a new country, of learning a new language and of pursuing my academic career. I also want to express my gratitude to faculty and students of the Center for Sytems in Neuroscience "ZNV" for giving me the opportunity to take part of this program.

Furthermore, I would like to thank Dr. Henrik Oster for having enabled me to do some research in his laboratory and for getting to know the nice people of his lab. Moreover, I am grateful as ever for the ongoing scientific support from my former colleagues and teachers at UNAM in Mexico City, in special to Dr. Fanjul, Dr. Elsa Escamilla and M in Sc. Julio Prieto.

I would like to express my deepest gratitude to my parents Jose and Mercedes, my brother Isaac, my sisters Teresa and Sara and to my wife who have always supported and believed in me as well as family and friends in Mexico, Switzerland and Germany. I am especially grateful to my wife Mira who has stood at my side for the past 4 years and who has always been an inspiration. 
To my Family 


\section{TABLE OF CONTENTS}

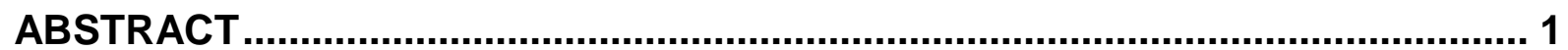

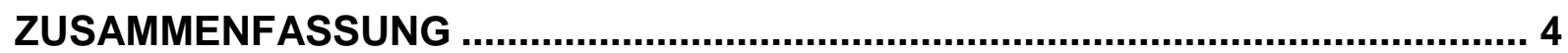

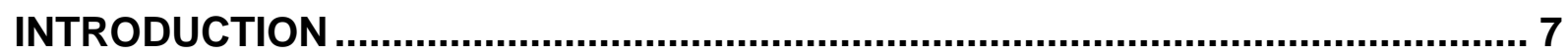

Crayfish as model for the study of circadian rhythms ....................................................... 7

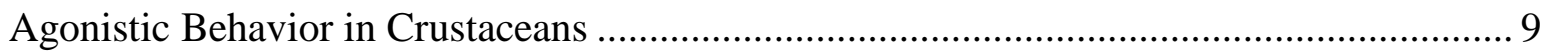

Circadian Systems in arthropods and the function of PDH.......................................... 12

Serotonin and its metabolites: $N$-acetylserotonin and Melatonin in circadian systems ....... 16

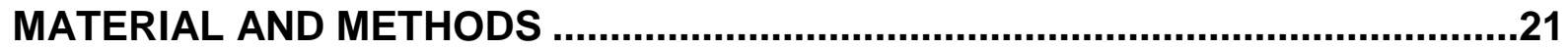

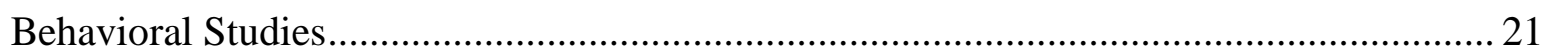

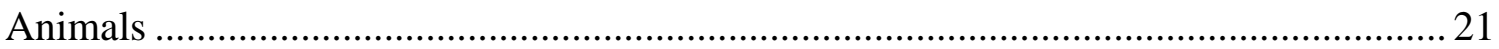

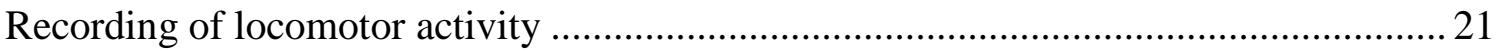

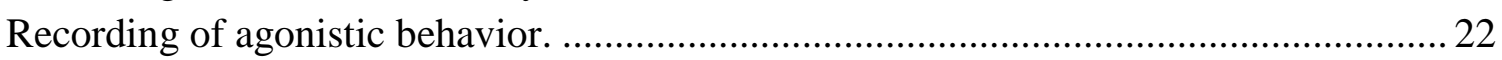

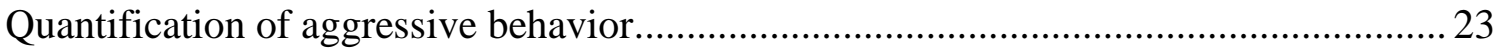

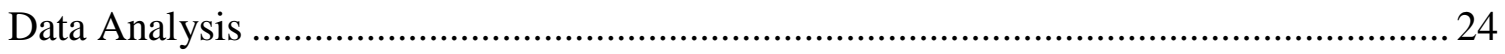

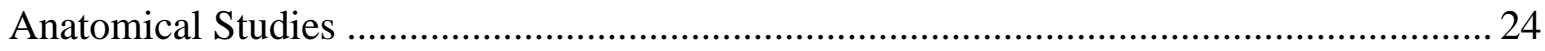

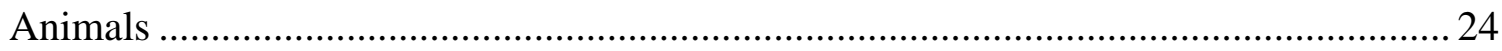

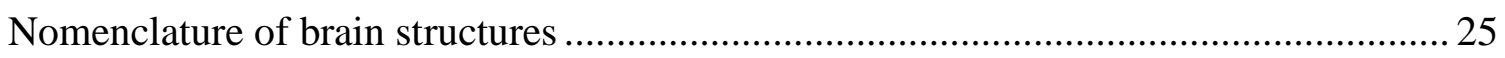

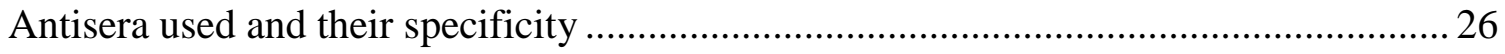

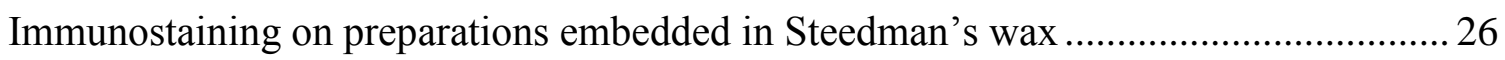

Immunostaining on preparations embedded in gelatin/albumin ................................ 27

Immunofluorescent staining for multi-labeling experiments ..................................... 28

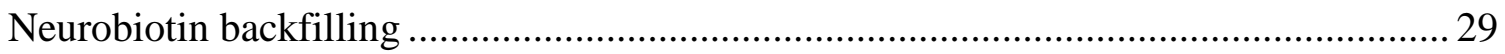

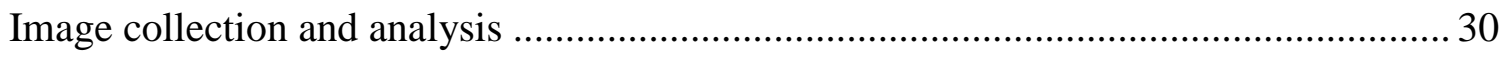

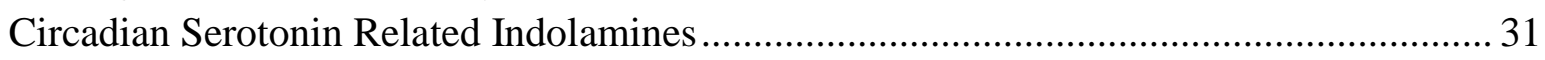

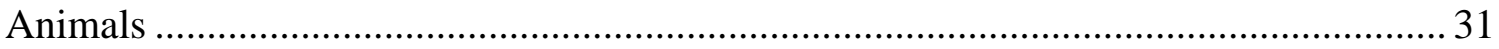

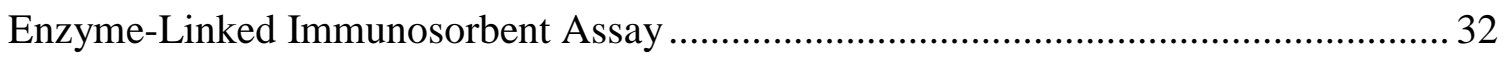

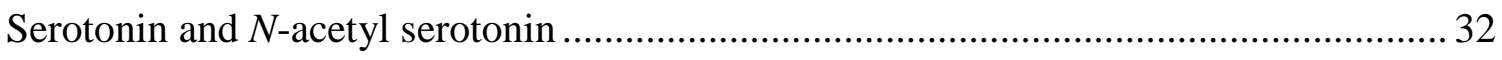

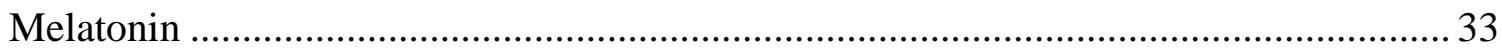

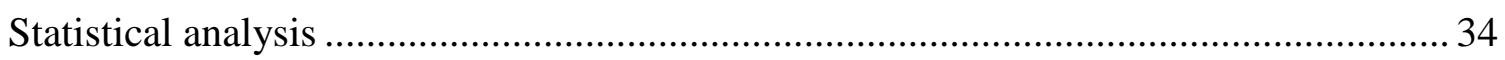

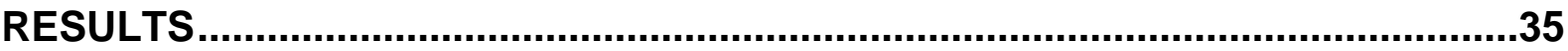

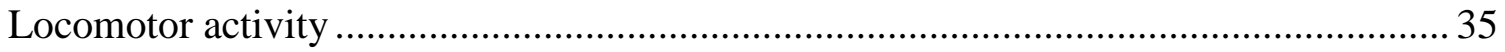

Agonistic behavior and establishment of hierarchies in crayfish groups ......................... 36

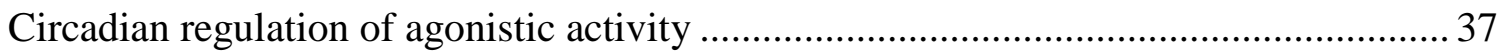

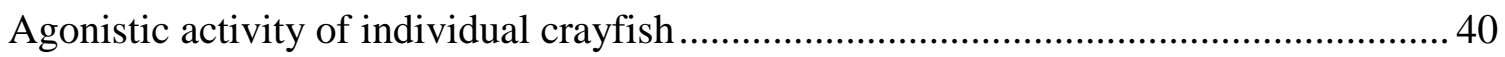

PDH expressing neurons in the brain of the marbled crayfish..................................... 42

FMRF expressing neurons in the eyestalk and brain of the marbled crayfish ................. 47

Colocalization of FMRF- and PDH-ir in the eyestalk .............................................. 50

Backfills reveal centrally projecting PDH-neurons of the eyestalk ...............................52

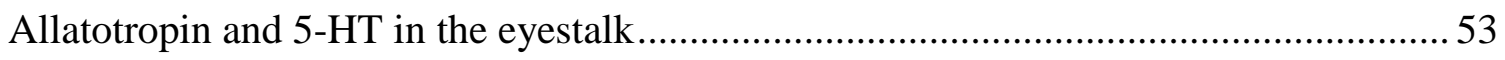

Serotonin, NAS and Melatonin diurnal concentrations in brain and eyestalks................58

The marbled crayfish as a model for analysis of circadian rhythms in crustacea ................ 64 
Behavioral rhythms in the marbled crayfish Procambarus spec. ...................................... 65

Diurnal and circadian cotrol of locomotor activity and agonistic behavior ..................... 65

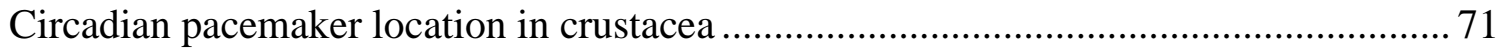

Are PDH-neurons of the eyestalk homologous to insect PDFMe/LNv? ......................... 76

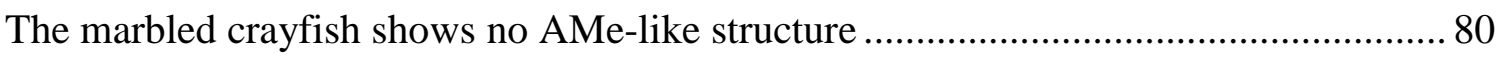

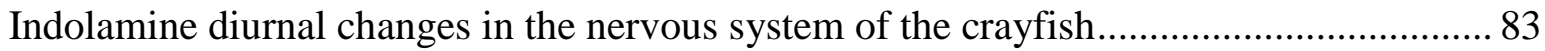

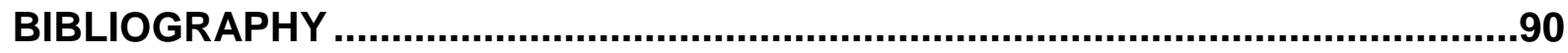




\section{$\underline{\text { ABSTRACT }}$}

Crustaceans have frequently been used to study the neuroethology of diverse function as agonistic behavior and circadian rhythms. Whether the highly stereotyped and quantifiable agonistic activity in crustaceans is controlled by circadian pacemakers has so far not been investigated. In order to address this question, I introduce the marbled crayfish (Procambarus spec.), an easy to breed parthenogenetic decapod crustacean of unknown regional origin, as a new preparation for neuroethological studies. Isolated marbled crayfish displayed rhythmic locomotor activity under 12 hours light-12 hours darkness (LD12:12) and rhythmicity persisted after switching to constant darkness (DD) for nine days, suggesting the presence of endogenous circadian pacemakers. Isogenetic females of parthenogenetic marbled crayfish displayed all behavioral elements known from agonistic interactions of previously studied decapod species including the formation of hierarchies. Previously isolated marbled crayfish initially displayed high numbers of agonistic encounters during the first hour of their cohabitation in groups of six animals. With the formation of hierarchies, the frequency of agonistic encounters was reduced to low levels. Group agonistic activity was entrained to periods of exactly 24 hours under LD12:12 and peaks of agonistic activity coincided with light-to-dark and dark-to-light transitions. After switching to DD, enhanced agonistic activity was only observed at times corresponding with light to dark transitions during the preceding three days in LD 12:12. During four days under DD, agonistic activity remained rhythmic with an average circadian period of $24.83 \pm 1.22 \mathrm{~h}$ in all crayfish groups tested. Analysis of individual agonistic activities revealed that the most dominant crayfish participated in more than half of all agonistic encounters within the group and initiated most of them. Only the most dominant crayfish revealed clear endogenous rhythmicity in their agonistic behavior. Subordinate individuals, depending on their social rank, initiated only between 19.4 and 0.03 $\%$ of all encounters in constant darkness and displayed no statistically significant rhythmicity. The results indicate that both, locomotion and agonistic social interactions are rhythmic behaviors of marbled crayfish, which are controlled by light-entrained endogenous pacemakers. The availability of isogenetic populations of marbled crayfish may foster the future analysis of these pacemakers in crustaceans.

Crustaceans and insects appear to be sister groups, but their circadian systems seem to differ in degrees of centralization of pacemaker centers in their brains. However, also in 
Crustacea at least part of the circadian control resides in the optic lobes. In insects, optic lobe pacemaker neurons reside in a specialized neuropil, the accessory medulla (AMe). The insect AMe is innervated by neurons expressing the neuropeptide pigment-dispersing factor (PDF), and because of that it is known as PDFMe. PDF is homologous to the crustacean pigmentdispersing hormone $(\mathrm{PDH})$, which in crustacea is expressed in a variety of brain neurons. With combined immunocytochemical and backfill studies, I identified neural structures in the marbled crayfish that probably correspond to the insect optic lobe circadian pacemaker. In this work, the PDH-expressing neuron system of the crayfish was studied in eyestalks and brain, and results show a tripartite $\mathrm{PDH}$-ir neuron cluster that appeared to be homologous to the insect PDFMe according to the homology criteria of similar position and neurochemical quality. However, I did not find a structure comparable to the insect AMe, thus leading to the assumption, that the insect $\mathrm{AMe}$ is a newly attained structure in the evolution of the insect optic lobe, which was not present in the common ancestor of crustaceans and insects. This work opens first insights into the evolution of the arthropod circadian system and presents new valuable information about the location of circadian pacemakers in crustaceans.

Melatonin, the classical time messenger of vertebrates, is present in most organisms studied so far. In the melatonin biosynthetic pathway, the indoleamines serotonin (5-HT) and $\mathrm{N}$-acetylserotonin (NAS) are formed from 5-hydroxytryptophan. Serotonin is important for a variety of functions, in both vertebrate and invertebrate animals. In contrast, the knowledge about potential functions of $\mathrm{N}$-acetylserotonin and melatonin in invertebrates is relatively limited. In this work, I adapted an ELISA procedure for the analyses of crustacean tissues, in order to measure serotonin, $\mathrm{N}$-acetylserotonin and melatonin in the brain and eyestalks of the marbled crayfish Procambarus spec. over a complete daily cycle (LD12:12). Serotonin showed mean levels in the range of $21.05 \pm 0.93 \mathrm{ng} / \mathrm{ml}$ in brains and $6.75 \pm 0.36$ (mean \pm SEM) $\mathrm{ng} / \mathrm{ml}$ in eyestalks. NAS concentrations were slightly lower than those of serotonin with $5.65 \pm 0.29 \mathrm{ng} / \mathrm{ml}$ in brains, and $3.12 \pm 0.23 \mathrm{ng} / \mathrm{ml}$ in eyestalks. Strikingly, melatonin showed levels 1000 times lower than NAS, in brains $30.82 \pm 1,61$ and in eyestalks $21.66 \pm$ $1.54 \mathrm{pg} / \mathrm{ml}$. Significant changes between minima and maxima over one day cycle were found for serotonin and melatonin levels in both central nervous structures. NAS differences were not significant in both structures, but in eyestalks they were very close to significance. Cosinor analysis did not show a significant $(\mathrm{p} \leq 0.05)$ fit to a sinusoid with a period of $24 \mathrm{~h}$, but significance was close to be reached in some cases. These results enable some assumptions about the biosynthesis of melatonin in the nervous system of arthropods, 
specifically in the crayfish Procambarus espec. This is the first time that NAS is measured in arthropods and provides new insights into metabolic pathways that form melatonin in invertebrates. 


\section{ZUSAMMENFASSUNG}

Krebse sind bevorzugte Präparationen für neuroethologische Studien zur Verhaltenskontrolle und zur Untersuchung circadianer physiologischer Rhythmen. Ob das in verschiedenen Krebsarten beschriebene stereotype agonistische Verhalten durch circadiane Schrittmacher kontrolliert wird, habe ich Gruppen von parthenogenetisch reproduzierenden Marmorkrebsen (Procambarus spec.) unter verschiedenen Beleuchtungsbedingungen beobachtet. Wie andere Krebse auch, zeigten isolierte Marmorkrebse rhythmische Lokomotionsaktivität unter regelmäßigen Licht-Dunkel-Wechseln (LD12:12), die über neun Tage im Dauerdunkel (DD) aufrechterhalten wurde. Dies deutete auf die Präsenz endogener circadianer Schrittmacherzentren hin, welche die rhythmische Aktivität unter konstanten Bedingungen aufrechterhielten.

Isogenetische Marmorkrebsweibchen führten alle typischen Elemente des bei anderen dekapoden Krebsen beschriebenen agonistischen Verhaltens durch und etablierten stabile, weitgehend lineare Hierarchien. Gruppen von jeweils sechs zuvor isolierten Marmorkrebsen führten zunächst hohe Anzahlen agonistischer Interaktionen mit vergleichsweise hoher Intensität durch, in denen der relative Dominanzstatus der Tiere untereinander festgestellt wurde. Mit Etablierung der Hierarchien sanken Anzahl und Intensität agonistischer Interaktionen, da rangniedere Tiere zunehmend Kämpfen mit der ranghöheren Tieren auswichen. Eine individuelle Analyse der agonistischen Aktivität innerhalb der Krebsgruppen zeigte, dass das absolut dominante Individuum an etwa der Hälfte aller Kämpfe beteiligt war und die meisten dieser Konfrontationen selbst initierte.

Unter LD12:12 Bedingungen war die agonistische Aktivität der Gruppe genau mit dem 24 Stunden Rhythmus des Lichtwechsels synchronisiert, wobei der Beginn der Perioden mit erhöhter agonistischer Aktivität dem Licht-an Stimulus folgte und dem Licht-aus Stimulus antizipatorisch vorausging. Nach Wechseln zu konstanter Dunkelheit (DD) trat eine erhöhte agonistische Aktivität nur noch zum Zeitpunkt des vorherigen Beginns der Dunkelphase auf. Ein circadianer Rhythmus dieser Aktivität wurde über die gesamte Beobachtungsdauer von vier Tagen in DD mit einer durchschnittlichen Periodendauer von $24,83 \pm 1.22$ Stunden aufrechterhalten. Im Gegensatz zur rhythmischen Aktivität der untersuchten Gruppen zeigte nur der absolut dominante Flusskrebs einen signifikanten endogenen Rhythmus seiner agonistischen Aktivität. Subordinate Krebse beteiligten sich, je nach Rang in der Hierarchie 
nur an 19,4 bis 0,03\% der gesamten agonistischen Interaktionen und zeigten dabei keinen statistisch signifikanten Rhythmus. Die Ergebnisse deuten darauf hin, dass neben der Lokomotion isolierter Krebse auch das von mindestens zwei Individuen abhängende agonistische Verhalten von Marmorkrebsen durch endogene circadiane Schrittmacher kontrolliert wird, die durch den exogenen Lichtwechsel synchronisiert werden.

Krebse und Insekten sind zwar phylogenetisch verwandte Gruppen, zeigen aber Unterschiede in der funktionellen Organisation ihrer zirkadianen Systeme. Bei Krebsen scheinen mehrere, miteinander wechselwirkende lokale Schrittmacher vorzuliegen, die zumindest teilweise in den optischen Loben lokalisiert sind. Insekten scheinen dagegen ein zentralisierteres circadianes System zu haben, deren Hauptkomponenten in einem spezialisierten Neuropil in den optischen Loben zusammengefasst sind, der Akzessorischen Medulla (AMe). Die AMe der Insekten ist durch Neurone innerviert, die das Neuropeptid Pigment Dispersing Factor (PDF) exprimieren und deshalb PDFMe genannt werden. PDF ist dem Crustacean Pigment Dispersing Hormone (PDH), homologe das bei Krebsen in verschiedene Neuronen exprimiert wird. Mit Hilfe der Immunohistochemie und Backfill Technik konnte ich im Hirn des Marmorkrebses Strukturen identifizieren, die möglicherweise ähnlich zu Schrittmachern den optischen Lobus der Insekten sind. In diese Arbeit wurde das gesamte PDH Neuronensystem im Augenstiel und Hirn des Marmorkrebsens identifiziert, wobei die Ergebnisse auf dreifach PDH-immunoreaktive Gruppen hinweisen, die aufgrund Homologie Kriteriums der ähnlichen Position und spezifischen Qualität homolog zum den Insekten PDFMe homologe zu sein scheinen. Trotzdem wurde keine ähnlich Struktur zu den Insekten AMe gefunden, was darauf hinweist dass die Insekten AMe eine neue Struktur der optische Lobe ist, die nicht in den gemeinsamen Vorfahren der Insekten und Krebsen präsent war. Diese Arbeit öffnet eine neue Sicht auf die Evolution des zirkadianischen Systems der Arthopoda und liefert neue Information über den möglichen Sitz der zirkadianischen Schrittmacher in Krebsen.

Melatonin, der klassische Zeitsignal Botenstoff der Saugetiere, ist in den meisten aller untersuchten Organismen präsent. Der Biosynthese Weg des Melatonins umfasst als Zwischenstufen die Indolamine Serotonin (5-HT) und $N$-acetylserotonin (NAS), welche aus 5-Hydroxytryptophan synthetisiert werden. Serotonin spielt eine wichtige Rolle in verschiedene Funktionen bei Vertebraten und Wirbellosen. Trotzdem, sind die Kenntnisse über Invertebraten $N$-acetylserotonin relative begrenzt, und auch für Melatonin werden weitere Analyse benötigt um genauere Aussagen über seine Funktionen treffen zu konnen. In 
dieser Arbeit wurde ein ELISA Protokoll adaptiert um rund um die Uhr (in LD12:12) Melatonin, $\mathrm{N}$-acetylserotonin und Serotonin aus Hirn und Augenstiel des Marmorkrebses Procambarus spec. zu messen.

Serotonin wurde durchschnittliche Konzentrationen von 21,05 \pm 0,93 ng/ml im Hirn und $6,75 \pm 0.36$ (mean $\pm \mathrm{SEM}$ ) ng/ml im Augenstiel gefunden. Die NAS Konzentrationen waren, mit 5,65 $\pm 0,29 \mathrm{ng} / \mathrm{ml}$ im Hirn und 3,12 $\pm 0,23 \mathrm{ng} / \mathrm{ml} \mathrm{im}$ Augenstiel etwas kleiner als die von Serotonin. Auffälliger weise wurde Melatonin in einer 1000 mal niedrigeren Konzentrationen als NAS detektiert, im Hirn $30.82 \pm 1,61$ und in Augenstiel 21,66 $\pm 1,54 \mathrm{pg} / \mathrm{ml}$. Ein signifikanter Unterschied zwischen den Minima und den Maxima des Melatonins und Serotonins in einem Tages Zyklus wurden in beide Strukturen gefunden. Die NAS Konzentrations-unterschiede waren in beiden Strukturen nicht Signifikant gefunden. Mittels Cosinor Analyse wurde keine signifikante $(\mathrm{p} \leq 0.05)$ Abweichung von einer Sinuskurve mit 24 Stunden Periodenlänge gefunden, wenngleich einige Werte nahe der Signifikanzschwellelagen. Diese Ergebnisse fordern zu den Annahmen nach der Biosynthese Weg des Melatonins im Nervensystem der Arthropoda, bzw. der Flusskrebs Procambarus spec. Die vorliegende Arbeit misst zum ersten mal NAS in Arthropoden und liefert neue Erkenntnis über den metabolische Wege der Melatonin Synthese in Wirbellosen. 


\section{INTRODUCTION}

\section{Crayfish as model for the study of circadian rhythms}

Arthropods including insects and crustaceans have been extensively used to study the basis of circadian rhythms emerging from endogenous mechanisms that repeat itself with periods of approximately 24 hours under constant environmental conditions (Helfrich-Forster, 2005; Vansteensel et al., 2008). In crustaceans, no single central nervous structure seems to possess the complete features of a central circadian pacemaker ("master clock"). Rather, circadian rhythmicity is controlled by multiple independent pacemakers, situated in the eyestalks, the retina, and the supraoesophageal ganglion, which in the intact animal interact by neural and humoral pathways (Pollard and Larimer, 1977; Barrera-Mera and Block, 1990; Arechiga et al., 1993). Circadian rhythms have been reported for various physiological functions and behaviors in a number of crustacean species. Endogenous circadian pacemakers modulate the sensitivity of sensory organs like the eyes (Arechiga et al., 1974) and caudal photoreceptors (Rodriguez-Sosa et al., 2008), determine the movements of pigments (Webb and Brown, 1965) and regulate blood sugar (Reddy et al., 1981; Tilden et al., 2001), glutathione levels (Duran-Lizarraga et al., 2001), the capacity to take up oxygen (Fingerman and Lago, 1957; Reddy, 1991) and the activity of effector systems such as heart rate and ventilation (Pollard and Larimer, 1977; Hernandez-Falcon and Ramon, 1998; Farca Luna, 2004). Most behavioral studies investigated spontaneous locomotor activity and found a robust circadian rhythm with maxima at the beginning and ongoing activity throughout dark phases (Schallek, 1942; Palmer, 1971; Page and Larimer, 1972; Fanjul-Moles et al., 1996; 
Miranda-Anaya and Fanjul-Moles, 1997). In addition, plugging of burrows has also been demonstrated to be controlled by circadian pacemakers (de la Iglesia et al., 1994).

Despite of the profuse knowledge about circadian rhythms in crustaceans, just the exact location(s) of the circadian pacemaker(s) together with their entrainment, synchronization, and output pathways are virtually unknown in these animals. To unveil pacemaker locations in crustaceans, ablation, surgical interference, and in vitro studies were performed by various authors (Arechiga and Rodriguez-Sosa, 1998; Saenz et al., 1997). Most of these studies pointed to the eyestalks and central brain as potential structures to contain circadian pacemakers. However, from those studies derived ambiguous information; e.g., if eyestalks were ablated, some circadian rhythmic parameter were abolished or at least altered, but other remained intact (reviewed by Arechiga et al., 1993; Fanjul-Moles and Prieto-Sagredo, 2003; Barrera-Mera et al., 1980). In one of the earlier studies, the central brain was proposed to control the electroretinogram (ERG). However, later experiments indicated that circadian changes in ERG amplitude appeared to be locally controlled by the retina, since explanted retinae and eyestalks in vitro showed intact circadian rhythms of ERG amplitude (Arechiga and Rodriguez-Sosa, 1998). These results supported the idea that ERG rhythms are controlled rather by the eyestalk than by the circumesophageal ganglion. Similarly, glycemic responses in protocerebrum ablated animals displayed a circadian response similar to that of intact animals. However, the sudden response produced by asphyxia in intact animals was suppressed in operated animals (Puche and Barrera-Mera, 1993). In the same way, locomotor activity has been analyzed after extraction or damage of the eyestalks or brain. In initial studies, locomotor activity increased but was arrhythmic after removal of the optic lobes (Kalmus, 1938). Later experiments refuted those observations, when locomotor activity remained rhythmic after eyestalk removal. However, when the circumesophageal connectives were lesioned, rhythmic locomotor activity vanished. Contrary to this report, rhythmic 
locomotor activity continued after brain removal (Fuentes Pardo and Inclan Rubio, 1981). Since these functional studies were unable to determine the central nervous location of the circadian pacemakers in crustaceans new approaches should combine behavioral, physiological and anatomical techniques.

The molecular mechanisms of circadian pacemaker cells could be largely elucidated in a variety of invertebrate and vertebrate animals (reviewed by Stanewsky, 2002; Bell-Pedersen et al., 2005; Siepka et al., 2007; Vansteensel et al., 2008). As components of these mechanisms, several genes and proteins are well conserved in taxa that are evolutionary separated for more than 500 million years. In crustacea, efforts have been undertaken to locate circadian pacemakers by identification of canonical circadian genes and their products. Immunostaining of the clock elements PER (period protein) and CRY (cryptochrome protein), revealed evidence for their presence in the nervous system of crayfish (Arechiga and Rodriguez-Sosa, 1998; Fanjul-Moles et al., 2004). Despite the advances of genetical approaches in the last decades, the genetic information in decapods is relatively scarse, and so far only the gene clock from the prawn Machrobrachium rosenbergii has been sequenced (Yang et al., 2006).

\section{$\underline{\text { Agonistic Behavior in Crustaceans }}$}

Arthropod species have also been used to study the neural basis of aggression, since they display prominent sequences of actions during intraspecific competition for territories, shelters, food and mating partners (crickets: (Stevenson et al., 2005; Iwasaki et al., 2006); fruit flies: (Chen et al., 2002; Nilsen et al., 2004; Dierick and Greenspan, 2006); lobsters: (Heinrich et al., 2000; Huber and Kravitz, 1995; Kravitz, 2000); crayfish: (Huber et al., 
1997a; Edwards et al., 2003); crabs: (Sneddon et al., 2000). However, no study has explored a possible circadian rhythm of agonistic behavior in crustaceans. A functional link between crustacean circadian pacemakers and agonistic behavior may be established by the biogenic amine serotonin, which has been shown to enhance aggressive motivation in lobster and crayfish (Huber et al., 1997b; Huber et al., 1997a; Doernberg et al., 2001). Serotonin releasing neurons in the cerebral ganglion and the eyestalks, as well as serotonergic neurons that innervate the neurosecretory X-organs have been demonstrated to periodically change their activity in parallel to the circadian modulation of visual sensitivity, controlling the realease of neuropeptid hormones. Further, serotonin is suggested to play a role in other physiological functions under circadian control (Arechiga et al., 1990; Saenz et al., 1997; CastanonCervantes et al., 1999). In addition, lesions in protocerebral projection areas of serotonergic neurons caused changes in patterns of circadian behavioral activity (Reddy, 1991). Therefore, serotonin may serve as a circadian modulated signal in addition to its established role in the regulation of agonistic behavior.

Whether levels of aggression fluctuate on a circadian timescale has not been thoroughly investigated in invertebrates, although one study on cockroaches reported increased agonistic behavior during the dark portion of the photocycle (Breed et al., 1975). Only some studies on vertebrate species including fish (Radilova et al., 1991), rodents (Landau, 1975; Russell and Singer, 1983) and monkeys (Martensz et al., 1987) addressed this question and found enhanced agonistic activity during particular periods. Nonetheless, whenever periods of enhanced aggression coincide with periods of increased general activity, a potential direct regulation of neural circuits that control aggressive behavior by circadian pacemakers is difficult to assess. In humans, peaks of aggression against other patients and hospital staff has been observed in psychiatric patients (Manfredini et al., 2001) and aggressive offences occur more frequently during evenings and at night (Laubichler and Ruby, 1986). 
Periodic changes of aggression have been demonstrated for the molting cycle of lobsters, with highest levels occurring shortly before the next molt (Tamm and Cobb, 1978; Cromarty et al., 2000). Agonistic behavior, including the formation of stable hierarchies, has been studied in a number of decapod crustaceans. It is performed in order to conquer, defend, or provide future access to limited resources such as territories, shelters, food, or mating partners (Archer, 1988; Ranta and Lindström, 1993; Goessmann et al., 2000; Stocker and Huber, 2001; Herberholz et al., 2007) and consists of stereotype individual actions and postural components that can be associated with different levels of aggression (Huber and Kravitz, 1995). Size and body weight have been identified as the major predictors for the outcome of agonistic confrontations (Berrill and Arsenault, 1984), but experience from previous fights can profoundly alter the motivation for agonistic interactions for up to several days (Karavanich and Atema, 1998; Rutishauser et al., 2004) . While most studies on agonistic behavior of crustaceans used pairs of animals to observe and quantify the details of their interactions, few studies investigated the formation and persistence of hierarchies within small groups of individually labeled crayfish (Bovbjerg, 1953; Issa et al., 1999; Herberholz et al., 2007). In these studies, frequent and intensive fighting followed initial grouping of crayfish, but fighting activity declined with the formation of stable hierarchies. Relative rank order within the group determined an individual's access to food and shelters. The marbled crayfish has previously been studied with regard to its anatomy, mode of reproduction, phylogeny, ecology, and development (Vogt et al., 2004; Braband A. , 2006; Alwes and Scholtz, 2006; Vilpoux et al., 2006). This species produces isogenic offspring by parthenogenetic reproduction and offers the chance to generate genetically altered lines of animals. My behavioral studies on the marbled crayfish demonstrate the presence of endogenous circadian pacemakers that modulate both, spontaneous locomotor activity and the performance of agonistic behavior including the formation of hierarchies that is very similar to previously 
described behaviors of non-parthenogenetic decapod crustaceans. As a new approach, I studied the circadian regulation of agonistic behavior in co-habitated groups of six marbled crayfish and found rhythmic peaks in the numbers of agonistic encounters coinciding with light-to-dark and dark-to-light changes. Agonistic activity remained rhythmic after switching from regular night-day cycle to constant darkness, and enhanced activity coincided with the beginning of dark phases during preceding LD 12:12 conditions. Analysis of the contribution of individual crayfish to the overall agonistic activity of the group revealed that the majority of encounters were initiated by the most dominant individual, while contributions of subordinate crayfish seemed to vary with their social rank.

\section{Circadian Systems in arthropods and the function of PDH}

Circadian pacemakers of arthropods are mainly studied in insects and their apparent sister group (Dohle, 2001; Richter, 2002), the Crustacea. In many insects, including the fruit fly Drosophila melanogaster, but also in orthopteromorph insects like cockroaches and crickets, a master clock controlling circadian behavior and eclosion rhythms is located in each of the two optic lobes, which are protocerebral brain parts processing visual information from the compound eyes (Helfrich-Forster et al., 1998). These optic lobe pacemakers communicate via neuronal connections to effector areas in the central brain. Disruption of these connections, lead in most cases, to complete and long-lasting permanent breakdown of circadian rhythmicity in behavior. In crustaceans, however, the localization of a master pacemaker controlling circadian behavior in specific brain areas has revealed more ambiguous sults as in insects. Although lesion studies in crustaceans point to the central brain as well as to the eyestalks of crustaceans as clock locations (Barrera-Mera and Block, 1990; Page and Larimer, 
1976) it is clear that crustacean eyestalk clocks are not as indispensable to sustain circadian rhythmic locomotor behavior as it is in many insects (reviewed by Fanjul-Moles and PrietoSagredo, 2003). It appears that the circadian system of crustaceans is not as centralized as in insects, but rather comprises a network of brain oscillators to create a circadian output with additional oscillators situated in the optic lobes as important part of this network.

Lesion and transplantation experiments in orthopteran insects, such as cockroaches and crickets, implied that pacemakers were confined to a small region of the optic lobe (reviewed by Helfrich-Forster et al., 1998). In a corresponding region of the optic lobe of Drosophila, a set of so-called lateral neurons (LNs) was found to be indispensable to maintain stable circadian rhythmic behavior under totally non-rhythmic environmental conditions (reviewed by (Stach, 2002). These LNs are organized in a dorsal and a ventral group (LNds and LNvs, respectively). Subsequently, the LNvs is further subdivided in 5 small and four large LNvs. The LNs express a variety of substances that are components of the molecular circadian clockwork, including Period (PER), Timeless (TIM), Clock (CLK), and Cycle (CYC). The LNvs further express the PDF, which is apparently not part of the clockwork itself, but an essential output signal. This signal provides circadian phase information from the clock neurons to downstream effectors of the central protocerebrum, including the dorsal neurons (DNs) which are clock components, too (Taghert et al., 2001; Taghert and Shafer, 2006). PDF was also found in many other non-dipteran insects to be expressed by neurons that appear to be homologous to Drosophila's LNvs, and which are also discussed as components of the circadian clock (Homberg et al., 1991a; Nässel, 1991; Frisch et al., 1996; Sauman and Reppert, 1996; Sato et al., 2002; Settembrini and Villar, 2005; Bloch et al., 2003; Sehadová et al., 2003; Závodská et al., 2003). These neurons are generally called PDF-expressing medulla neurons (PDFMe) and show a conserved morphology among all insects studied herein. This includes the position of the somata anteriorly between medulla and lobula, centrifugal 
innervation of medulla, lamina, and, in some insects, the lobula, centripetal innervation of large areas of the central protocerebrum, and commissural projections to the contralateral brain half including contralateral optic lobe. Additionally, a small neuropil compartment of the medulla near the PDFMe somata, and the accessory medulla (AMe), is densely invaded by processes of the PDFMe (Homberg et al., 1991b; Reischig and Stengl, 1996). The AMe is exceptionally rich in neuropeptides, including members of the FaRPs (FMRFamid related peptides) family and allatotropin. Contrary to other optic lobe neuropils, the AMe shows a peculiar nodular, non-retinotopic structure (Petri et al., 1995; Reischig and Stengl, 2003b; Soehler et al., 2008). This information suggests that the AMe is an integration center for timing information in insects, with the PDFMe as important pacemaker and/or output, forming an ensemble of the circadian clock (Reischig and Stengl, 2003a).

The insect PDF is homologous to the crustacean $\beta$-pigment-dispersing hormone ( $\beta$-PDH) (Matsushima et al., 2004). Both are groups of 18 -amino acid peptides with only small differences in amino acid sequences among and between each other. In crustacea, $\beta$-PDH was characterized upon its action on retinal and epidermal pigment granules (Rao and Riehm, 1989). The liberation of $\beta$-PDH from the sinus gland of the optic stalk causes migration of distal retinal pigment to a more proximal position, thus leaving the eye in a light adapted state. $\beta$-PDH and PDF are both specifically recognized by an antiserum against synthetic Uca$\beta$-PDH (Dircksen et al., 1987). In insects, this antiserum labels the PDFMe (as described above) and, in most non-dipteran insects, two groups of neurons that are situated at the posterior lamina (dorsal and ventral PDFLa). Furthermore, only in a few species some neurons of the central protocerebrum are labeled by the antibody (Dircksen et al., 1987; Frisch et al., 1996; Pyza and Cymborowski, 2001; Nässel et al., 1991; Sauman and Reppert, 1996; Sato et al., 2002; Settembrini and Villar, 2005; Bloch et al., 2003; Sehadová et al., 2003; Závodská et al., 2003). In crustaceans, the anti-Uca- $\beta$-PDH labels several groups of 
neurons in the optic stalks, central brain, and stomatogastric system (Mangerich et al., 1987; Mangerich and Keller, 1988). Thus, the system of PDH-neurons in crustacea is larger and more complex than in insects and comprises neuroendocrine optic stalk neurons releasing PDH to facilitate pigment migration via the sinus gland, as well as a number of optic stalk and central brain neurons utilizing PDH as a paracrine neuromodulator. In this context it is very interesting that recent studies point to a function of PDH in the circadian system of crustacean species, additionally to the known function of $\mathrm{PDH}$ as a circadian driven output signal for daily pigment migration cycles (Verde et al., 2007).

The well-conserved structure of the $\beta$-PDH/PDF peptides in crustaceans and insects, together with functions in their circadian systems, led us to the question about a possible common origin of the circadian systems of both taxa. In particular I was interested in which of the PDH-ir neuron groups of crustacea could be homologous to the PDF neurons found in insects. That information could lead to the recognition of the cricadian pacemaker in crustaceans and may identify a homologous structure to the insect AMe in the crustacean optic lobe. I performed immunohistological and backfill studies in brains of the marbled crayfish (Procambarus spec.), a parthenogenetic fresh water dwelling decapod crustacean, which is of increasing importance as a new model organism to study crustacean physiology and neurobiology. I first fully reconstructed the PDH-ir and FMRFamid-ir neuron systems of the brain. Due to positions of somata, projection patterns, and colocalization of immunoreactive labeling, I identified subgroups of PDH-ir neurons of the optic lobe as possible homologues to the insect clock neurons. However, I did not find a structure in the optic lobe of the marbled crayfish that resembles the insect AMe. My results support a hypothesis of a rather dispersed circadian network in the predecessors of the crustacea/insect taxon, the Tetraconata, which includes PDH/PDF expressing neurons, and the formation of the AMe as a new brain area for processing timing information in insects. Centralized versus 
dispersed circadian systems in insects and crustaceans respectively might reflect different adaptational requirements of this two groups.

\section{$\underline{\text { Serotonin and its metabolites: } N \text {-acetylserotonin and Melatonin in }}$} circadian systems

Melatonin is formed from the amino acid tryptophan via 5-hydroxytryptophan. Upon decarboxylation of the last compound, numerous metabolites can be produced, among which the ubiquitous neurotransmitter serotonin is frequently in the focus of interest. In the course of melatonin formation, serotonin is usually first $\mathrm{N}$-acetylated by specific arylalkylamine $\mathrm{N}$ acetyltransferases (AA-NATs) or, alternately, by less specific $\mathrm{N}$-acetyltransferases (Hardeland and Poeggeler, 2003; Hardeland et al., 1993). This step is followed by O-methylation, catalyzed by a specific hydroxyindole O-methyltransferase (HIOMT) or less specific other Omethyltransferases. This pathway of melatonin biosynthesis seems to be highly conserved, because it can be found in organisms as different as dinoflagellates, fungi and vertebrates (Hardeland et al., 2007; Hardeland and Poeggeler, 2003). It can be generally stated that melatonin is present in numerous, phylogenetically distant taxa, from bacteria and eukaryotic unicells to macroalgae, plants, fungi and animals (Hardeland et al., 1996; Pandi-Perumal et al., 2006; Hardeland et al., 2007). As a few examples for the formation of melatonin in members of invertebrate groups, the sea anemone Renilla koellikeri (Mechawar and Anctil, 1997), the planaria Dugesia dorotocephala (Morita et al., 1987), the mollusc Sepia officinalis, and, among several arthropods, the insect Locusta migratoria and the crustacean Carcinus maenas (Vivien-Roels and Pévet, 1986) can be mentioned. 
In vertebrates, melatonin is considered to convey a chemical message on phase position and duration of the dark phase within the 24-h cycle, from the central nervous system to the rest of the body, thereby participating in precise internal timekeeping within the organism (Vivien-Roels and Pévet, 1986; Vivien-Roels and Pévet, 1993). Melatonin was first discovered as a hormone of the pineal gland (Lerner et al., 1960). Meanwhile various other sites of formation are known in the vertebrate body, in particular, retina, Harderian gland, bone marrow, gastrointestinal tract. Nevertheless, the role of melatonin released from pineal has to be distinguished from that locally present in other organs. Melatonin synthesis in the mammalian pineal gland is under control of the SCN, the circadian master clock. The SCN is synchronized to external light received by the eyes and transmitted via the retinohypothalamic tract. The information is further mediated to the paraventricular nuclei, upper thoracic cord, superior cervical ganglion and its postganglionic sympathetic fibers to the pineal (Reiter, 1993). In all vertebrates, melatonin production and secretion by the pineal gland increase during night, resulting from a nocturnal upregulation of its rate-limiting enzyme AA-NAT (Figure 1). Melatonin is released both to the circulation and, via the pineal, to the third ventricle of the brain (Tricoire et al., 2002). Since melatonin is secreted in a circadian manner, it can act as an internal synchronizing element of physiological, endocrinological and behavioral functions (Tamarkin et al., 1976). Moreover, melatonin feeds back to the SCN, which is a major site of membrane-bound, $\mathrm{G}$ protein coupled melatonin receptors $\mathrm{MT}_{1}$ and $\mathrm{MT}_{2}$ (Reppert, 1997). Irrespective of whether a species is diurnal or nocturnal, melatonin production in the pineal is always maximal in the dark phase (Kumar, 1997).

In addition, animals can determine the time of the year by measuring daily changes in melatonin production, a type of photoperiodism based on the scotophase-dependent width of of the day and the time of the year (daily and seasonal time) (Reiter, 1992; Reiter, 1993). 


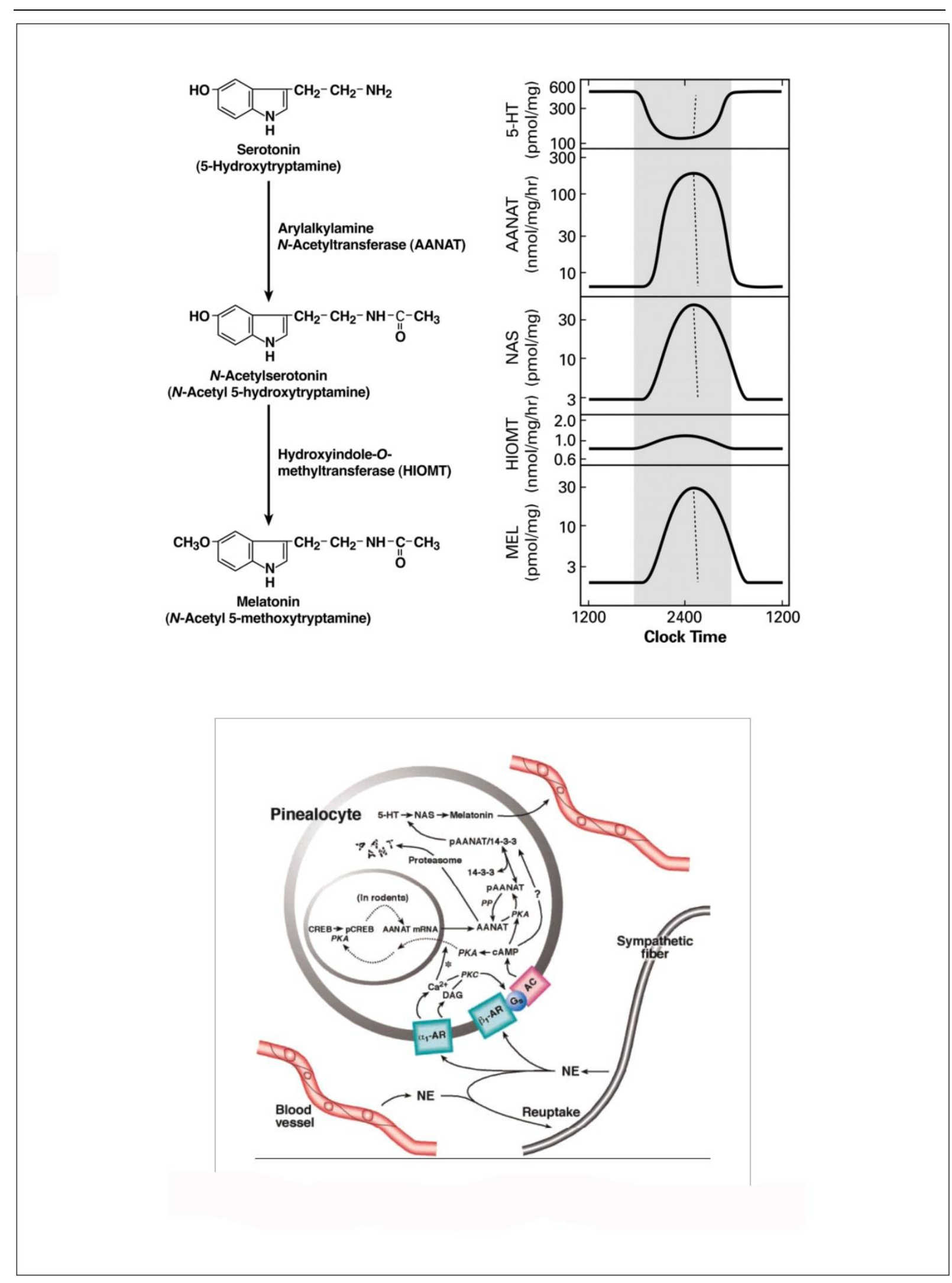

Figure 1. Schematic representation of the melatonin biosynthetic pathway in mammals, with the activity of the two enzymes involved: Arylalkylamine $N$-acetyltransferase AA-NAT and hydroxyindole-O-methyltransferase (HIOMT) (Ganguly et al., 2002). 
The presence of melatonin has been reported for some insects and crustaceans (Callebert et al., 1991; Vivien-Roels and Pévet, 1993; Finocchiaro et al., 1988). In the fruitfly, Drosophila melanogaster, the same biosynthetic pathway of melatonin as found in vertebrates, has been suggested to be present in both larvae and adults (Finocchiaro et al., 1988). In the silkworm, Bombix mori, a circadian rhythm of melatonin content was found, having a nocturnal peak in haemolymph and head a periodicity that disappeared in constant light (Itoh et al., 1995a). Similarly, melatonin was highest during scotophase in the nervous system of Trichoplusia ni, in particular in the protocereburm, optic lobes, subesophageal ganglion and thoracic ganglia (Linn et al., 1995). Other arthropods showed higher levels of melatonin at different timepoints of the day and in different tissues. The damselfly Ischnura verticalis showed rhythmic melatonin concentrations relative to body mass, with peaks in the photophase (Tilden et al., 1994). On the other hand, Enallagma civile and Acyrthosiphon pisum did not show significant changes in melatonin concentration between scotophase and photophase (Tilden et al., 1994), but in the latter species, orally administered melatonin induced the production of virginoparus/oviparous intermediate females (Hafner et al., 1980). In Gryllus bimaculatus, some tissues showed higher melatonin levels during scotophase (eyes, brain and palps), but other tissues such as cerci, ovipositors, hindlegs, ovaries and Malpighian tubules exhibited melatonin maxima during photophase (Itoh et al., 1995b). Seasonal changes of melatonin contents are also known. Heads and abdomina of the honey bee, Apis mellifera, contained significantly higher amounts of melatonin during winter than during summer (Meyer-Rochow and Vakkuri, 2002). In the blood-sucking bug, Rhodnius prolixus, melatonin was shown to vary diurnally in the hemolymph. Larvae arrested in the last instar showed a strong diurnal rhythm of melatonin that was lost when animals started adult development (Farca Luna, 2004). However, this rhythm reappears in fully developed adult animals (Gorbet and Steel, 2003). In other arthropods, such as crustaceans, melatonin has 
been studied, too. In the giant prawn, Machrobrachium rosenbergii, NAT activity and melatonin levels were subject of investigation showing higher levels of the indoleamine in the optic lobe during the middle of photophase, while lowest levels occurred during scotophase. In this report, NAT activity did not show diurnal variations (Withyachumnarnkul et al., 1992). The enzyme involved in the last step of melatonin synthesis, HIOMT, has also been found to be present in the eyestalk of crustaceans, such as the giant tiger shrimp, Penaeus monodon, in which the activities of both NAT and HIOMT were demonstrated (Withyachumnarnkul et al., 1995). In various other crustaceans, melatonin has been also detected (Agapito et al., 1995; Vivien-Roels and Pévet, 1986; Balzer et al., 1997; Tilden et al., 2003; Verde et al., 2007) and diurnal and circadian rhythms reported, but data about peaks and levels are controversial. Although activities of both enzymes, NAT and hydroxyindole-O-methyltransferase have been reported (Withyachumnarnkul et al., 1995) and the existence of NAS, could be assumed, this product has not been reported in crustacean. Last, 5-HT has been amply studied in crustaceans; its effects are related to the phase shift of the locomotor activity; in modifying the electrical activities of retinal and extraretineal photoreceptors, and impacting in the secretion of peptidic hormones. 


\section{MATERIAL AND METHODS}

\section{$\underline{\text { Behavioral Studies }}$}

\section{$\underline{\text { Animals }}$}

Experiments were performed with adult specimen of the marbled crayfish Procambarus spec. So far, only females of this parthenogenetically reproducing species have been described and it is unknown whether males may emerge under certain environmental conditions (Scholtz et al., 2003). Intermolt stage crayfish of 1.20-2.98 g body weight were taken from the breeding tanks of the laboratory and immobilised by cooling in $5^{\circ} \mathrm{C}$ cold water for approximately 10 minutes. Animals were labeled with unique symbols made from reflective foil (Scotchlite No. 7610) that were fixed to the dorsal carapace with Pattex ${ }^{\circledR}$ glue. Prior to the experiments, crayfish were isolated for 5 days in continuously aired tanks at a temperature of $22-24^{\circ} \mathrm{C}$. They were fed once with fish and carrots on the third day of isolation during the afternoon. After this, no food was provided during the entire period of the experiment. During the pre-experimental period, the crayfish were subjected to a photoperiod LD 12:12 (twelve hours light, twelve hours darkness), by use of normal fluorescent lamps regulated with a timer. Light periods started at 8:00 am.

\section{$\underline{\text { Recording of locomotor activity }}$}

Single marbled crayfish were placed into individual aquaria with a base area of $12 \mathrm{~cm} \mathrm{x}$ $25 \mathrm{~cm}$. Infrared light diodes and detectors on the opposite side produced light beams that transected the water-filled aquaria at 5, 10, 15 and $20 \mathrm{~cm}$ at a height of $1 \mathrm{~cm}$ above the ground. Every interruption of a light beam, caused by the moving crayfish, was recorded by a computer. Counts were summed for every 10 minutes and stored for later analysis. Water was changed once per week. Continuous recordings lasted for at least 7 days under either LD 
12:12 or constant darkness (DD). Locomotor activity was analyzed by the circadian rhythms evaluation program Tempus 1.7 (Reischig and Stengl, 2003a). Actograms and periodograms (Chi square periodogram; Sokolove and Bushell, 1978) were constructed in Excel (Micrsosoft). Rhytmicity over confidence levels ( $\mathrm{p}=0.01$ ) was considered as significant.

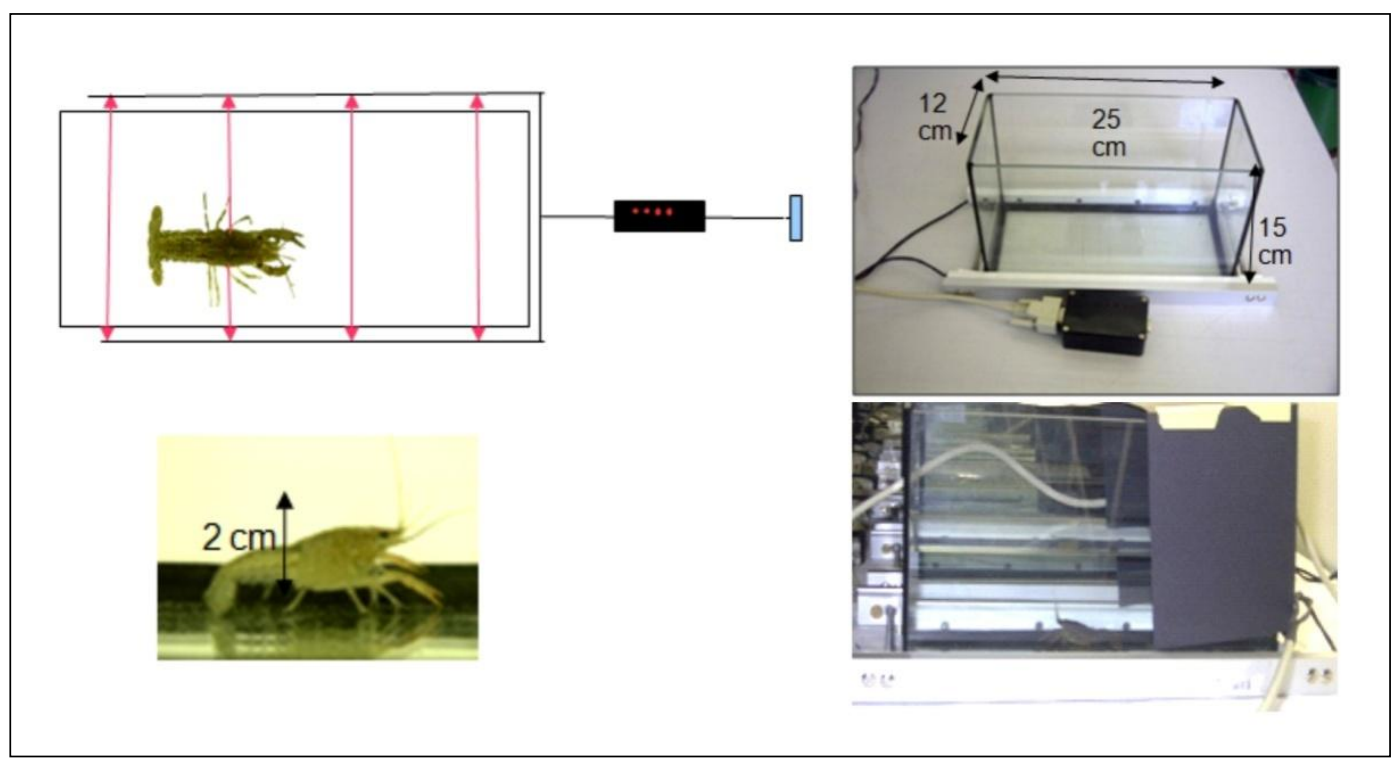

Figure 2. Set-up for locomotor activity recordings (see text for explanation)

\section{$\underline{\text { Recording of agonistic behavior. }}$}

Groups of six individually marked marbled crayfish were placed together in one aquarium with a base area of $40 \times 55 \mathrm{~cm}$ that was placed on a white underground. Crayfish were initially kept under regular light/dark periods (LD 12:12) for three days before continuous darkness was applied for another four days. During the entire period of seven days, agonistic interactions of crayfish were continuously monitored with a digital camera (Panasonic NV GS150 3CCD) that was positioned above the arena. The camera was programmed for night shot (infrared light) to increase sensitivity under dim light conditions (less than 1 lux). Red light of low intensity was continuously applied to enable identification of crayfish and tracking of their positions during dark phases. Crayfish have been demonstrated to be insensitive to dim red light (Cronin and Goldsmith, 1982). Camera recordings were directly 
transmitted to a computer that captured the videos with the software Windows Movie Maker (Microsoft). The movies were stored as DV-AVI formats on DVDs. The experiment was repeated three times with six marbled crayfish included in each run. Each crayfish was used only once.
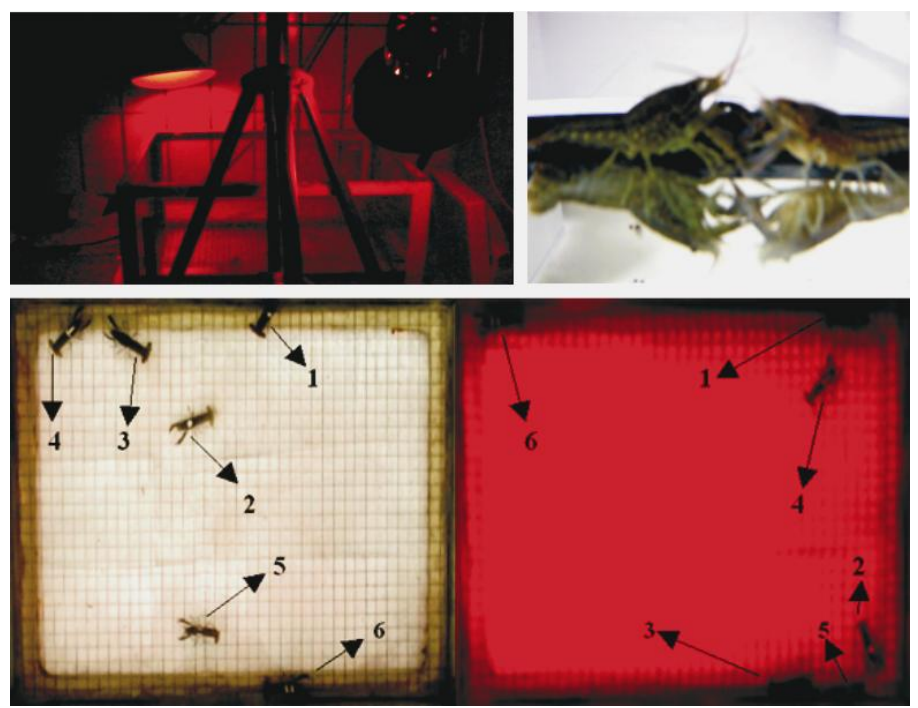

Figure 3 Setup of video recordings of agonistic behavior in groups of the marbled crayfish Procmbarus spec. (Details in text)

\section{Quantification of aggressive behavior}

Protocols for quantification of lobster and crayfish agonistic behaviors have been developed by various laboratories (Huber and Kravitz, 1995; Karavanich and Atema, 1998; Herberholz et al., 2001). Since in my experiments agonistic interactions of several crayfish were observed from above and without the possibility of close-up views, a simplified scoring system was used. Interactions between two crayfish, such as lunges, persecution, claw lock, and claw ripping were easily identified from above and counted as parts of agonistic encounters. For each agonistic encounter the following parameters were evaluated: which animal initiated the encounter, which retreated from the encounter, type of interaction, occurrence (time of the day or night) and duration of the encounter. Behavior was evaluated by replaying the recorded movies with Windows Media Player (Microsoft) on a computer screen. Data were collected and evaluated in Excel (Microsoft). 


\section{$\underline{\text { Data Analysis }}$}

I evaluated the occurrence and outcome of all agonistic encounters of each individual marbled crayfish. According to the numbers of won encounters, a rank order of dominance within the group was created. In order to assess the daily course of agonistic activity within the entire group, the numbers of all agonistic encounters were pooled. Periodograms and actograms of agonistic behavior under LD and DD conditions were calculated as described above for the analysis of locomotor activity. A similar analysis was applied to agonistic activities of individual marbled crayfish. Graphs were generated and labeled with Excel (Microsoft) and assembled to figures with Photoshop (Adobe).

\section{$\underline{\text { Anatomical Studies }}$}

\section{$\underline{\text { Animals }}$}

I used the marbled crayfish Procambarus spec. in adult and intermolt stage. Because this species is parthenogenetic and male specimens are not known, sex determination was not relevant. Animals were obtained from aquaria of the Johann-Friedrich-Blumenbach-Institute for Zoology and Anthropology. Prior to the experiments, animals were maintained for at least two weeks under standard conditions in continuously aired tanks at a temperature of $22-24^{\circ} \mathrm{C}$. They were fed once with fish and carrots on the third day of isolation during the afternoon. After this, no food was provided during the entire period of the experiment. During the preexperimental period, the crayfish were subjected to a photoperiod of LD 12:12 (twelve hours light, twelve hours darkness), by the use of normal fluorescent lamps, which were regulated with a timer. Light periods started at 8:00 am. 


\section{Nomenclature of brain structures}

The nomenclature for anatomical structures of the crayfish nervous system follows the standard nomenclature proposed by Sandeman et al. (1992), with exception of the optic ganglia situated at the distal eyestalk, which are described according to the nomenclature of (Strausfeld and Nässel, 1981). There, lamina ganglionaris, medulla externa, and medulla interna are named lamina, medulla, and lobula, respectively. This reflects the most likely homology of these neuropils to their correlates in the insect optic neuropils. The proximal eyestalk is termed the lateral protocerebrum and contains the medulla terminalis and the hemiellipsoid body with its two subdivisions neuropil I (HNI) and neuropil II (HNII). In the medial protocerebrum, cell body clusters (CBCs) described by Sandeman et al. (1992) are numbered consecutively from 1-17 (from anterior to posterior); here named with ' $\mathrm{CBC}$ ' as prefix, in order to avoid confusion with numbers of cells.
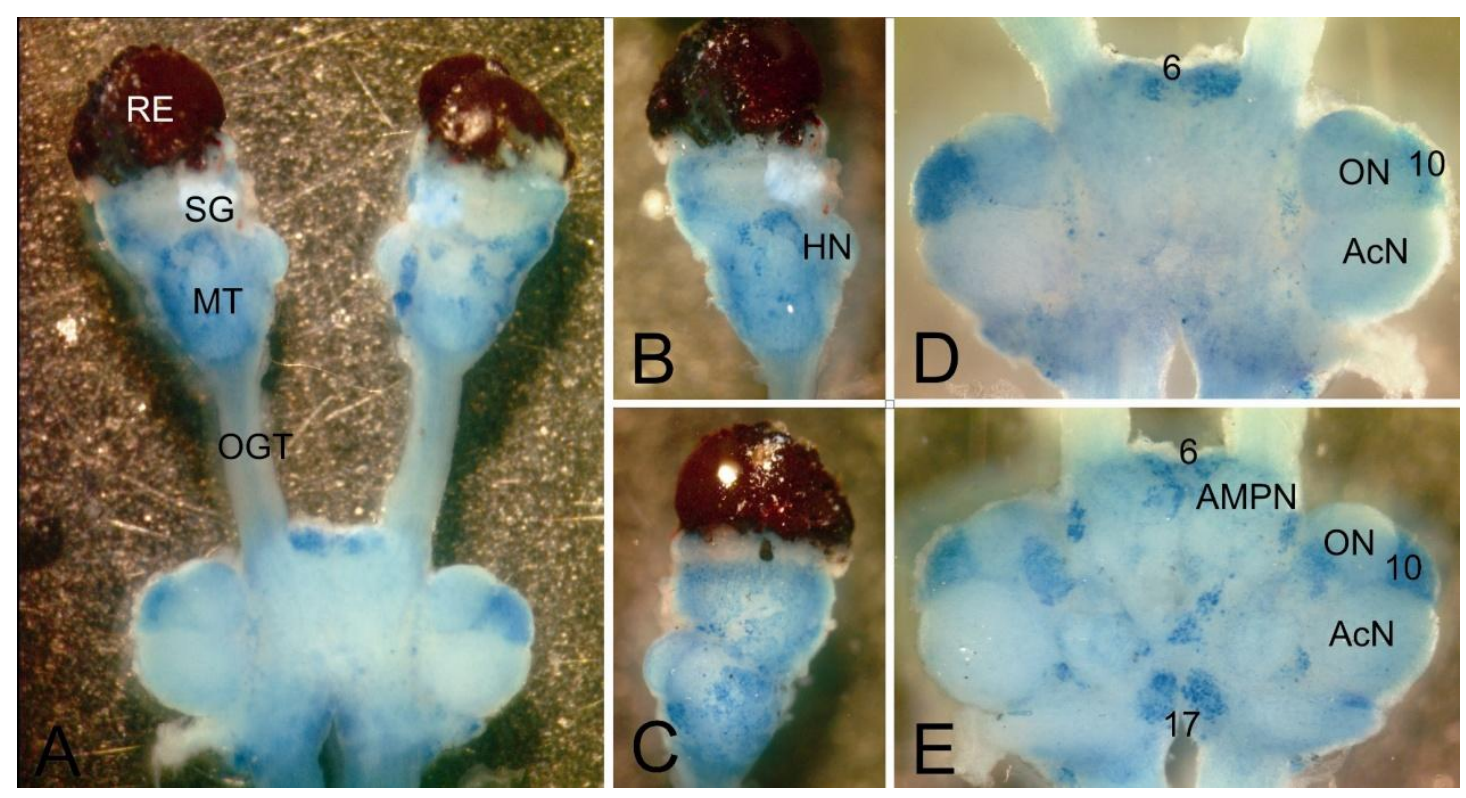

Figure 4. Eyestalk and circumesophagic ganglion of the crayfish Procambarus espec. stained with methylene blue and photographed through a light microscope. (A) Dorsal view. (B) Dorsal detail of the left eyestalk. (C) Ventral view of the eyestalk. Circumesophagic ganglion, detail of the dorsal view is shown in (D) and of the ventral view in (E). AMPN, anterior medial protocerebral neuropil; HN hemiellipsoid body; La, lamina; L, lobula; Me, medulla; MT medulla terminalis; OGT olfactory globular tract; ON olfactory lobe; Re, retina; 6, 10 and 17 correspod to CBC cell body clusters. 


\section{Antisera used and their specificity}

a- $\beta$-PDH: Polyclonal antiserum from rabbit against synthetic $U c a-\beta-P D H$ (Dircksen et al., 1987); used in various studies in insects and crustacea; well characterized; does not stain $\alpha$ $\mathrm{PDH}$. Control preparations in which the first antibody was omitted resulted in the complete absence of immunostaining.

a-Droso-PDF: Manufactured by J. Blau; stains same cells as a-Uca- $\beta$-PDH of Dircksen in cockroaches.

a-FMRFamide: Polyclonal antibody developed in Guinea pig. Gift from D. Nässel. 1:1000. a-FMRFamide: Polyclonal antibody raised in rabbit. ImmunoStar (Hudson, Wisconsin). $1: 1000$.

a-Mas-Allatotropin: Veenstra and Hagedorn, 1993.

a-5-HT: Polyclonal antibody developed in rabbit. Sigma (Steinheim, Germany) 1:1000. a-5-HT Polyclonal antibody raised in goat. Acris (for double and triple immunostainings).

\section{Immunostaining on preparations embedded in Steedman's wax}

Animals were dissected and fixed immediately in a formaldehyde/picric acid solution (aqueous Bouin's solution modified after Hollande (Romeis, 1989), $4 \%$ picric acid, $4 \%$ formaldehyde, $1 \%$ glacial acid) overnight at room temperature. After fixation, tissue was washed several times in water and then dehydrated in an ethanol series from 30, 50, 70, 90, 96 to $100 \%$ for 10 minutes each. The brains were embedded in Steedman's wax (PolyEthylenglycol-Distearat containing 1\% 1-Hexadecanol; Sigma-Aldrich, Steinheim, Germany). Serial frontal and transversal $10-\mu \mathrm{m}$-thick sections were obtained as ribbons on a cooled microtome. The ribbons were mounted on glass slides coated with chrome alum and allowed to dry over night. Then, mounting medium was removed by immersion of the slides in $100 \%$ ethanol for 10 minutes twice and the sections were rehydrated in a descending alcohol series 
ending in Tris-buffered saline $0.1 \mathrm{M} \mathrm{pH} 7.4$ (TBS) containing $0.1 \%$ Triton X-100 (TrX). The following incubation steps were carried out on slides. Blocking of unspecific protein binding sites ('preincubation') was performed with 5\% normal goat serum (NGS) in TBS containing $0.5 \% \operatorname{Tr} \mathrm{X}$ for one hour. PDH immunostaining was performed with the rabbit anti-Uca- $\beta$ PDH-antiserum (Dircksen et al., 1987) diluted at 1:10,000 in TBS containing 0.5\% TrX over night. Primary antibody was detected (Sternberger, 1979) by goat anti-rabbit IgG (1:50 in TBS with $0.5 \% \operatorname{TrX}, 1 \mathrm{~h}$ ), followed by incubation with rabbit peroxidase-anti-peroxidase (PAP) complex (1:100 in TBS with $0.5 \% \mathrm{TrX}, 1 \mathrm{~h}$; both from Jackson Immunoresearch, Newmarket, UK). Peroxidase was labeled with 3,3'diaminobenzidine $/ \mathrm{H}_{2} \mathrm{O}_{2}(0.03$ and $0.05 \%$, respectively, in $0.1 \mathrm{M}$ phosphate buffer $\mathrm{pH}$ 7.4). To visualize additional brain structures I counterstained some preparations with $1 \%$ methylene blue. The sections were then dehydrated with 70 and $96 \%$ ethanol (there, the methylene blue staining was differentiated), $100 \%$ isopropanol, and xylene, and cover slides were mounted with Entellan (Merck, Darmstadt, Germany).

\section{Immunostaining on preparations embedded in gelatin/albumin}

The brains were dissected in saline and fixed immediately with Zamboni's solution (4 \% paraformaldehyde, $7.5 \%$ picric acid diluted in $0.1 \mathrm{M}$ Phosphate buffer $\mathrm{pH} 7.4$ for two hours. After that, tissue was briefly washed with phosphate buffer $0.1 \mathrm{M}, \mathrm{pH} 7.4(\mathrm{~PB})$ and excess of buffer was absorbed from the brains with filter paper. The brains were embedded in a albumin/gelatin mixture (24.2 g chicken albumin and $5.7 \mathrm{~g}$ gelatin from porcine skin diluted in $91 \mathrm{ml} \mathrm{H}_{2} \mathrm{O}$ ) and postfixed in phosphate-buffered paraformaldehyde $4 \%$ overnight at $4{ }^{\circ} \mathrm{C}$. Blocks were cut with a vibrating blade microtome (vibratome; Leica, Germany) into $50 \mu \mathrm{m}$ thick sections. The following incubation steps were carried out on free floating sections. Preincubation was performed with 5\% NGS in TBS containing $0.5 \% \operatorname{TrX}$ for one hour. PDH- 
immunostaining was performed with the rabbit anti- $\beta$-PDH diluted in TBS containing $0.5 \%$ $\operatorname{TrX}$ and $1 \%$ NGS as above, but best staining was achieved with a concentration of 1:5,000, and the incubation time was at least 2 days. After washing with several rinses of TBS containing $0.1 \% \operatorname{TrX}$, the sections were incubated with an anti-rabbit secondary antibody coupled to horse radish peroxidase (Dianova, Hamburg, Germany) diluted 1:300 in TBS containing $0.5 \% \operatorname{TrX}$ and $1 \%$ NGS for two hours. Peroxidase was detected with 3,3'diaminobenzidine/ $\mathrm{H}_{2} \mathrm{O}_{2}(0.03$ and $0.05 \%$ respectively in $0.1 \mathrm{M}$ phosphate buffer $\mathrm{pH}$ 7.4). Then, the sections were washed in PB, incubated in a mixture of $50 \%$ glycerol and $50 \%$ PB, mounted in anatomical order on microscope slides, and coverslipped.

\section{$\underline{\text { Immunofluorescent staining for multi-labeling experiments }}$}

For multiple immunolabelings of crayfish brains and optic lobes with up to three antibodies, brains were dissected, fixed in Zamboni's solution, embedded in gelatin/albumin, and cut with a vibratome to $50 \mu \mathrm{m}$ thick slices as described above. After blocking with $5 \%$ normal serum (from goat or donkey, depending on donor species of secondary antiserum) in TBS containing $0.5 \% \operatorname{Tr} \mathrm{X}$ for at least $2 \mathrm{~h}$, primary antisera were applied for at least two days to the free-floating sections at working dilutions (in TBS containing $0.5 \% \operatorname{TrX}$ and $1 \%$ normal serum) given in table 1 . After washing in TBS containing $0.1 \% \operatorname{TrX}$, appropriate secondary antisera coupled with fluorescent dyes were diluted 1:300 together with $1 \%$ normal serum in TBS containing $0.5 \% \operatorname{TrX}$ and applied to the sections for $2 \mathrm{~h}$. Then, the sections were washed in $\mathrm{PB}$, cleared for $30 \mathrm{~min}$ in a mixture of $50 \%$ glycerol and $50 \% \mathrm{~PB}$, mounted in anatomical order on microscope slides, and coverslipped. Primary antisera were applied in the following combinations: rabbit anti- $\beta-\mathrm{PDH}$ with guinea pig anti-FMRFamide (detected with goat anti-rabbit $\mathrm{Cy} 2$ and goat anti-guinea pig Alexa 633, respectively), rabbit anti- $\beta$-PDH with goat anti-serotonin (detected with donkey anti-rabbit Cy2 and donkey anti- 
goat Cy5, respectively), and mouse anti-Drosophila-PDF with rabbit anti-allatotropin and goat anti-serotonin (detected with donkey anti-mouse $\mathrm{Cy} 2$, donkey anti-rabbit Cy3, and donkey anti-goat Cy5, respectively). Secondary antisera were obtained from Dianova, Hamburg, Germany.

\section{$\underline{\text { Neurobiotin backfilling }}$}

In order to investigate central and contralateral connections of $\mathrm{PDH}$-ir cells of the eyestalks, I applied neurobiotin as neuronal tracer by means of suction pipettes to the thin connections of the eyestalks to the central brain ('protocerebral stalks'). For that, animals were immobilized with wax and the eye capsule was cut to expose the protocerebral stalks. I pulled glass capillaries for electrophysiology to fine tips, which were then thoroughly broken to obtain a round and smooth tip orifice of about $300-400 \mu \mathrm{m}$ in diameter. This tip was filled with 1-2 $\mu$ l of $5 \%$ Neurobiotin (Vector Laboratories Inc. Burlingame, Canada) diluted in distilled water. Then, the protocerebral stalk was cut, and the tip of the application pipette was slipped over the remaining stump either on the optic lobe (to investigate which PDH-ir neurons of the optic lobe have central projections) or on the central brain (to investigate PDHir projections to the contralateral optic lobe). The pipette was fixed in this position with wax and the wound was sealed with vaseline. The animals were immersed with cold water and allowed to survive over night at $4{ }^{\circ} \mathrm{C}$. The next day backfilled optic lobes were dissected, fixed in Zamboni's solution, embedded in gelatin/albumin, and cut with a vibratome to 50 $\mu \mathrm{m}$-slices as described above. Double-immunolabeling with mouse anti-Drosophila-PDF and rabbit anti-FMRF (detected with goat anti-mouse Cy3 and goat anti-rabbit Alexa 633, respectively) was carried out as described above. To detect the neurobiotin, the solution for secondary antibodies additionally contained $1 \%$ streptavidin coupled with fluorescein isothiocyanate (FITC; Vector Laboratories, Burlingame, Canada). After the staining 
procedures, the sections were washed in $\mathrm{PB}$, cleared for $30 \mathrm{~min}$ in a mixture of $50 \%$ glycerol and 50\% PB, mounted in anatomical order on microscope slides, and cover slipped (Figure 5).
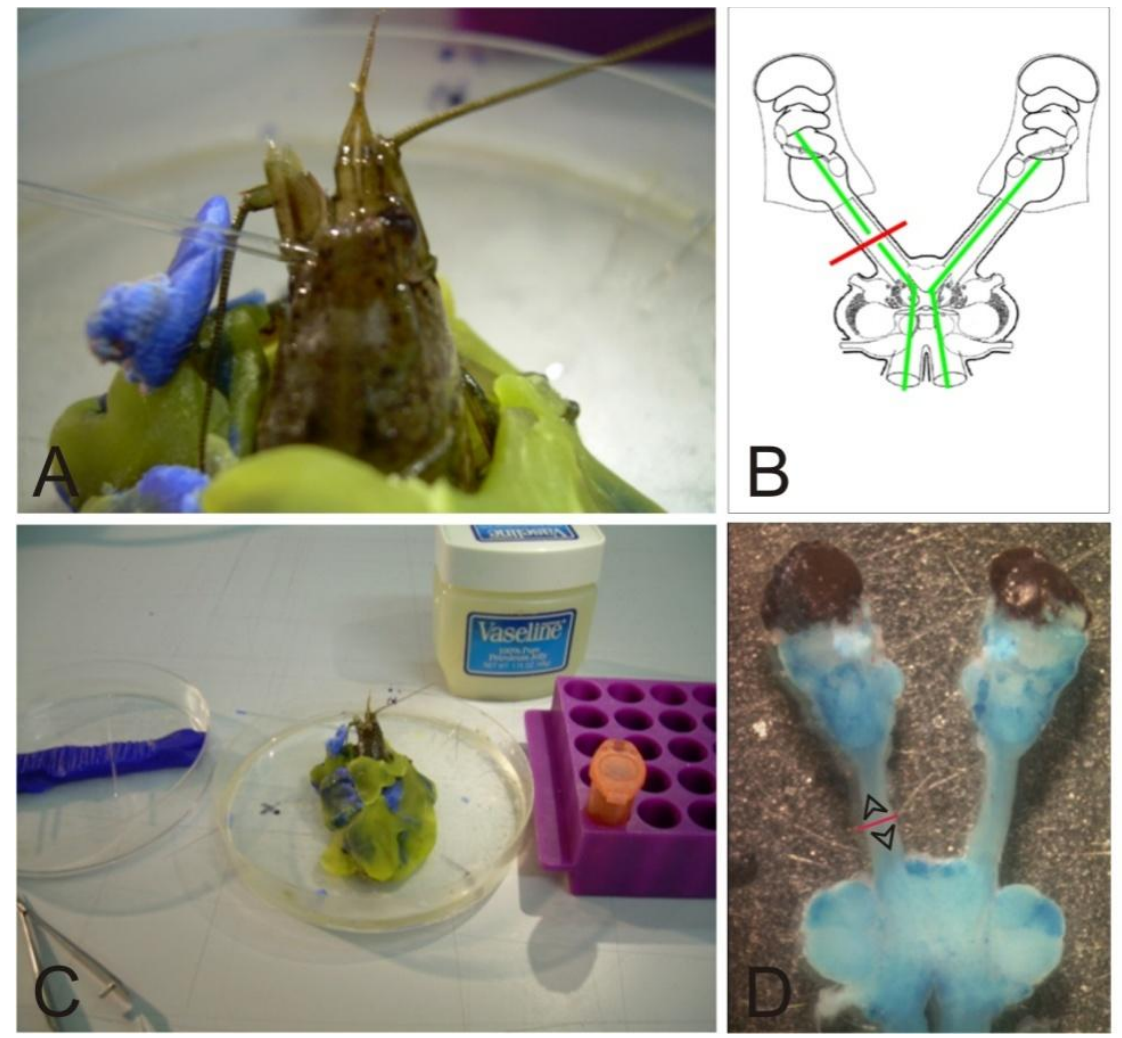

Figure 5. Neurobiotin backfilling procedure in the nervous system of the marbled crayfish Procmbarus espec. (A) (C) Crayfish with capillary containing the tracer. (B) schematic representation of the path tracked. (D) Brain preparation, arrowheads show the direction of backfills.

\section{$\underline{\text { Image collection and analysis }}$}

The preparations analysed by conventional light microscopy were photographed with a Zeiss microscope (Axioskop) equipped with a digital camera (SPOT RT3 Monochrome camera, 1,2 Mpixel, Diagnostic Instruments Inc.). Some specimens were photographed as complete image stacks. Global image corrections (brightness, contrast, sharpness) were performed with Adobe Photoshop 5.0.

The preparations labeled with fluorescent dyes were evaluated with a Leica confocal laser scanning microscope (CLSM) TCS SP2 equipped with an acusto-optical beam splitter unit (AOBS) for separation of excitation and emission light and a spectrophotometer unit for stepless selection of emission light spectra). In the double labeling experiments, Cy2- 
immunofluorescence was excited with the $488 \mathrm{~nm}$ line of an Ar laser and emission light was collected at 493-560 $\mathrm{nm}$ (narrowed down to $493-530 \mathrm{~nm}$ in the triple labeling experiments to avoid crosstalk with Cy3 labeling; same parameter were used for FITC in the backfills). Cy5 was excited with a $633 \mathrm{~nm}$ He-Ne laser and emission was detected at 650-800 nm (680-800 $\mathrm{nm}$ in the triple labeling experiments). In the triple labeling experiments, Cy3 was excited with $543 \mathrm{~nm}$ He-Ne laser and emission light was collected at 590-610 nm. In all experiments, Cy2 and FITC, respectively, were simultaneously scanned with Cy5, since emission spectra are sufficiently different. In the triple labeling experiments, Cy3 was scanned separately in a sequential scan routine to avoid crosstalk artifacts.

To reconstruct PDH-ir and FMRFamide-ir fiber systems of brains and optic lobes, complete stacks of micrograph images or CLSM scans were imported into the 3D visualization program Amira 4.1 (Visage Imaging, Berlin, Germany). The images were first aligned automatically through landmarks and alignment was manually improved with the alignment editor of Amira. Aligned images were drawn on transparency pasted on a computer screen. Numbers of immunoreactive cells were determined by counting every immunoreactive soma and the count number was multiplied by the correction factor $\mathrm{c}=\mathrm{t} /(\mathrm{t}+\mathrm{h})$ where $\mathrm{t}=$ slide thick and $h=$ average diameter of somata by Amercombie (1946).

\section{Circadian Serotonin Related Indolamines}

\section{$\underline{\text { Animals }}$}

Adult marbled crayfish Procambarus espec. from laboratory supply were used. Animals were reared in 301 aquaria under standard conditions: temperature $20-21^{\circ} \mathrm{C}$, continuous aeration and a light regime 12 hours light and 12 hours darkness (LD12:12). Animals were fed on fish while they were maintained in stock aquaria. Prior to experiments, groups of 
animals were separated in acclimatization aquaria under the same standard conditions for at least 7 days. During this period food was not provided to prevent external sources of serotonin and melatonin.

\section{Enzyme-Linked Immunosorbent Assay}

Concentrations of serotonin and its derivatives $\mathrm{N}$-acetylserotonin and melatonin were measured by Enzyme-Linked Immunosorbent Assay (ELISA). Melatonin ELISA Kit and Serotonin Elisa Kit (IBL, Hamburg) were used and adjusted to assay crayfish tissues. Animals were dissected at different time points of the day under $\operatorname{LD} 12: 12(9,13,17,21,1$ and $5 \mathrm{~h})$. Animals were anesthetized for some minutes on iced water and then dissected under stereoscopic microscope. Tissues were transferred immediately to plastic tubes containing $150 \mu \mathrm{l}$ EDTA HCL solution ( $\mathrm{pH}$ 8). After that, tissues were homogenized with a plastic pistel. Pairs of eyestalks were pooled in the same tube and brains were processed separately in single tubes. Probes were frozen immediately after homogenization to be processed later. To initiate ELISA protocols, samples were thawn at room temperature, vortexed and then centrifuged for 10 minutes at $3000 \mathrm{~g}$.

\section{$\underline{\text { Serotonin and } N \text {-acetyl serotonin }}$}

$50 \mu \mathrm{l}$ supernatant were transferred to glass tubes containing $100 \mu 1$ assay buffer (Phosphate buffer). This step was duplicated: in one tube $25 \mu$ l acetylation reagent was added in order to measure 5-HT, in the second $25 \mu \mathrm{l}$ acetone in order to measure $N$-acetylserotonin. All tubes were vortexed and incubated in a water bath at $37^{\circ} \mathrm{C}$ for 30 minutes. After that, 1 $\mathrm{ml}$ assay buffer was added to each tube and centrifuged again for 10 minutes at $1500 \mathrm{~g}$. Up to this step, probes were processed immediately in 96-wells microplate. Standards were assayed in the first 7 wells and in the next wells acetylated and not acetylated probes were measured. 
To every well $50 \mu 1$ of standards was added and then mixed with $50 \mu 1$ serotonin biotin and 50 $\mu 1$ 5-HT antiserum (provided in the kit). Then, microplate was incubated overnight (ca. 16 hours) on a shaker at $4^{\circ} \mathrm{C}$. After incubation, fluid was discarded and wells were washed three times with washing buffer (phosphate buffer, Tween $0.1 \%$, Thimerosal). $150 \mu$ l of enzyme conjugate was added to every well and incubated for 120 minutes on a shaker (500 rpm) at room temperature. Fluid was discarded again and the samples washed 3 times with washing buffer. $200 \mu \mathrm{l}$ PNPP (p-Nitrophenil Phosphate) solution was added to every well and incubated on a shaker for one hour at room temperature. Finally, reaction was stopped with PNPP solution (1M NaOH, 0.25 M EDTA). Microplate was read in a Microplate reader (Dynatech MRX, Denkendorf, Germany) at $405 \mathrm{~nm}$. Standard curves were established (0.2, $1.175,3.29,9.24,28.2,86.9$ and $258.5 \mathrm{ng} / \mathrm{ml}$ ) and used to calculate the amounts of serotonin and $\mathrm{N}$-acetylserotonin in the samples.

\section{$\underline{\text { Melatonin }}$}

For melatonin measurement, the supernatants resulting from centrifugation were directly transferred to glass tubes and diluted 1:3 with assay buffer (phosphate buffer, Tween). A 50 $\mu 1$ sample from every tube was transferred to individual wells and mixed with $50 \mu 1$ melatonin antiserum and $50 \mu \mathrm{l}$ melatonin biotin. Microplate was incubated overnight on an orbital shaker $(500 \mathrm{rpm})$ at $4^{\circ} \mathrm{C}$. Next day, fluid was discarded and wells washed three times with $250 \mu \mathrm{l}$ washing buffer. $150 \mu \mathrm{l}$ enzyme conjugate was added to wells and incubated on a shaker $(500 \mathrm{rpm})$ for 2 hours. After incubation, enzyme conjugate was discarded and wells washed again with $250 \mu$ l washing buffer three times. $200 \mu$ PNPP substrate solution were pipetted to every well and let incubate for 40 minutes. Reaction was stopped with $50 \mu 1$ PNPP

solution. Microplate was read and concentrations calculated by comparison with a standard curve that was created with $1,31.75,62.6,125,250,500$ and $1000 \mathrm{pg} / \mathrm{ml}$ melatonin. 


\section{$\underline{\text { Statistical analysis }}$}

Comparisons of concentrations obtained at different timepoints were made and statistically evaluated by analysis of variance ANOVA (Sigma Stat, Jandel Scientific). In order to detect diurnal rhythms, circadian analysis was performed by cosinor analysis (COSANA). 


\section{$\underline{\text { RESULTS }}$}

\section{$\underline{\text { Locomotor activity }}$}

Locomotor activity of isolated adult marbled crayfish was assessed under LD 12:12 and DD by counting the numbers of interruptions of infrared light sensor barriers. Under LD 12:12 crayfish displayed increased locomotor activity when lights were turned off and, though weaker, when lights were turned on again (Fig. 6A). Evaluation of the period of peaks in locomotor activity for this crayfish revealed a duration of $\tau=24.0 \mathrm{hrs}$ (Fig. 6C). All of the 22 crayfish tested under identical LD12:12 conditions displayed similar diurnal rhythms of locomotor activity as the example shown in Figure $6 \mathrm{~B}$ and the average duration of the circadian period was $\tau=24.0 \mathrm{hrs}(\mathrm{n}=22)$. After switching to DD after day 12 , most crayfish retained peaks of locomotor activity at circadian times coinciding with the previous light-todark and dark-to-light transitions. In the example shown in Figure 6, peaks of activity continued for the entire observation period of nine days in DD (Fig. 6A) and this crayfish exhibited an endogenous circadian period of $\tau=22.5 \mathrm{hrs}$ (Fig.6D). Out of 22 crayfish that were tested in this experiment 18 crayfish displayed a clear periodicity of locomotor activity under DD. The average endogenous circadian period of these animals was $\tau=23.22 \pm 0.91$ hrs $(\mathrm{n}=18, \mathrm{p} \leq 0.01)$. Four out of 22 crayfish displayed peaks of activity with circadian periods close to $24 \mathrm{hrs}(\tau=21.7 \mathrm{hrs} \mathrm{h}, 23.9 \mathrm{hrs}, 21.8 \mathrm{hrs}$ and $23.0 \mathrm{hrs})$ that were not significantly elevated over the confidential level ( $p>0.01)$. One crayfish that displayed a stable rhythm of locomotor activity with a period of $\tau=29.8 \mathrm{hrs}$ was excluded from the analysis. 


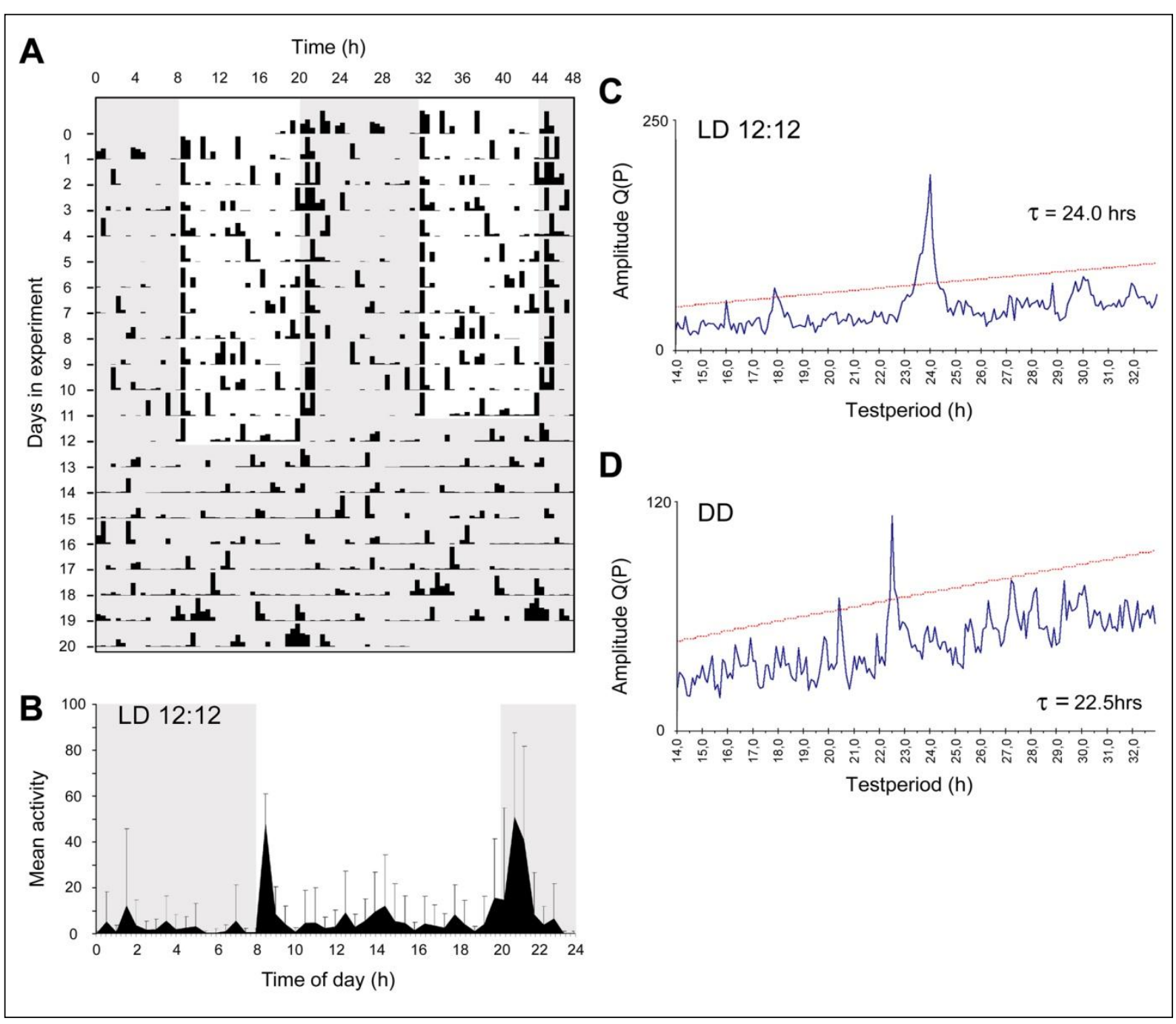

Figure 6. Circadian rhythmic locomotor activity of marbled crayfish. (A) Double-plot display of locomotor activity of one isolated marbled crayfish under LD 12:12 for twelve days followed by nine days in constant darkness. Dark periods are indicated by grey colour. (B) mean (with S.D.) values of locomotor activity under LD12:12, from day 1 to day 12 . (C, D) $\chi^{2}$ periodogram analysis of locomotor activity during twelve days under LD 12:12 (B) and nine days in constant darkness DD (C). Diagonal line represents the Sokolove significance line for $\mathrm{p}=0.01$ (Sokolove and Bushell 1978). $\tau$ circadian period.

\section{$\underline{\text { Agonistic behavior and establishment of hierarchies in crayfish groups }}$}

Three hours before behavioral recordings started with the beginning of the dark period of the first experimental day, 6 marbled crayfish were set together in the arena. Immediately after introduction of formerly isolated crayfish into the arena, high frequencies of agonistic interactions appeared in all three runs of the experiment. Subsequently, agonistic activity declined to low levels within the first three hours, suggesting that hierarchies had been established in which the relative subordinate crayfish avoided further agonistic interactions 
with the relative dominant. Similar observations have been made in earlier studies on agonistic interactions within groups of other crayfish species (Issa et al., 1999; Edwards et al., 2003) and have been explained by the capability of crayfish to recognize the relative social status of conspecifics following direct agonistic interactions by chemical cues (Zulandt Schneider et al., 2001). In the example presented in figure 7 (Fig. 7A, B) the six crayfish performed 221 agonistic encounters, most of which happening during the first two hours of the adjustment period. Based on the proportion of won and lost encounters during subsequent three days under LD 12:12 and another four days in constant darkness, a clear dominance hierarchy could be recognized. In the experiment presented as an example for the three runs evaluated (Table1) the most dominant crayfish was involved in more than $50 \%$ of all agonistic encounters and won more than $90 \%$ of these (Table 1). A lower proportion of won encounters in subordinate crayfish was usually associated with lower numbers of initiated encounters and generally reduced agonistic activity of these subordinates. High aggressive motivation reflected by high numbers of initiated encounters was not generally associated with the capability of winning many of these encounters. As an example, crayfish No. 3 initiated 130 of the 144 encounters that it was involved but won only $36.8 \%$ of these, while crayfish No. 2 initiated only 24 of its 130 encounters and won $65(53.3 \%)$ of these during the first three days under LD 12:12 (Table 1). While the proportion of won encounters remained basically unchanged during the following 4 days of constant darkness, the number of fights that were initiated by crayfish 3 dropped to a level similar with that of crayfish 2 , suggesting a reduction of fighting motivation without changing the probability of winning an encounter.

\section{Circadian regulation of agonistic activity}

Following the adjustment period of three hours, which was not included into the analysis of circadian modulation of agonistic activity, agonistic interactions of crayfish groups were 


\begin{tabular}{|c|c|c|c|c|c|c|}
\hline \multirow{2}{*}{} & \multicolumn{3}{|c|}{$\begin{array}{c}\text { Three days under LD 12:12 } \\
\text { Total No. of encounters: 305 }\end{array}$} & \multicolumn{3}{c|}{ Total Nour of encounters: 330 } \\
\hline Crayfish & $\begin{array}{c}\text { Encounters } \\
{[\%]}\end{array}$ & $\begin{array}{c}\text { Initiated } \\
{[\%]}\end{array}$ & $\begin{array}{c}\text { Won } \\
{[\%]}\end{array}$ & $\begin{array}{c}\text { Encounters } \\
{[\%]}\end{array}$ & $\begin{array}{c}\text { Initiated } \\
{[\%]}\end{array}$ & $\begin{array}{c}\text { Won } \\
{[\%]}\end{array}$ \\
\hline 1 & $50.8(155)$ & $39.7(121)$ & 95.0 & $52.4(173)$ & $47.2(157)$ & 92.5 \\
\hline 2 & $40.0(122)$ & $7.9(24)$ & 53.3 & $39.6(131)$ & $19.4(65)$ & 53.4 \\
\hline 3 & $47.2(144)$ & $42.6(130)$ & 36.8 & $45.4(150)$ & $19.1(62)$ & 37.3 \\
\hline 4 & $33.4(102)$ & $3.3(10)$ & 23.5 & $34.2(113)$ & $8.9(29)$ & 24.8 \\
\hline 5 & $27.2(83)$ & $5.9(18)$ & 18.1 & $27.8(92)$ & $5.2(17)$ & 17.4 \\
\hline 6 & $1.4(4)$ & $0.7(2)$ & 25 & $0.3(1)$ & $0.03(1)$ & 0 \\
\hline
\end{tabular}

Table 1. Agonistic activities of six crayfish continuously monitored over three days under LD 12:12 followed by four days in constant darkness. Crayfish were introduced to the arena three hours before behavioural recording started. The most dominant crayfish participated in more than $50 \%$ of all agonistic encounters and initiated most of them. Based on the percentage of won encounters, the six crayfish established a dominance hierarchy. With prolonged time of co-habitation, relative dominance (= rank position) matches with aggressive motivation represented by the number of initiated encounters. The most subordinate crayfish avoided almost any agonistic interaction. Numbers in brackets represent absolute numbers of contributed or initiated encounters.

monitored for three days under LD 12:12 and four days under DD. During three days under LD 12:12, I observed 1635, 338, and 305 agonistic encounters in the three runs of the experiment. As shown in figure 7, peaks of agonistic activity coincided with light-to-dark and dark-to-light transitions (Fig. 7A, B). The highest absolute numbers of agonistic interactions where observed following the first two changes in light conditions (light-to-dark and dark-tolight of first experimental day) and remained variable on a lower level during subsequent days (Fig. 7A, B). Agonistic activity under LD 12:12 conditions was clearly rhythmic with a period duration of $\tau=24.0 \mathrm{hrs}(\mathrm{n}=3, \mathrm{p}<0.01)$ in all three runs of the experiment (Fig 7C).

After switching to DD for four days, the three groups of marbled crayfish performed 1146, 399 and 324 agonistic encounters. As shown in figure 8A, agonistic activity in constant darkness was more evenly distributed over the entire day and peaks of activity that coincided with times of light-to-dark changes from previous LD 12:12 conditions were far less pronounced than in the light entrained situation (compare with Fig. 7B). Nonetheless, agonistic activity remained rhythmic during four days in constant darkness in all three groups 
of crayfish examined with an average circadian period of $\tau=24.83 \pm 1.22 \mathrm{~h}(\mathrm{n}=3, \mathrm{p}<0.01)$

(Fig. 8B). Since endogenous circadian periods differed between the six crayfish of each experimental group, the circadian period was less sharply defined than in the preceding period under LD 12:12, where all individual rhythms were entrained by the light signal (Fig. 7B).

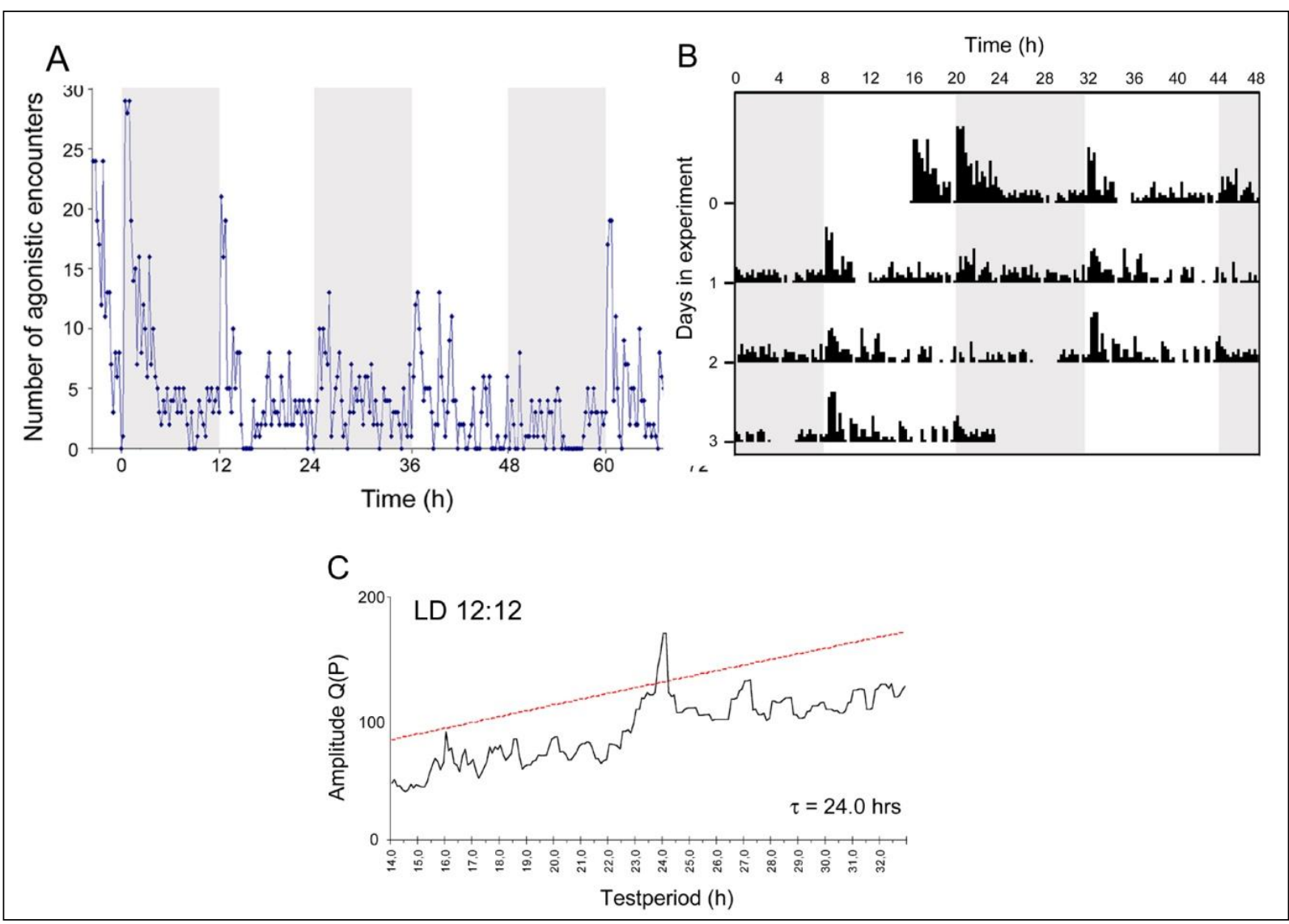

Figure 7. Daily rhythm of agonistic behavior in a group of six marbled crayfish. A Number of agonistic encounters per 15 min. An initially high frequency of agonistic encounters declines to low levels as dominance hierarchy establishes. Subsequently, periods of enhanced agonistic activity follow light-to-dark and dark-to-light changes. Dark phase is indicated by grey colour. B Double-plot presentation of agonistic encounters during three hours adjustment time followed by three days in LD 12:12 conditions. C $\chi^{2}$ periodogram analysis of agonistic activity during three days under LD 12:12. Diagonal line represents the Sokolove significance line for $\mathrm{p}=0.01$ (Sokolove and Bushell, 1978). $\tau$ circadian period. 


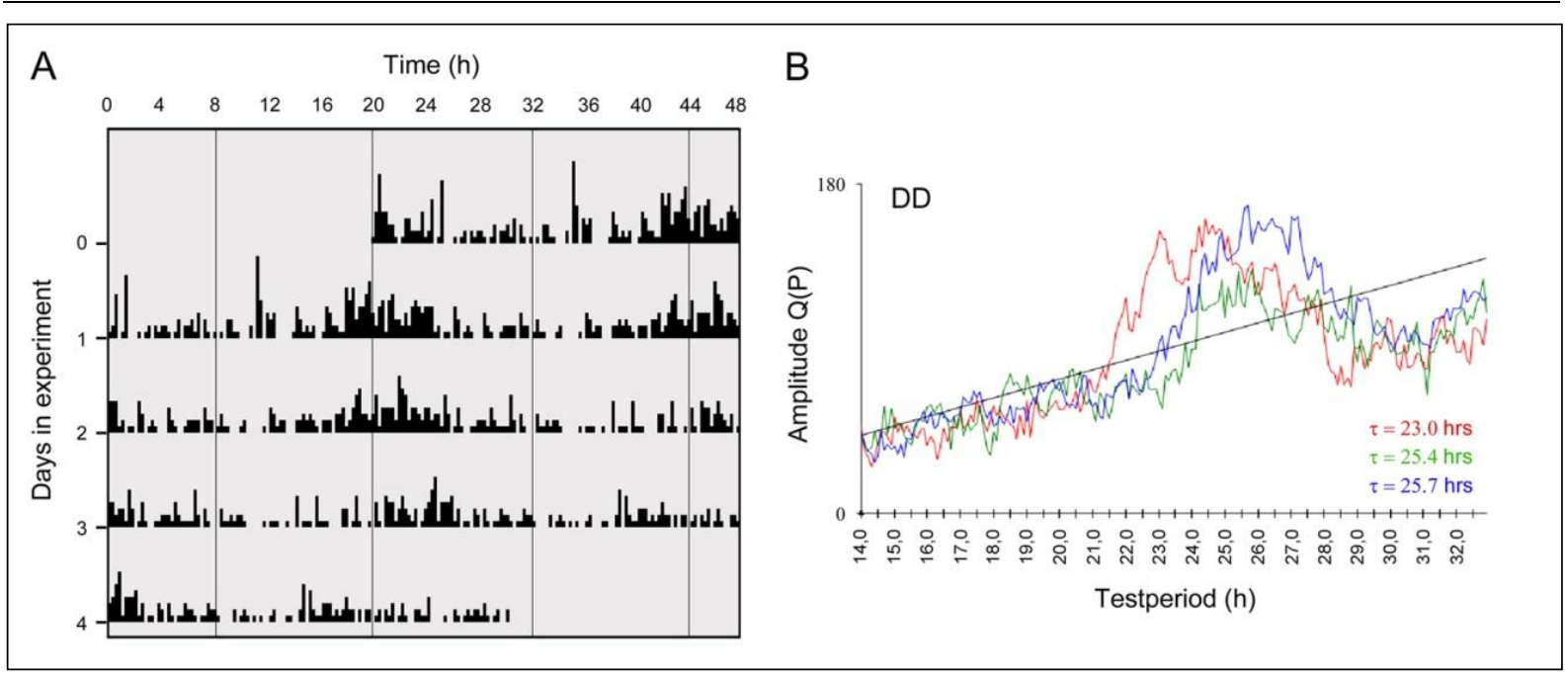

Figure 8. Circadian rhythmic agonistic behaviour in a group of six marbled crayfish under constant darkness (DD). A Double-plot representation of agonistic encounters during four days in constant darkness. The experiment is a continuation of the experiment shown in Fig. 7. Periods of enhanced agonistic activity correlate with times of light-to-dark transitions during preceding three days in LD 12:12. B $\chi^{2}$ periodogram analysis of agonistic activity during four days in constant darkness in three groups of six marbled crayfish. Diagonal line represents the Sokolove significance line for $\mathrm{p}=0.01$ (Sokolove and Bushell 1978). $\tau$ circadian period.

\section{$\underline{\text { Agonistic activity of individual crayfish }}$}

Although overall agonistic activity was clearly rhythmic in all three groups of crayfish studied, individual animals contributed quite differently to this. The most dominant crayfish (based on the percentage of won encounters) were also the most active ones that initiated the highest numbers of agonistic encounters. In all three experiments one crayfish gained dominance during the first few hours after placement in the arena and substantiated it until the end of the experiment (3 days under LD 12:12 plus 4 days under DD) (Table 1 provides one example). In all groups, the most dominant animals initiated the majority of all agonistic encounters $(47.5 \pm 5.2 \% \mathrm{SD})$ while individual subordinate animals initiated between $42 \%$ and (in the most passive case) $0.3 \%$ of all encounters, depending on their rank position in the hierarchy. Only in experiment 3 (Table1), the second subordinate (crayfish No. 3) initiated even more agonistic encounters (130 vs. 121) during the three days under LD 12:12 than both the dominant and first subordinate though it was capable of winning only $36.8 \%$ (compared to $95.0 \%$ won encounters of the dominant and $53.3 \%$ of the first subordinate). While entire 
agonistic activity of all crayfish groups evaluated over four days in constant darkness was rhythmic (see above and Fig. 8B), analysis of individual agonistic activity revealed that only the most dominant crayfish of two experimental groups displayed a statistically significant circadian rhythmicity with periods of $\tau=26.3 \mathrm{~h}$ (Fig. 9) and $\tau=23.0 \mathrm{~h}$. In the third experiment, rhythmicity of agonistic activity of the dominant crayfish in constant darkness was not significant $(\tau=25.5 \mathrm{hrs})$. None of the subdominant crayfish in any of the three groups displayed significant circadian rhythmicity of agonistic behavior in constant darkness and eight of them already showed no significant rhythmicity during the preceding three days under LD 12:12 (data not shown).

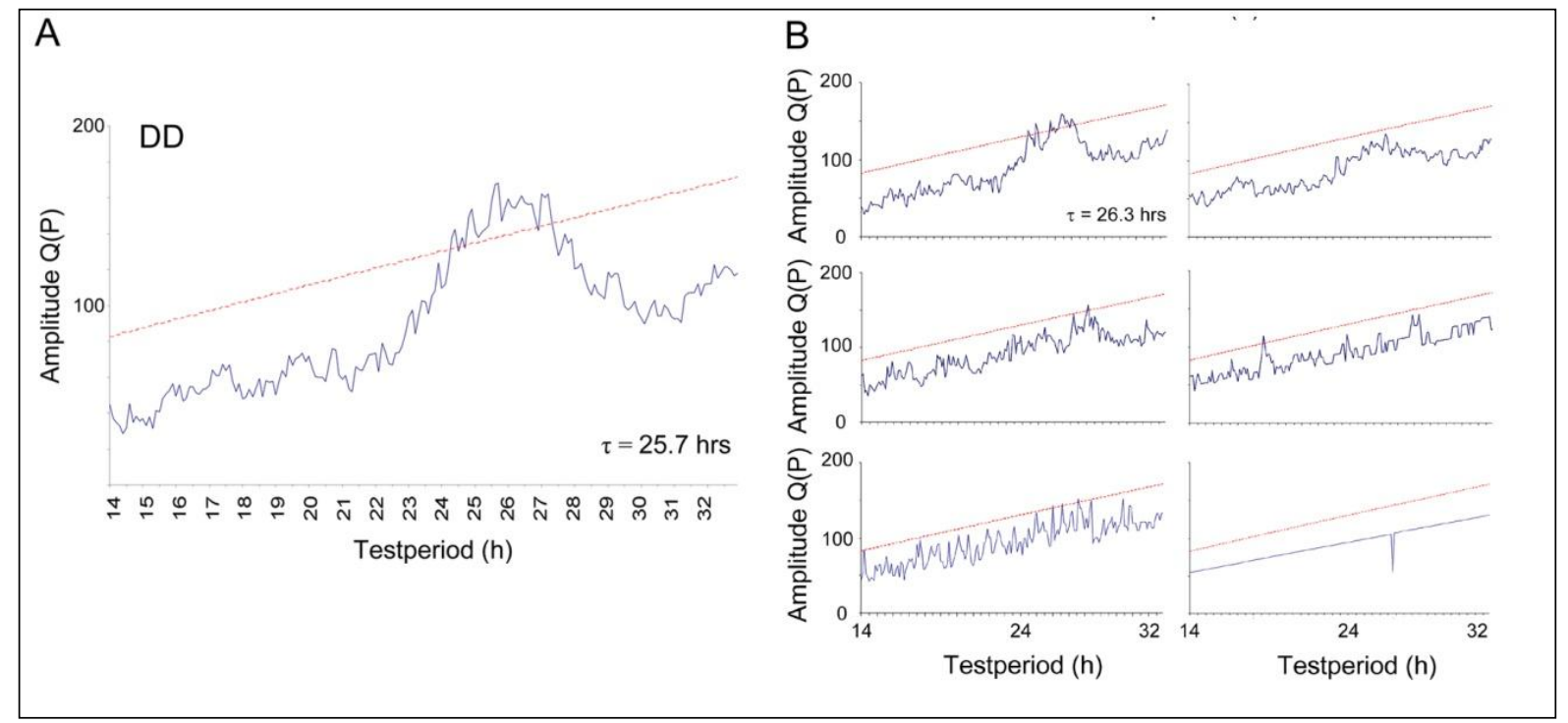

Figure 9. Individual contribution to the circadian rhythmic agonistic behaviour in a group of six marbled crayfish under constant darkness (DD). A $\chi^{2}$ periodogram analysis of agonistic activity during four days in constant darkness in a group of six marbled crayfish. B $\chi^{2}$ periodogram analysis of agonistic activity of individual crayfish from the same group. Only the most dominant crayfish exhibits a significant circadian rhythm of its agonistic behavior. Diagonal lines represent Sokolove significance lines for $\mathrm{p}=0.01$ (Sokolove and Bushell 1978). $\tau$ circadian period. 


\section{PDH expressing neurons in the brain of the marbled crayfish}

To explore the expression pattern of PDH in the brain and optic lobes of the crayfish, I performed immunolabeling with anti- $\beta$-PDH on wax and vibratome brain sections. I found PDH-immunoreactivity in different soma clusters and processes throughout the eyestalk and median protocerebrum (Figs. 10-11). In the eyestalk, four main groups of PDHimmunopositive cells were identified, which were named PDH-La, PDH-A, PDH-B and PDH-C (with subgroups PDH-C1 and PDH-C2; more details below). All neuropils of the optic lobes were invaded by PDH-immunoreactive (-ir) fibers, and numerous PDH-ir fibers were observed running along the protocerebral stalk. In the median protocerebrum, PDHimmunoreactivity was found in four groups of neurons, and PDH-ir fibers innervated large areas of the central brain neuropils. A schematic reconstruction of the crayfish's PDH-ir neuron system in optic lobe and median protocerebrum derived from a complete series of sections is presented in Fig. 10.

The largest group of PDH-ir neurons of the optic lobe was the PDH-ir lamina neurons (PDH-La). Their somata were scattered proximally to the lamina in the area of the first optic chiasm Figs. 10A, 11A, B). The number of somata within this group ranged from 128 to 148 (136 \pm 9 cells, $\mathrm{n}=6$ animals). All PDH-La were connected to the lamina through neurites extending distally, which branched in the lamina. Fibers ramifying in the lamina showed weaker immunoreactivity than other PDH-ir fibers of the eyestalk. The lamina was additionally innervated by fine PDH-ir fibers that arose from the distal part of the medulla and followed other fibers of the first optic chiasm. However, some fibers of the first optic chiasm appeared to originate from somata of the PDH-La (Fig. 11B). The PDH-ir fibers within the lamina were distributed throughout the neuropil in a rather reticulated manner, but a fiber concentration in two layers was faintly visible. In the medulla and lobula however, tangential PDH-ir fibers innervated distinct layers of the medulla and lobula with the single layers 


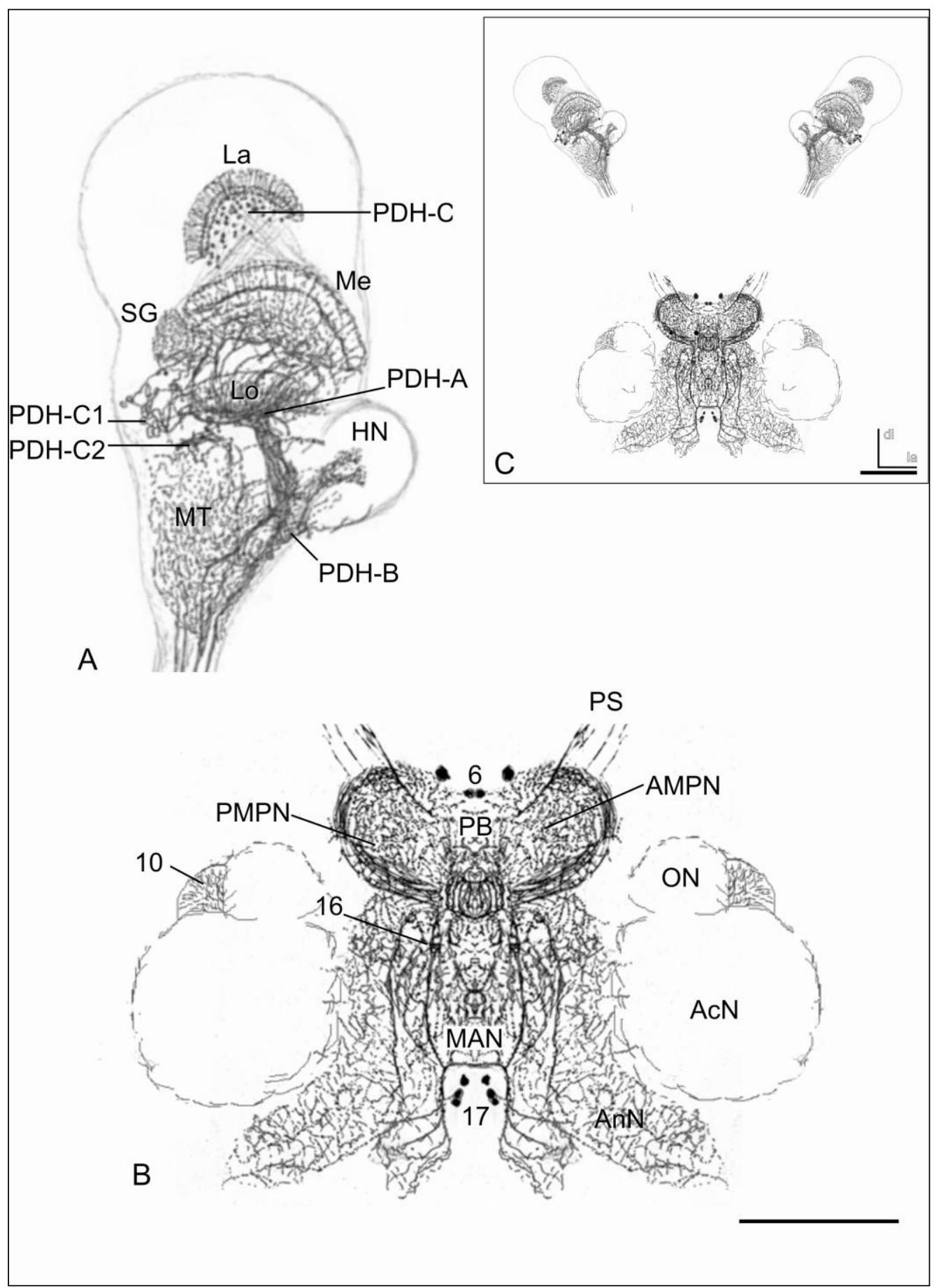

Figure 10. Schematic reconstruction of pigment dispersing hormone immunoreactivity in the eyestalk and the central brain of the marbled crayfish Procambarus spec. Reconstructions were drawn from a complete immunostained horizontal series of 50 $\mu \mathrm{m}$-sections. (A) PDH immunoreactivity in the eyestalk was found in cells associated with the lamina (PDH-La) and three additional groups: PDH-A, PDH-B, and PDH-C, the latter with subgroups PDH-C1 and PDH-C2. (B) In the central brain, somata were found in four groups named PDH-CBC6, PDH-CBC9, PDH-CBC16, and PDH-CBC17 (numbers 6, 9, 16, and 17, respectively). (C) Overview of PDH-ir reconstruction in central brain demonstrates size relations of eyestalk and central brain structures. AcNm, accessory lobe; AMPN, anterior medial protocerebral neuropil; AnN, antenna II neuropil; DCN, deutocerebral commissure neuropil; HN hemiellipsoid body; La, lamina; LAN, lateral antennal I neuropil; Lo, lobula; MAN, median antennal I neuropil; Me, medulla; MT medulla terminalis; OC esophageal connectives; OGTN, olfactory globular tract neuropil; ON, olfactory lobe; OT, optic tract; PB, protocerebral bridge; PMPN posterior medial protocerebral neuropil; PS, protocerebral stalk; PT, protocerebral tract; Scale bars: $500 \mu \mathrm{m}$. 
interconnected by columnar fibers (Fig. 11C, D). In the medulla, the most proximal, the most distal, and two middle layers were PDH-ir. In the lobula, three layers were PDH-ir, but not the most distal and proximal layers. The medulla terminalis was differentially innervated with PDH-ir fibers, but without forming layers (Fig. 11E). A conspicuous stalk of PDH-ir fibers extended into the HN1 part of the hemiellipsoid body (Fig. 10A). Most of the PDH-ir fibers that innervated medulla, lobula, medulla terminalis, and hemiellipsoid body appeared to arise from the groups $\mathrm{PDH}-\mathrm{A},-\mathrm{B}$, and -C. The largest group was $\mathrm{PDH}-\mathrm{C}$ consisting of about 18-20 somata with diameters of $32.04 \pm 1.96 \mu \mathrm{m}$ (mean \pm SEM) (Fig. 12C). This group was regularly subdivided in a group $\mathrm{PDH}-\mathrm{C} 1$ lying more anteriorly of the optic lobe and consisting of smaller somata $(18.56 \pm 1.38 \mu \mathrm{m})$, and a group PDH-C2 lying more dorsally. In some preparations, the $\mathrm{PDH}-\mathrm{C} 2$ formed two further subgroups. The $\mathrm{PDH}-\mathrm{A}$ and $\mathrm{PDH}-\mathrm{B}$ consisted of $1-3$ and 2 cells, respectively, of about $18 \mu \mathrm{m}$ diameter $(18.36 \pm 0.78 \mu \mathrm{m})$ (Fig. 11E). The PDH-A was located at the distal margin of the hemiellipsoid body, while the PDHB was situated at its proximal margin, the latter probably as part of the X-organ. It is likely that most (if not all) of these groups contributed to a thick bundle of PDH-ir neurites that originated at the proximal lobula and headed between medulla terminalis and hemiellipsoid body to the optic peduncle (Fig. 10A). A large portion of the fibers innervating the medulla terminalis and the fibers innervating the hemiellipsoid body appeared to arise from this bundle. However, most of the layered PDH-ir projections of the medulla and lobula appeared to arise from the PDH-C, as probably are the PDH-ir fibers of the sinus gland, which release PDH into the hemolymph. However, corresponding projection areas of the PDH-A-C groups were difficult to determine due to extensive overlap of fibers. In the central brain consisting of median protocerebrum, deutocerebrum, and tritocerebrum, PDH-ir cells formed four bilateral groups (Figs.10B, C, 11F-I). The first group situated in the CBC6 (PDH-CBC6) comprised one large soma accompanied by one or two somata of smaller diameter $38 \pm 0.57 \mu \mathrm{m}$ per side 
(Fig. 11G). All these cells projected neurites to the anterior medial protocerebral neuropil (AMPN), where they ramified and mixed with profuse PDH-ir fiber innervation originating from the ipsilateral and possibly contralateral eyestalks and run along the optic peduncle to the median protocerebrum. A second group found in Neuropil 9 (PDH-CBC9) included about 8 cells per side and projected neurites posteriorly that ramified in deutocerebral neuropil masses. Nearby in CBC16 resided a group of about 6 neurons (PDH-CBC16) with apparently similar projection areas, but their posteriorly projecting neurites were positioned more medially to that of PDH-CBC9. The last cluster was situated in the CBC 17 (PDH-CBC17; Fig. 11H, I). It consisted of three somata per side, which projected neurites through the circumesophageal connectives to the subesopageal ganglion. Axons from PDH-CBC17 probably innervate also the antenna II neuropils $(\mathrm{AnN})$ of the tritocerebrum. Nearly all neurons of the $\mathrm{CBC} 10$ were faintly labeled, but this labeling was just above background level and difficult to discern as real immunostaining, for which reason I considered them not to be PDH-ir.

Most neuropils of the central brain contained PDH-ir fibers, except the olfactory and accessory lobes, which where surrounded by a thin sheath of PDH-ir fibers (Fig. 10B and C). The densest projections were found in the dorsal-anterior and ventral-posterior parts of the AMPN, the ventral part of the posterior medial protocerebral neuropil (PMPN), the median antenna 1 neuropil (MAN), and the AnN (Figs 11F-I). At least in the AMPN, a huge part of its PDH-ir fibers originated from somata in the eyestalks. They form, apparently together with neurites of the PDH-CBC6, a conspicuous arc of fiber bundles that run from the base of the protocerebral stalks distally and posteriorly along the AMPN and PMPN to the brain midline and to the contralateral hemisphere (Fig. 10C). Other PDH-ir fibers of the eyestalks continued to more posterior regions of the central brain, innervating on their way the central body, MAN and AnN. Whether innervations of these structures originate from the contralateral or 


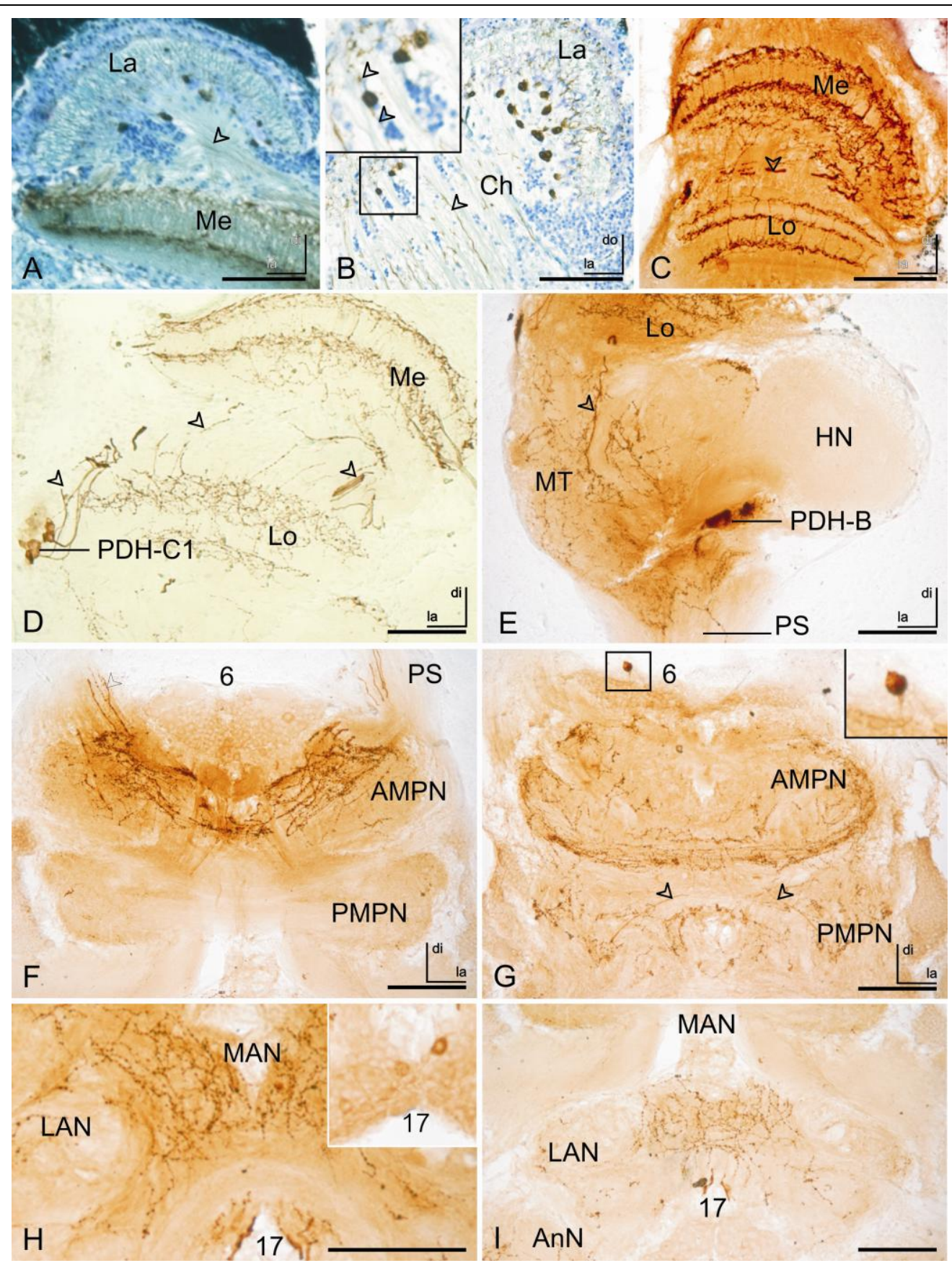

Figure 11. PDH immunoreactivity expressed in the eyestalk and central brain of the marbled crayfish Procambarus spec. (A) Lamina cells (PDH-La) and their axons project to the lamina, where weak immunoreactivity was found. Arrowheads: PDH-ir fibers in the first chiasm. (B) Some PDH-La form projections through the first optic chiasm (ch) to the medulla additionally to their normal projections to the lamina (arrowheads). However, most chiasmic PDH-ir fibers appear not to originate from the PDH-La. (C, D) PDH-ir in the medulla and lobula of the eyestalk. Both structures show a layered arborization pattern. The open arrowhead shows PDH-ir fibers projecting between lobula and medulla through the second optic chiasm. The filled arrowhead shows primary neurites of the PDH-C1. (E) The PDH-B at the proximal margin of the hemiellipsoid body (HN; in this section plain none of its PDH-ir fibers are visible) appear to belong to the X-organ. PDH-ir fibers running through the medulla terminalis (MT, arrowhead) could be traced into the protocerebral stalk. (F) Fibers from the eyestalks innervate central brain regions, as the anterior medial protocerebral neuropil (AMPN) through the protocerebral stalk (PS). (G) In this section plain further ventrally, also the posterior medial protocerebral neuropil (PMPN) is innervated with PDH-ir fibers. The inset shows a neuron belonging to the PDH-CBC6 (6), which projects to the central complex region. Some fibers proceed from the AMPN/PMPN to deutocerebral regions (arrowhead). (H) and (I) show PDH-immunoreactive fibers in the deutocerebrum, including the median antennal I neuropil (MAN), lateral antennal I neuropil (LAN), and antenna II neuropil $(\mathrm{AnN})$. The inset in $\mathrm{H}$ shows somata of the PDH-CBC17 in a more dorsal section plane. AnN, antenna II neuropil. HN hemiellipsoid body; La, lamina; Lo, lobula; Me, medulla; MT medulla terminalis; Scale bars: $100 \mu \mathrm{m}$ (except E: $500 \mu \mathrm{m}$ ). 
ipsilateral eyestalk was difficult to asses and fibers crossing the brain midline were detected at different places. As in the optic lobe, the exact assignment of fiber projections in the central brain to particular soma groups was difficult to assess owing to overlap of fiber projections.

\section{FMRF expressing neurons in the eyestalk and brain of the marbled crayfish}

FMRFamide immunoreactivity in the crayfish brain was assessed on vibratome sections and labeled with fluorescent markers. Nearly all neuropils of the eyestalks and central brain contained FMRFamide-ir fibers, which originated from relatively few somata grouped in different areas of the brain (Figs. 12, 13). Many FMRFamide-ir somata were found in similar locations as PDH-ir cells bodies.

In the eyestalk, five groups of FMRFamide-ir somata were found. Two groups lied near the lamina. The FMRF-Lal was clustered at the posterior border of the lamina, while the FMRF-La2 (see filled arrowhead in Figure 14E) was dispersed near the proximal surface of the lamina, similar to the PDH-La (Fig 10 A). At the proximal and distal margin of the hemiellipsoid body, two groups of FMRFamide-ir neurons resided at the locations were PDHA and PDH-B were found and were named FMRF-A and FMRF-B accordingly. A group named FMRF-C partly overlapped with the PDH-C (Fig 13B, and Fig 10 and 12 for reference). Other cells also coincide with the group $\mathrm{C}$, but seem to extend larger in the medial margin of the MT (Figure 12). The cells belonging to the group FMRH-La resemble the PDHLa cells in size and morphology, but with the difference that FMRF-immunoreactivity was weaker. In addition, in the most lateral region of the lamina and anterior to the medulla, a compact cluster of cells of similar size was observed in some samples. Groups A and B are both constituted of variable numbers of cells between individuals, ranging from 8 to 9 cells, and seem to send axons to the MT, those from group B running ventrally to the commissure joining the HN with the MT. FMRF-C is distributed from the lateral margin of the medulla to 
the base of the MT. It is constituted of two different cell types Some cells of large diameter (about 18) send axons to the MT but others of smaller size did not show axons (between 20 and 30, individual differences). Processes were also identified in the La and some in the Lamedulla chiasm, in the medulla and lobula, and in the medulla-lobula chiasm. Axons which originate from FMFR-C big cells innervate the MT. Many of these axons also form a bundle which diverges. One ramification innervates $\mathrm{HN} 1$ and the other forms a bundle that ramifies in a region at the base of the lobula, innervating this structure profusely.

Fibers from the MT also run along the OGT in direction of the brain. Those OGT fibers from the MT reach the AMPN where their branches form profuse thinner ramifications (Fig $13 \mathrm{C}$ and $\mathrm{D})$. Main fibers continue to the PMPN and bifurcate. One branch extends in direction to the midline crossing next to the eosophageal foramen and following posterior to the circumesophageal connectives. The second branch (on both sides) runs more lateral but also reaches the circumesophageal connectives and the AnN (Figure 13 D and E). FMRFimmunoreactivity was also displayed by cells of the brain. Many of the cells and fibers in the accessory lobes (AcN, ON, NP10 and NP11) showed FMRF immunostainnig (Fig 13 F). In addition, multiple cells of NP6 also contain FMRF (FMRF-NP6). The numbers of immunoreactive cells within this group varied among inviduals from 35 to 80. FMRF-NP6 cells send axons posteriorly, very likely to the central body (CB) where FMRF-ir was also found. A single cell, maybe belonging to $\mathrm{CBC} 12$ was found to contain FMRF as well as 3 cells in $\mathrm{CBC} 15$. Furthermore, strong immunoreactivity was detected in the protocerebral bridge (PB), the central body and surrounding the esophageal foramen and MAN as well as in the DCN and the AnN. Abundant immunoreactivity, in possible nerve terminals was observed in DCN and LAN (Figure 12). 


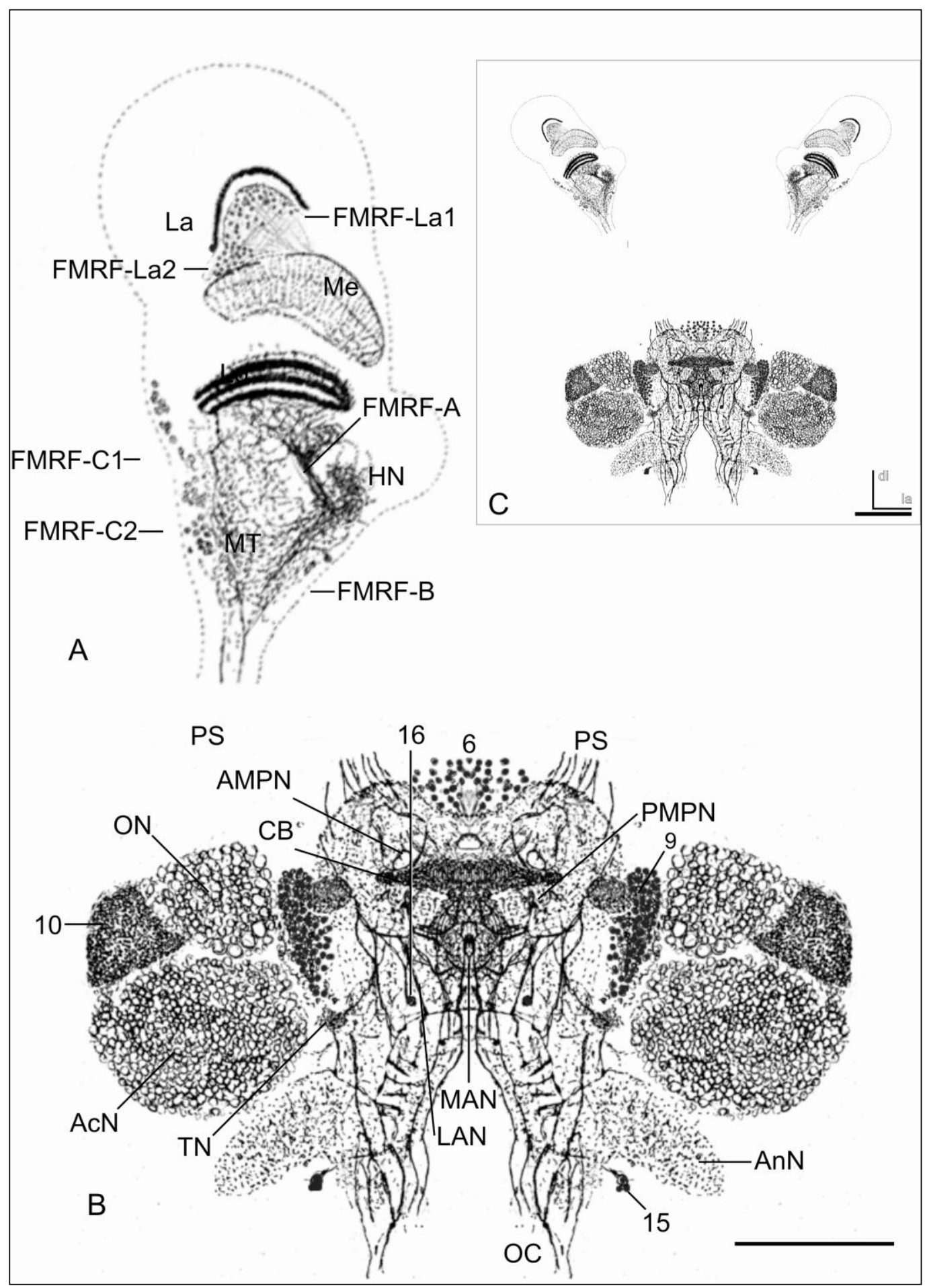

Figure 12. Reconstruction of FMRFamide immunoreactivity in the eyestalk and the central brain of the marbled crayfish Procambarus spec. Reconstructions were drawn from a complete immunostained horizontal series of $50 \mu \mathrm{m}$-sections. (A) FMRF immunoreactivity in the eyestalk was found in the proximity of the lamina (FMRF-La1, FMRF-La2) and in three groups of cells in the medulla terminalis: FMRF-A, FMRF-B, an FMRF-C (the latter with subgroups FMRF-C1 and FMRFC2). (B) In the central brain, several FMRFamide-ir soma groups were found: FMRF-CBC6, FMRF-CBC15, FMRF-CBC16, FMRF-CBC9, and FMRF-CBC10. FMRF-CBC12 with one soma per side is not visible here. (C) An overview of FMRFamide immunoreactivity in both eyestalks and the central brain is depicted in the square. AcN accessory lobe; AMPN, anterior medial protocerebral neuropil; AnN, antenna II neuropil; DCN, deutocerebral commissure neuropil; HN hemiellipsoid body; La, lamina; LAN, lateral antennal I neuropil; Lo, lobula; MAN, median antennal I neuropil; Me, medulla; MT, medulla terminalis; OC, esophageal connectives; OGT, olfactory globular tract; OGTN, olfactory globular tract neuropil; ON, olfactory lobe; PB, protocerebral bridge; PMPN, posterior medial protocerebral neuropil; TN, tegumentary neuropil; Scale bars: $500 \mu \mathrm{m}$. 


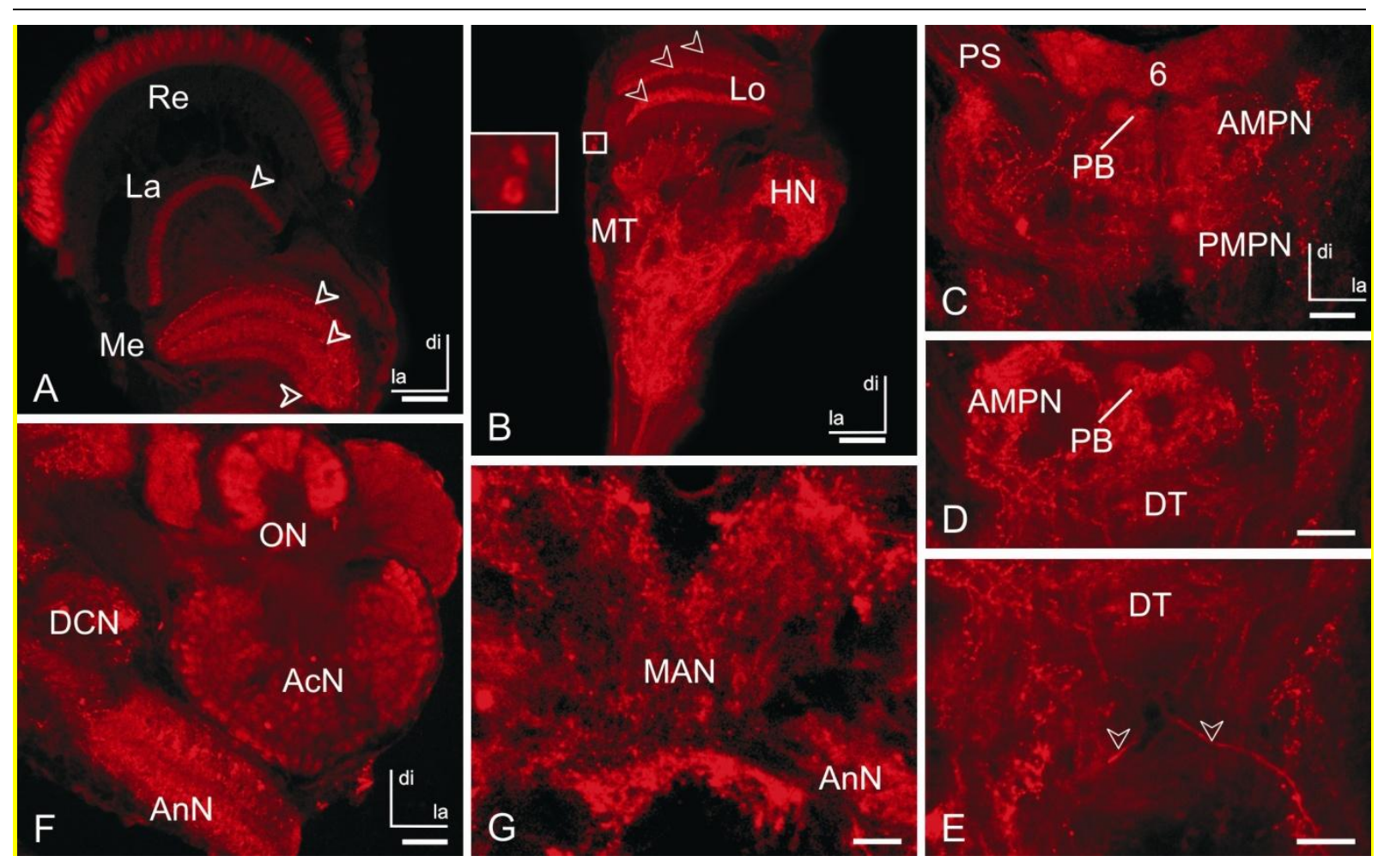

Figure 13. FMRFamide immunolabeling in horizontal sections of the eyestalk and central brain of the marbled crayfish Procambarus spec. (A) Detail of immunoreactivity in the lamina and the medulla, where one and three layers, respectively, can be distinguished (arrowheads). (B) FMRF-ir layers in the medulla (Me) and fibers innervating the medulla terminalis (MT) and hemiellipsoid body (HN). FMRFamide-ir fibers extend via the protocerebral stalk (PS) into the central brain. The inset shows magnified somata of FMRF-C neurons. (C, D) In the central brain, most regions were pervaded by FMRF-ir fibers. Many FMRFamide-ir somata were located in the CBC6 group (PDH-CBC6; 6). (D) In a more dorsal section following $\mathrm{C}$, neurites of FMRF-CBC6 reaching the protocerebral bridge (PB) could be observed. (E) FMRFamide positive fibers can be seen in the antenna II neuropil (AnN) and deutocerebral commissure neuropil (DCN), and weak immunoreactivity was found in the glomeruli of the olfactory neuropil $(\mathrm{ON})$ and accessory lobe $(\mathrm{AcN})$. $(\mathrm{F})$ and $(\mathrm{G})$ show immunoreactive fibers that branch in the deutocerebrum (e. g., the lateral antenna I neuropil; MAN) and tritocerebrum (e. g., antennal II neuropil, AnN), arrowheads show main fibers originated in eyestalks and projecting to caudally. AMPN, anterior medial protocerebral neuropil; CB, central Body; HN, hemiellipsoid body; L, lobula; La, lamina; LAN, lateral antenna I neuropil; Me, medulla; MT medulla terminalis; ON, olfactory lobe; PB, protocerebral bridge; PC, protocerebral stalk; PMPN, posterior medial protocerebral neuropil; Re, retina; Scale bar: $100 \mu \mathrm{m}$

\section{Colocalization of FMRF- and PDH-ir in the eyestalk}

My results from PDH and FMRF immunostaining revealed some groups of cells in the eyestalk containing both neuropeptides. In order to determine whether some homology of these cells with the PDH-Me and AccMe of insects exist the next step was to assay a double immunostaining of PDH and FMRFamide simultaneously (Fig 14). Double immunostainning showed colocalization of both neuropeptides in many cells of the La. In fact all PDF-ir cells showed also FMRF immunoreactivity (PDH-FMRF-La) (Fig 14 A - F). Contrary, the compact 


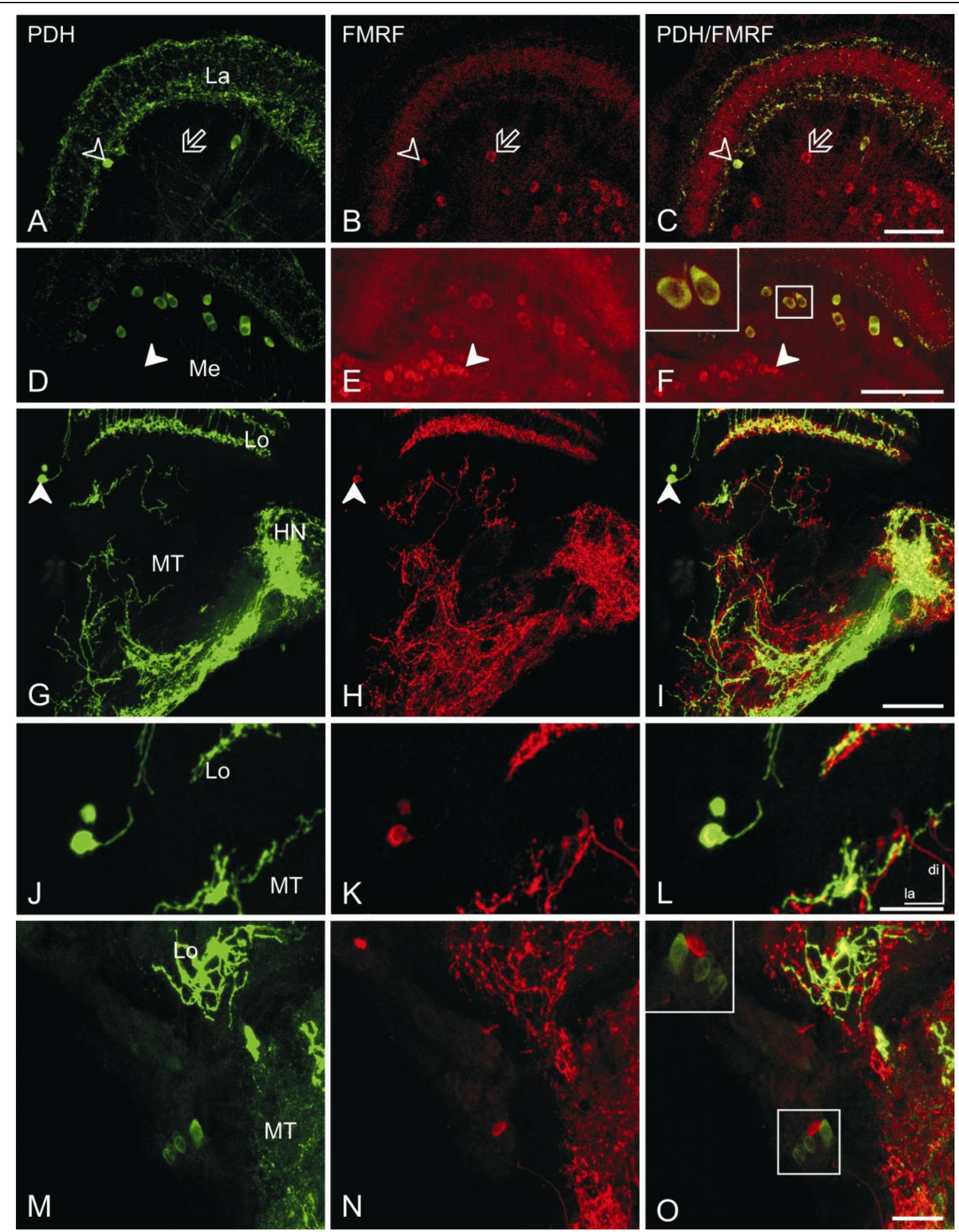

Figure 14. Double immunofluorescent labeling against PDH and FMRFamide in horizontal sections through the eyestalk of the marbled crayfish was performed on $50 \mu \mathrm{m}$-sections. The images show maximum projections of several CLSM optical sections scanned at $2 \mu \mathrm{m}$ z-distances. PDH-ir is pseudo-colored in green, FMRFamide-ir in red. Overlapping immunoreactivities appear in yellow. (A-F) All PDH-ir neurons of the lamina (PDH-La, open arrowheads in A-C) showed additional FMRFamide immunoreactivity and thus, were identical with the FMRF-La1 group. In contrast,, not all FMRF-La1 neurons were additionally PDH-ir (arrows in A-C). A compact group of FMRF-ir neurons associated with the lamina (FMRF-La2, filled arrowheads in D-F) was not PDH-ir. The detail in (F) shows colocalization of PDH and FMRFamide immunoreactivity in two selected PDH-La somata. (G-O) anti-PDH/FMRF colocalization was observed in somata of the group PDH-C (arrowheads in G-I). The group shown in G-H is magnified in (J-L). Other members of PDH-C did not show additional FMRF-ir, and also FMRF-C somata without PDH-ir were observed. HN, hemiellipsoid body; La, lamina; Lo, lobula; Me, medulla; MT, medulla terminalis; Scale bars: (C, F, L and O) $100 \mu \mathrm{m}$, in (I) $500 \mu \mathrm{m}$. 
cluster of cells immunoreactive to FMFR in the margin of the La and the medulla did not show PDH immunoreactivity (Fig. 14 E, arrowheads). All of the PDH-FMRF-La cells send axons to the La as described before. Fibers of the medulla and lobula, showed also simultaneous immunostaining to PDH and FMRF (Fig 14 A - F), in the same way as fibers of the MT and fibers in between those structures (Fig $14 \mathrm{G}-\mathrm{I}$ ). In the group A, double immunostainning was not observed, although differentially labeled cells were located next to each other. In group B, at least one cell was immunostained with both neuropeptide-antisera. In group $\mathrm{C}$ most of cells with large somata colocalized PDH and FMRF, as well as their axons (Fig $14 \mathrm{G}-\mathrm{L}$ ). Few cells contained only one of the neuropeptides (Fig 14, M-O). C' and C' also displayed the same pattern. Some cells colocalized bot peptides and others showed either FMRF- or PDH-ir. These results, point to the cells of group $\mathrm{C}$ as strong candidates to be homologous to medulla cells in insects which colocalize FMRF and PDH.

\section{Backfills reveal centrally projecting PDH-neurons of the eyestalk}

In order to identify possible inputs and outputs of double immunostained cells, mainly of group $\mathrm{C}$, neurobiotin was used to tract the projections of their axons and determine whether they communicate to the median protocerebrum or directly communicate with contralateral structures. The ipsilateral backfilling generated neurobiotin accumulation in cells that also showed PDH-FMRF. This was specially observed in cells belonging to group C (Figure 15). This observation suggests that PDH-FMRF-C neurons project to the protocerebrum. The question of whether they also send projections to contralateral eyestalks was studied by backfills into the central brain with neurobiotin. These did not label projections from PDHFMRF-C in any case (Figure 16). Neurobiotin staining successfully reached cells of the group $\mathrm{C}$ and even reached the medulla of contralateral eyestalks However no triple staining was detected (see Figure 16D). Again many cells showed PDH-FMRF immunoreactivity, as 
observed in previous double immunostainings, but none of these cells was accumulated neurobiotin via backfilling. These results exclude the idea of direct communication from possible pacemaker structures in the eyestalks with ther contralateral partners via direct connections of PDH-ir neurons.

\section{Allatotropin and 5-HT in the eyestalk}

Allatotropin immunoreactive cells were found in the eyestalk of the crayfish, but they were not localized in a particular arrangement. Some solitary allatotropin immunoreactive cells (Figure 17D) were found dispersed in the lamina and in the medulla. In the proximity of PDH-C immunoreactive cells, some somata contained allatotropin. Some of these cells also contained serotonin (Figure 18). Despite of a group of serotonin-allatotropin immunoreactive cells, no AcMe-like structure was found. PDH-C cells did not colocalize neither with allatotropin nor with serotonin (Figure 18D). Serotonin immunoreactivity was localized in a different locus of the eyestalk (described with more detail in the next section). Serotonin immunoreactive cells were also found in the region of the medulla terminalis, in the proximity of the $\mathrm{HN}$ and in the region of PDH-C cells, as well as in the region between the lamina and lobula, but no colocalization with PDH was found in any preparation (Figure 18). Serotonergic fibers were dispersed in the medulla terminalis and projected to the brain, sometimes in close proximity with PDH-ir fibers. 


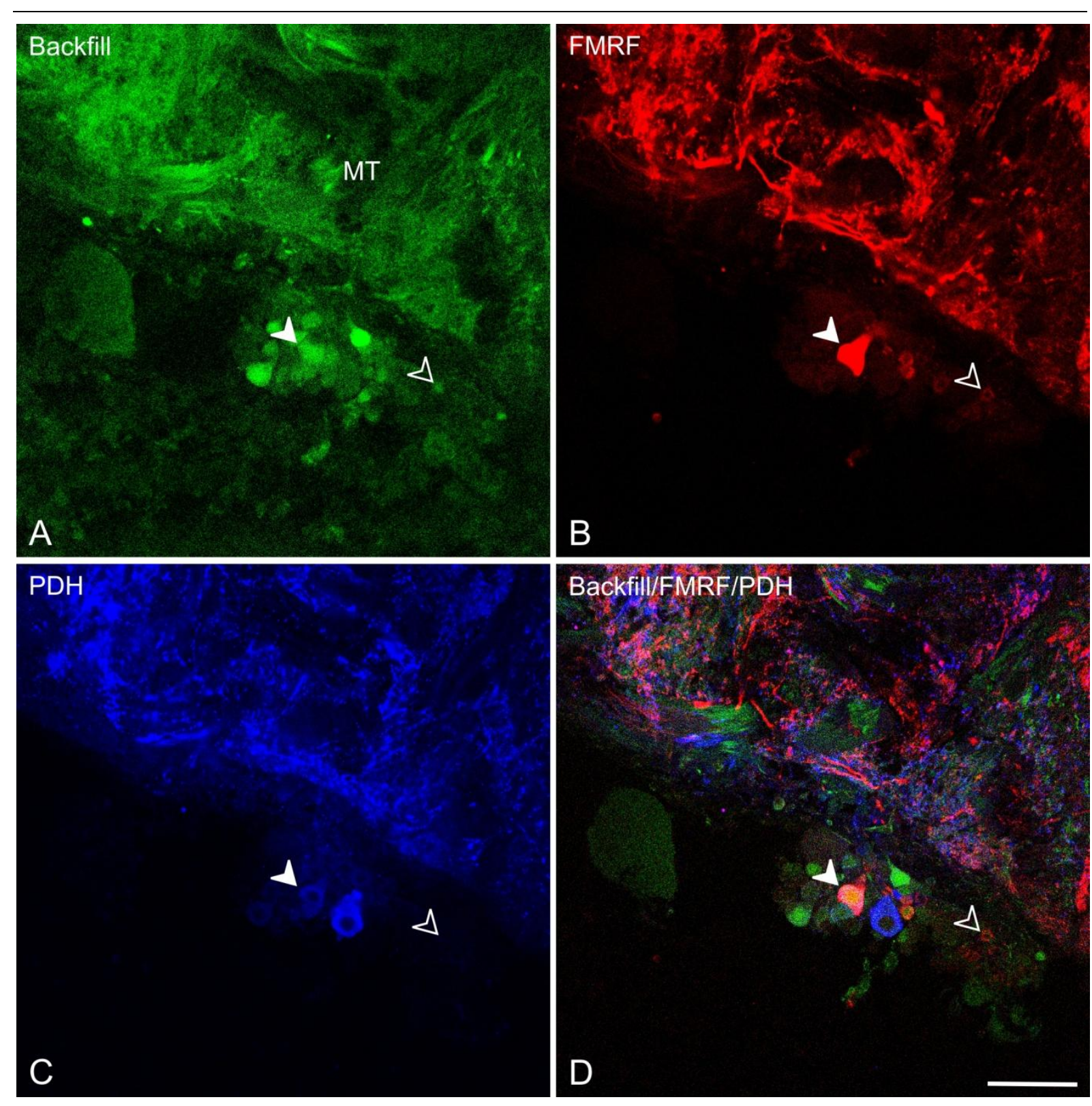

Figure 15. Neurobiotin backfill to the ipsilateral eyestalk combined with anti-PDH and anti FMRFamide immunocytochemistry. In order to track innervations from presumptive peacemaker cells in the eyestalk to the central brain, neurobiotin was applied to the protocerebral stalk. The figure shows three channels (A-C) and one overlay (D) of a maximum projection of a CLSM optical section series scanned at $2 \mu \mathrm{m}$ z-distance. Neurobiotin backfill is pseudo-colored in green, FMRFamide-ir in red, PDH-ir in blue. Near the medulla terminals (MT) neurobiotin impregnated neurons belonged to group PDH-C, which were also FMRFamide-ir (solid arrowheads), and which were therefore assumed to project to the central brain. Additionally, neurons of the FMRF-C group that were not PDH-ir showed biotin labeling (open arrowheads). In the vicinity of the PDH-C and FMRF-C additional cell bodies were backfilled that were not immunolabeled. Scale bar: 100 $\mu \mathrm{m}$. 


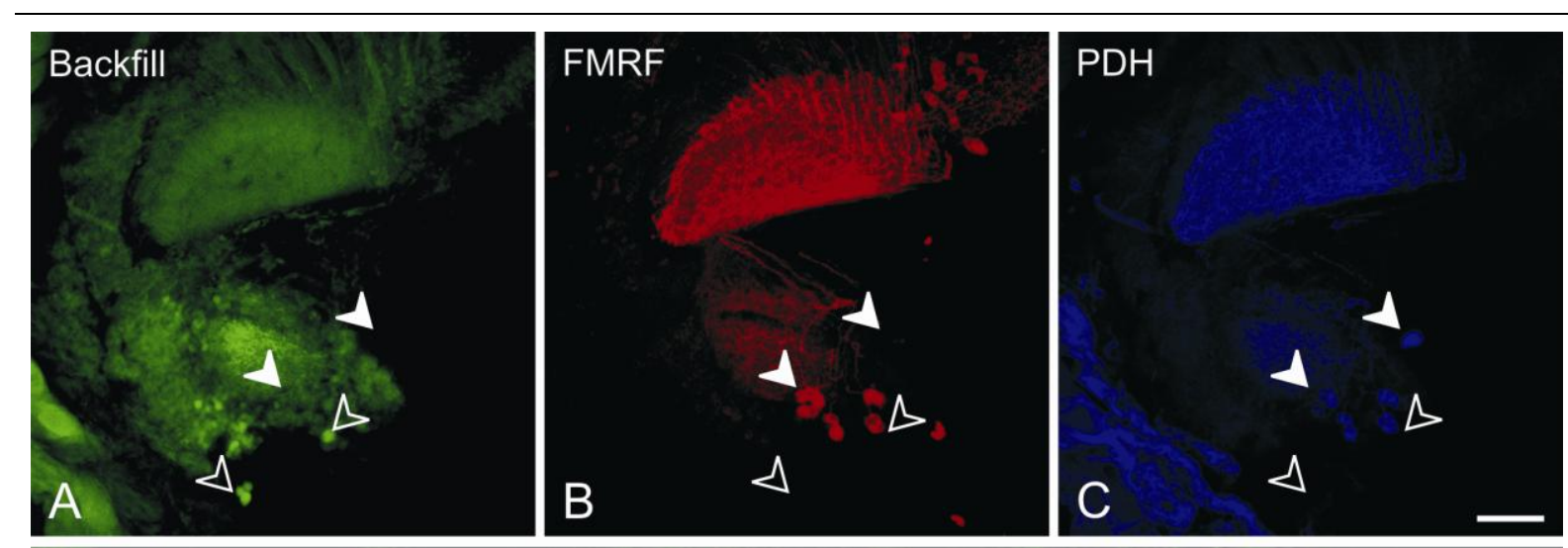

Backfill/FMRF/PDH

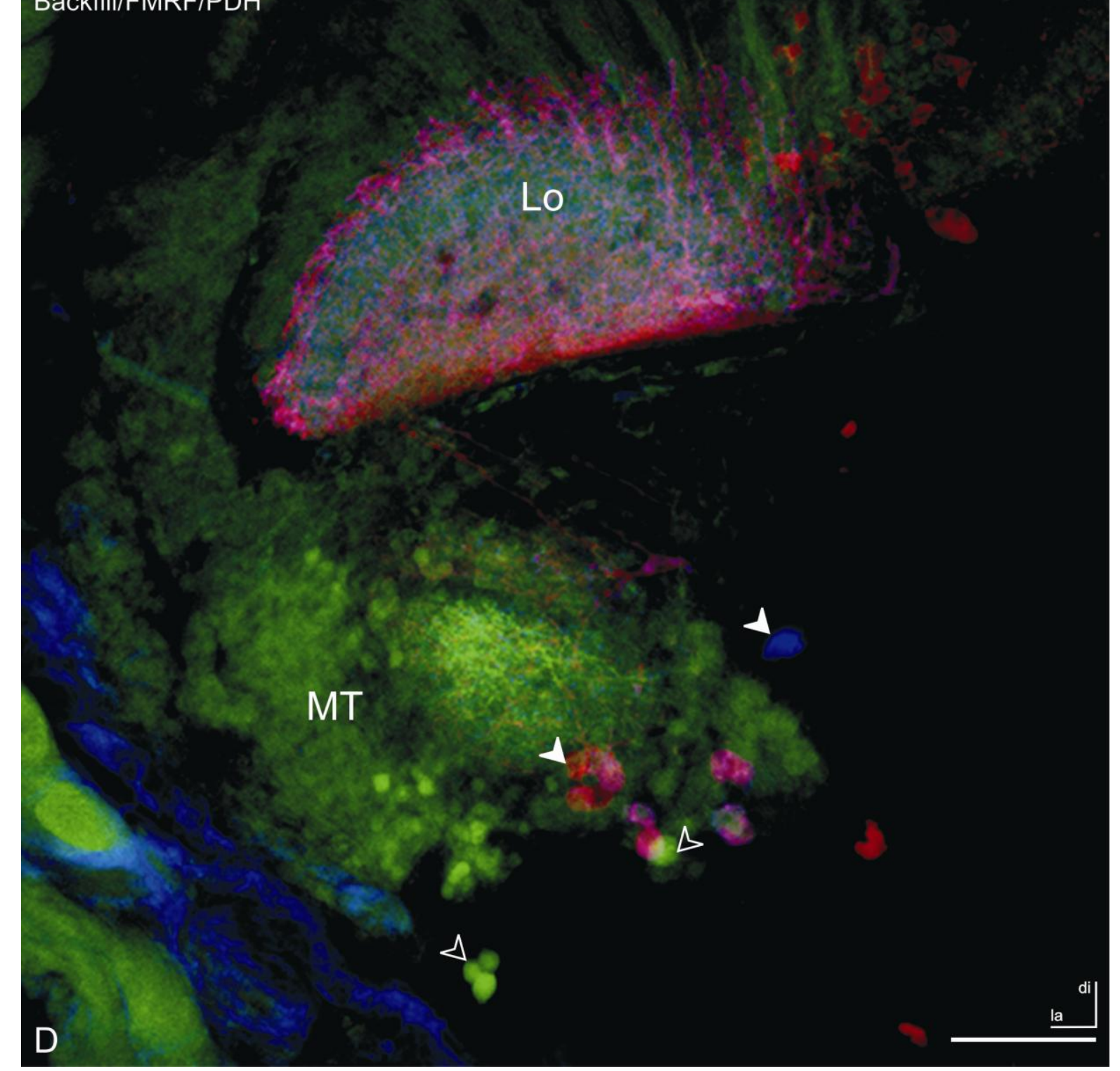

Figure 16. Neurobiotin backfill from one protocerebral stalk to the contralateral eyestalk combined with anti-PDH and antiFMRFamide immunocytochemistry. The figure shows three channels $(A-C)$ and one overlay (D) of a maximum projection of a CLSM optical section series scanned at $2 \mu \mathrm{m}$ z-distance. Neurobiotin backfill is pseudo-colored in green, FMRFamide-ir in red, PDH-ir in blue. Neurobiotin labeling reached somata near the PDH-C and FMRF-C, thus indicating that these neurons project to the contralateral optic lobe (open arrowheads). However, PDH- and /or FMRF-ir neurons (filled arrowheads) were never backfilled, thus indicating that PDH-C and/or FMRF-C neurons do not project to the contralateral eyestalk. Lo, lobula; MT, medulla terminalis. Scale bar: $100 \mu \mathrm{m}$. 


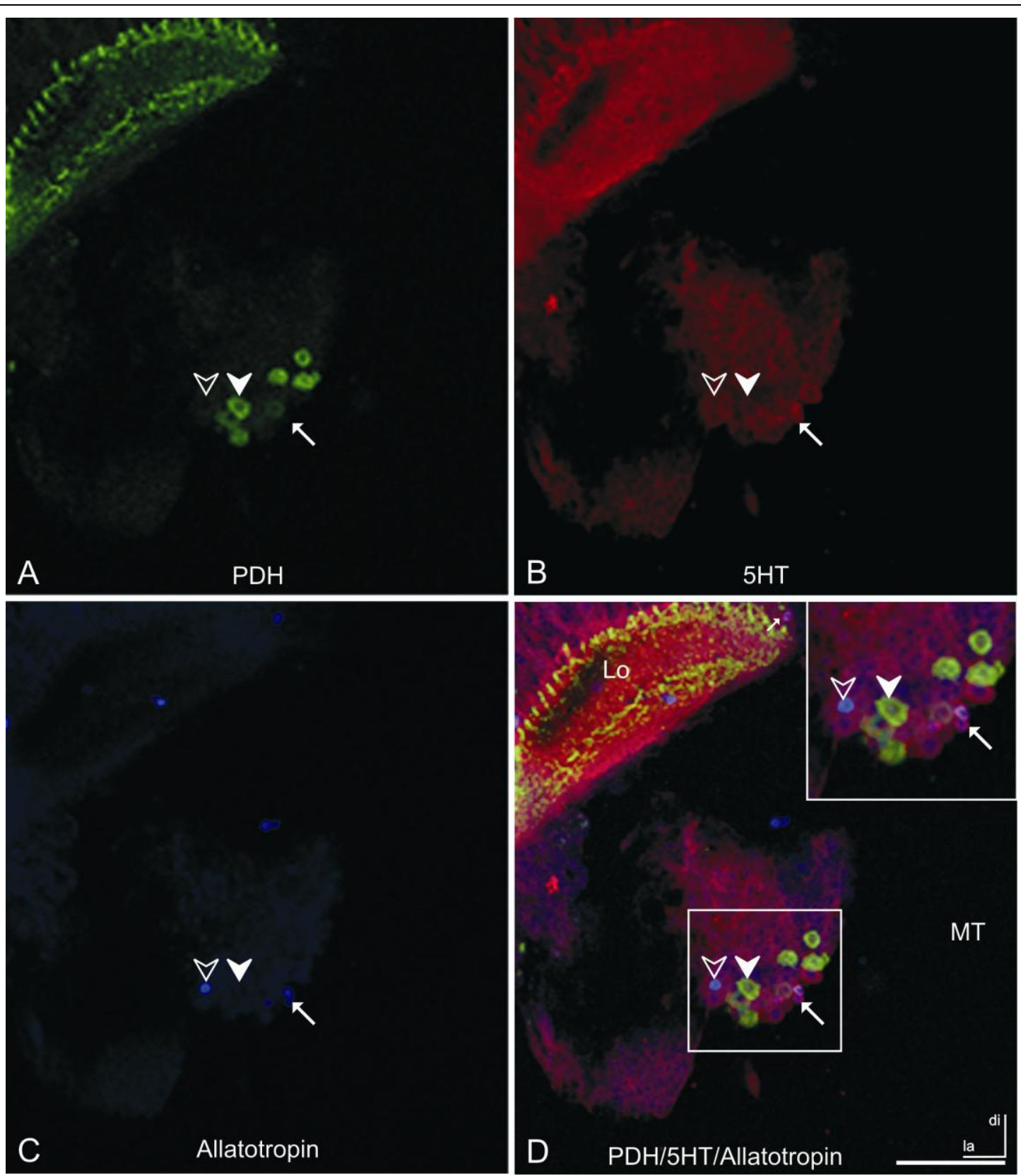

Figure 17. Triple immunolabeling against PDH (A), serotonin (5HT, B) and allatotropin (C) with overlay (D). The figure is a maximum projection of a CLSM optical section series through one optic lobe scanned at $2 \mu \mathrm{m}$ z-distance. PDH immunoreactive neurons, in this example members of the PDH-C (filled arrowheads and inset in (D)), were not immunoreactive against serotonin or allatotropin antisera. However, in their proximity and also scattered throughout the eyestalk, neurons showing allatotropin immunoreactivity alone (open arrowheads), serotonin immunoreactivity alone, and colocalized allatotropin and serotonin immunoreactivity (arrows) were observed. Lo, Lobula; MT, medulla terminalis. Scale bar: $100 \mu \mathrm{m}$. 


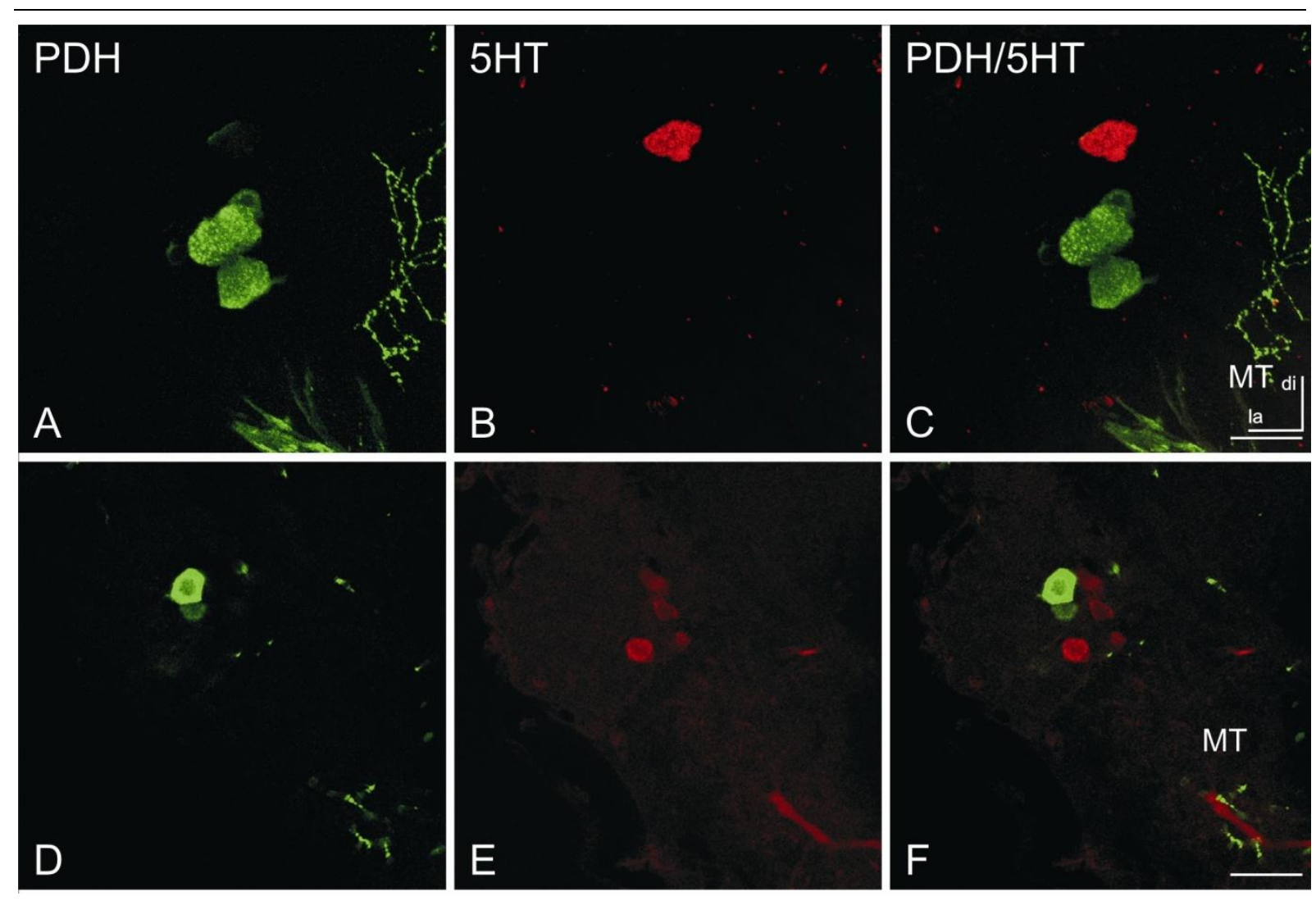

Figure 18. Double immunolabeling against PDH and serotonin (5HT) in the region of the PDH-C group in a crayfish's eyestalk. Images are maximum projections of a CLSM optical section series with $2 \mu \mathrm{m}$ z-distance. Serotonin-ir neurons were found in vicinity to PDH-C1 (A-C) and PDH-C2 (D-E), but no colocalization was detected in any preparation. MT medulla terminalis. Scale bar $100 \mu \mathrm{m}$. 


\section{Serotonin, NAS and Melatonin diurnal concentrations in brain and eyestalks}

Serotonin, N-acetylserotonin (NAS) and melatonin titers in brains and eyestalks of the marbled crayfish were measured by ELISA. Serotonin and N-acetylserotonin were assayed in the same system, whereas melatonin measurements were performed separately. Since the ELISA performed was an adaptation of ELISA protocols designed for measurements of signaling molecules in vertebrates, a new standard curve was established for crayfish tissues. The new standard curve for serotonin and NAS was sensitive to concentrations ranging from 0.2 to $258 \mathrm{ng} / \mathrm{ml}$ and that for melatonin to concentrations between 1 to $1000 \mathrm{pg} / \mathrm{ml}$. Mean values obtained for different nervous tissues (brain or both eyestalks) and for every substance (mean \pm S.E.M.) were as follows: for 5 -HT in brains $21.05 \pm 0.93 \mathrm{ng} / \mathrm{ml}, 5$-HT in eyestalks $6.75 \pm 0.36 \mathrm{ng} / \mathrm{ml}$, NAS in brains $5.65 \pm 0.29 \mathrm{ng} / \mathrm{ml}$, NAS in eyestalks $3.12 \pm 0.23 \mathrm{ng} / \mathrm{ml}$, melatonin in brains $30.82 \pm 1,61 \mathrm{ng} / \mathrm{ml}$, and melatonin in eyestalks $21.66 \pm 1.54 \mathrm{ng} / \mathrm{ml}$. In all cases concentrations in brain were higher than concentration in eyestalks.

In order to identify diurnal changes of the indolamine levels in eyestalks and brains, measurements at six different timepoints were performed. Values are presented as average from measurements of single brains and average obtained from values measured in eyestalk pairs (both eyestalk capsules including retina and cuticula). In the case of serotonin content in brains, highest concentrations occurred at the end of the photophase and were maintained until beginning of the scotophase with values of $23.83 \pm .4 .14 \mathrm{ng} / \mathrm{ml}$ and $23.22 \pm 1.62 \mathrm{ng} / \mathrm{ml}$ (17 and $21 \mathrm{hrs}$ ) and lowest values in the middle of the photopase (13 hrs) with $16.33 \pm 2.46$ $\mathrm{ng} / \mathrm{ml}$. A second increase occurred immediately after lights on (9 hrs) reaching $22.65 \pm 2.99$ $\mathrm{ng} / \mathrm{ml}$ (Figure 19A). Cosinor analysis showed $2.32 \%$ of rhythm $(\mathrm{p}<0.5)$ and ANOVA showed no significant differences between concentrations of serotonin in samples taken at different times $(\mathrm{p}=0.068)$. In the case of serotonin levels of the eyestalks, basal levels ranged from $5.17 \pm 0.57$ to $7.45 \pm 0.21 \mathrm{ng} / \mathrm{ml}$ over the day length, but serotonin titres increased to 
$10.40 \pm 1.54 \mathrm{ng} / \mathrm{ml}$ immediately after lights on (9 hrs) (Figure 19B). In this case, Cosinor analysis showed a $24.8 \%$ of rhythm (Acrophase $=9.31, \mathrm{p}=0.067)$. One way analysis of variance demonstrated a significant difference of the highest value with respect to the lowest value $(\mathrm{p}=0.011)$.

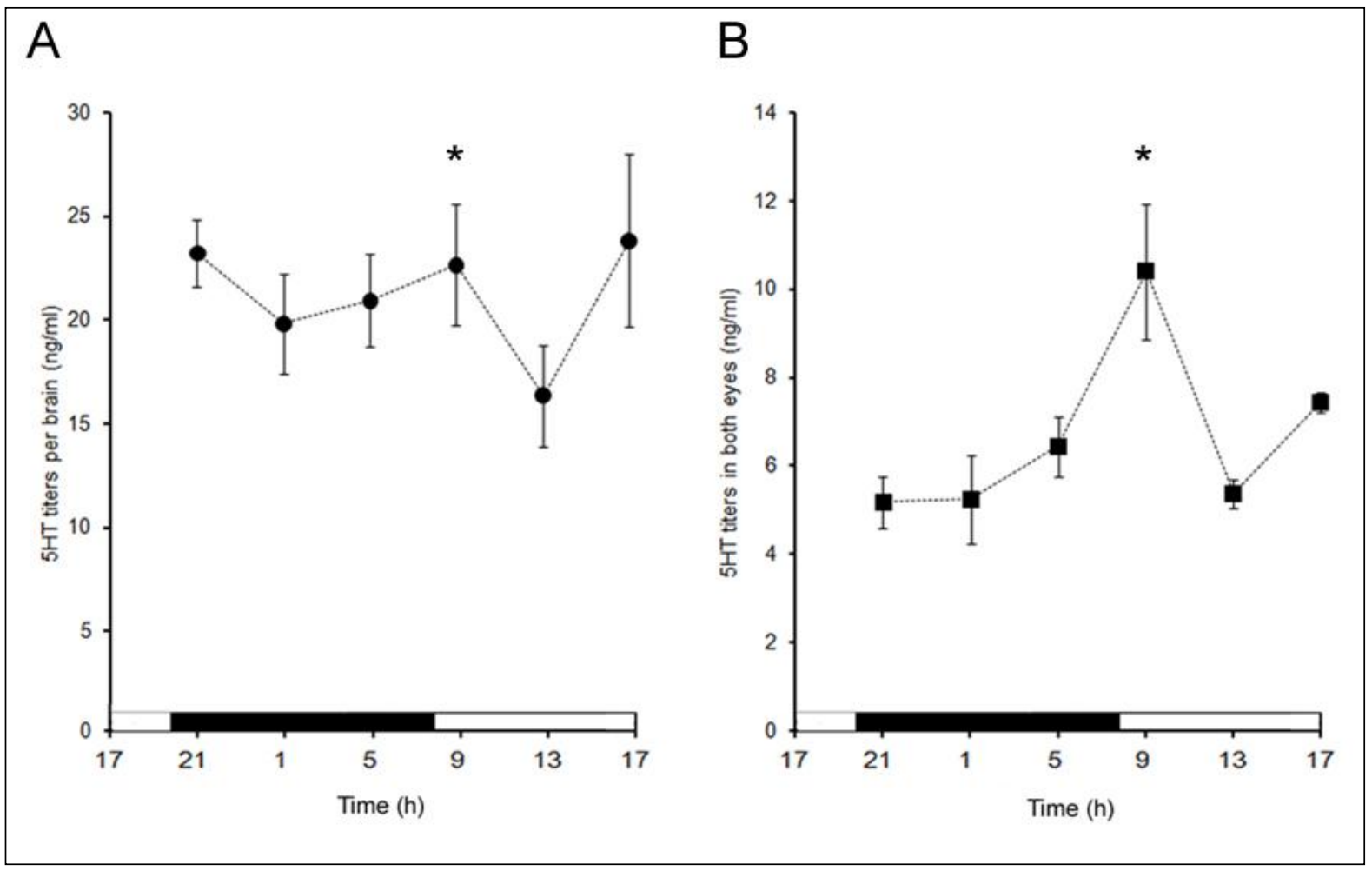

Figure 19. Diurnal changes of serotonin (5-HT) levels obtained by ELISA from brains (A) and eyestalks (B) of the marbled crayfish Procambarus spec. Each point represents mean \pm SEM $(n=3$ or 4 per time point). Samples were obtained every 4 hours. The first time point was one hour after lights on. Lights onset occurred at 8 hrs. Black bar represents 12 hours of scotophase and white bar 12 hours photophase (asterisk shows significant difference $\mathrm{p}=0.05$ ).

In the case of NAS concentrations of brains, highest values were observed during the middle and the end of the scotophase $(7.91 \pm 1.84 \mathrm{ng} / \mathrm{ml}$ and $7.88 \pm 1.50 \mathrm{ng} / \mathrm{ml}$ of NAS $)$, and started declining to reach the lowest concentrations at the end of the light phase (17 hrs) with lowest concentrations of $4.10 \pm 0.82 \mathrm{ng} / \mathrm{ml}$ of NAS (Figure 20A). In this case, analysis of variance showed differences between highest and lowest concentrations slightly above significance $(\mathrm{p}=0.061)$. The percentage of rhythm obtained was $16.82 \%(\mathrm{p}=0.83)$. 
Concerning NAS titers in the eyestalks the highest value occurred after lights off, at $21 \mathrm{hrs}$ with $4.08 \pm 0.83 \mathrm{ng} / \mathrm{ml}$ and decreased drastically to $1.72 \mathrm{ng} / \mathrm{ml}$ in the middle of the dark phase. Levels recovered at the end of the night to $3.65 \pm 0.20 \mathrm{ng} / \mathrm{ml}$, declined again to reach low values at the middle of the day with $2.46 \pm 0.70 \mathrm{ng} / \mathrm{ml}$ and recovered before light off. Differences between maxima and minima remained below significace $(\mathrm{p} \leq 0.05)$ (Figure 20B). In addition, cosinor analysis showed no significant adjustment to a sinusoidal curve, meaning the lack of significant rhythmicity $(3.19 \%$ of rhythm and $\mathrm{p}<0.05)$.

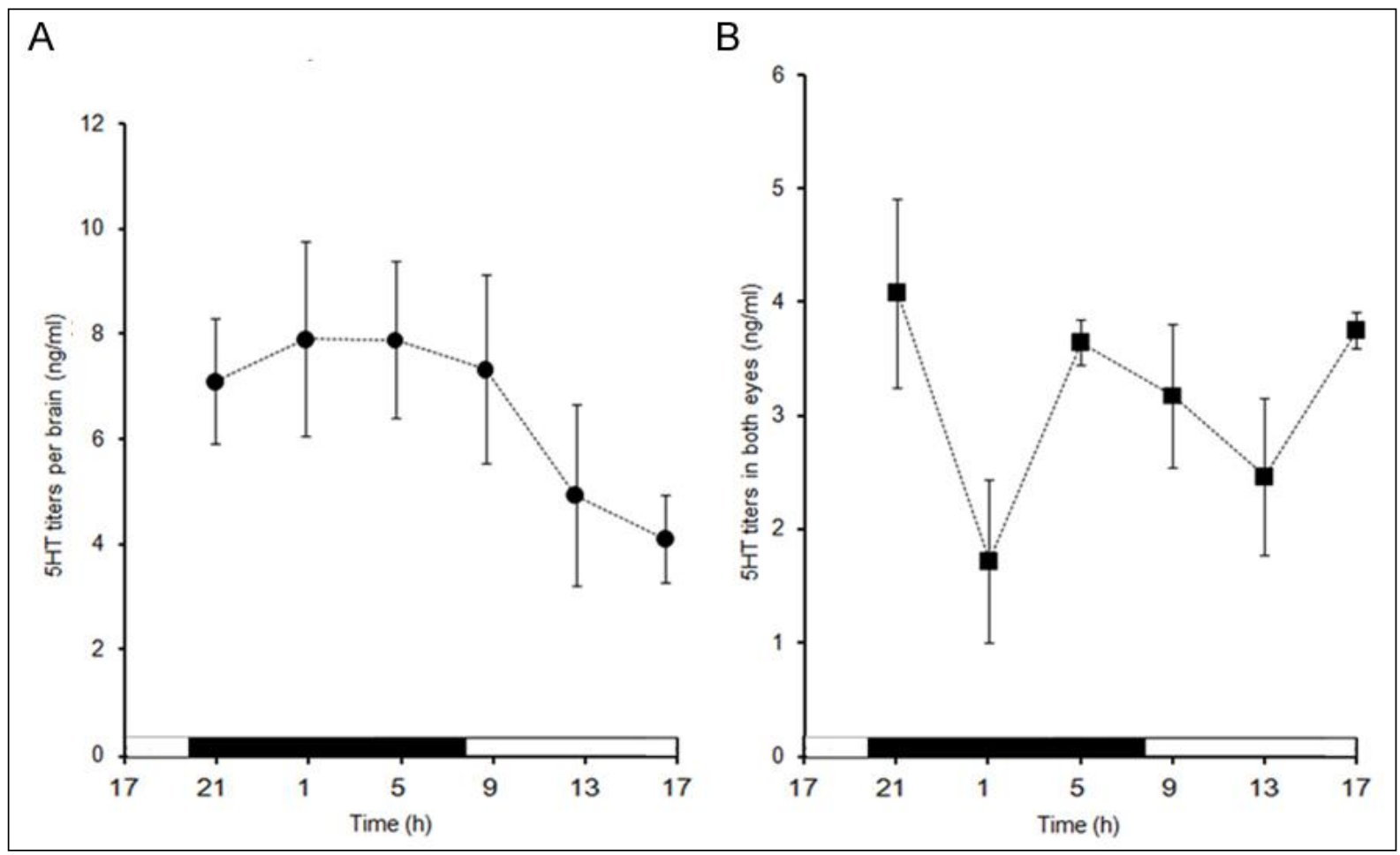

Figure 20. Diurnal changes of $N$-acetylserotonin (NAS) levels obtained by ELISA from the brains (A) and eyestalks (B) of the marbled crayfish Procambarus spec. Each point represents mean \pm SEM ( $n=5$ per time point). Samples were obtained every 4 hours. The first time point was one hour after lights on. Lights onset occurred at 8 hrs. Black bars represent 12 hours of scotophase and white bars 12 hours photophase.

Melatonin concentrations measured in brains showed higher concentrations at the end of the photophase and remained high until the beginning of the light phase, thereafter declining to close to 2.5 times at the middle of the photophase (from $36.67 \pm 2.97 \mathrm{pg} / \mathrm{ml}$ at $9 \mathrm{hrs}$ to 
$14.38 \pm 4.12 \mathrm{pg} / \mathrm{ml}$ at $13 \mathrm{hrs})$. Levels of melatonin increased again before lights off to $37.80 \pm$ $3.54 \mathrm{pg} / \mathrm{ml}$ and were maintained during the beginning of the scotophase (21 hrs with $37.20 \pm$ $2.56 \mathrm{pg} / \mathrm{ml})$. After that, titers dropped again to low levels at the last measurement point of the scotophase (5 hrs) with $21.33 \pm 2.34 \mathrm{pg} / \mathrm{ml}$ of melatonin in brain (Figure $21 \mathrm{~A}$ ). Melatonin levels did not significantly adjust to a sinusoidal oscillation, but values were close to significance $(22.47 \%$ of rhythm, acrophase $21.17, \mathrm{p}=0.61)$. Analysis of variance showed significant differences of melatonin content between highest and lowest peaks $(p=0.001$ for tissues, brain and eyestalks).

Last, melatonin concentrations of the eyestalks showed two peaks, the first peak occurred one hour after lights off ( $21 \mathrm{hrs}$ ) with titers of $25.50 \pm 4.79 \mathrm{pg} / \mathrm{ml}$ and descended to the half in the next timepoint $(12.53 \pm 2.70 \mathrm{pg} / \mathrm{ml})$. Melatonin reached the highest concentration in a second peak twelve hours later than the first one, reaching $33.25 \pm 2.25 \mathrm{pg} / \mathrm{ml}$ ( $9 \mathrm{hrs})$. After that, levels descended to reach $16.67 \pm 1.77 \mathrm{pg} / \mathrm{ml}$, almost half of this second peak (Figure 21B). Cosinor tested for 24 hours did not provide statistical significance of adjustment to a sinusoidal curve $(\%$ of rhythm $19.98, \mathrm{p}=0.12)$. Significant differences among both peaks and the valley were obtained by the anaylsis of variance $(\mathrm{p}=0.001$ and $\mathrm{p}=0.002$ respectively). Serotonin immunoreactivity in the brain of marbled crayfish has been described in the previous section. In order to localize possible associations with melatonin-producing sites, double immunostainings against both serotonin and melatonin wer performed. The immunohistochemical procedure labelled multiple serotonin-ir cells at the external margin of the HN in the medulla terminalis. This group of cells, which project to the sinusoidal gland, has been referred in other reports as the X-O (Andrew et al., 1978; Arechiga et al., 1985). A second group was also located in the medulla terminalis, but more distal from the HN and more anterior as the $\mathrm{XO}$ group, coinciding with the cells in the proximity of the PDH-C. This group of cells projects in part anteriorly and also to the central brain (Figure 22A). A third 


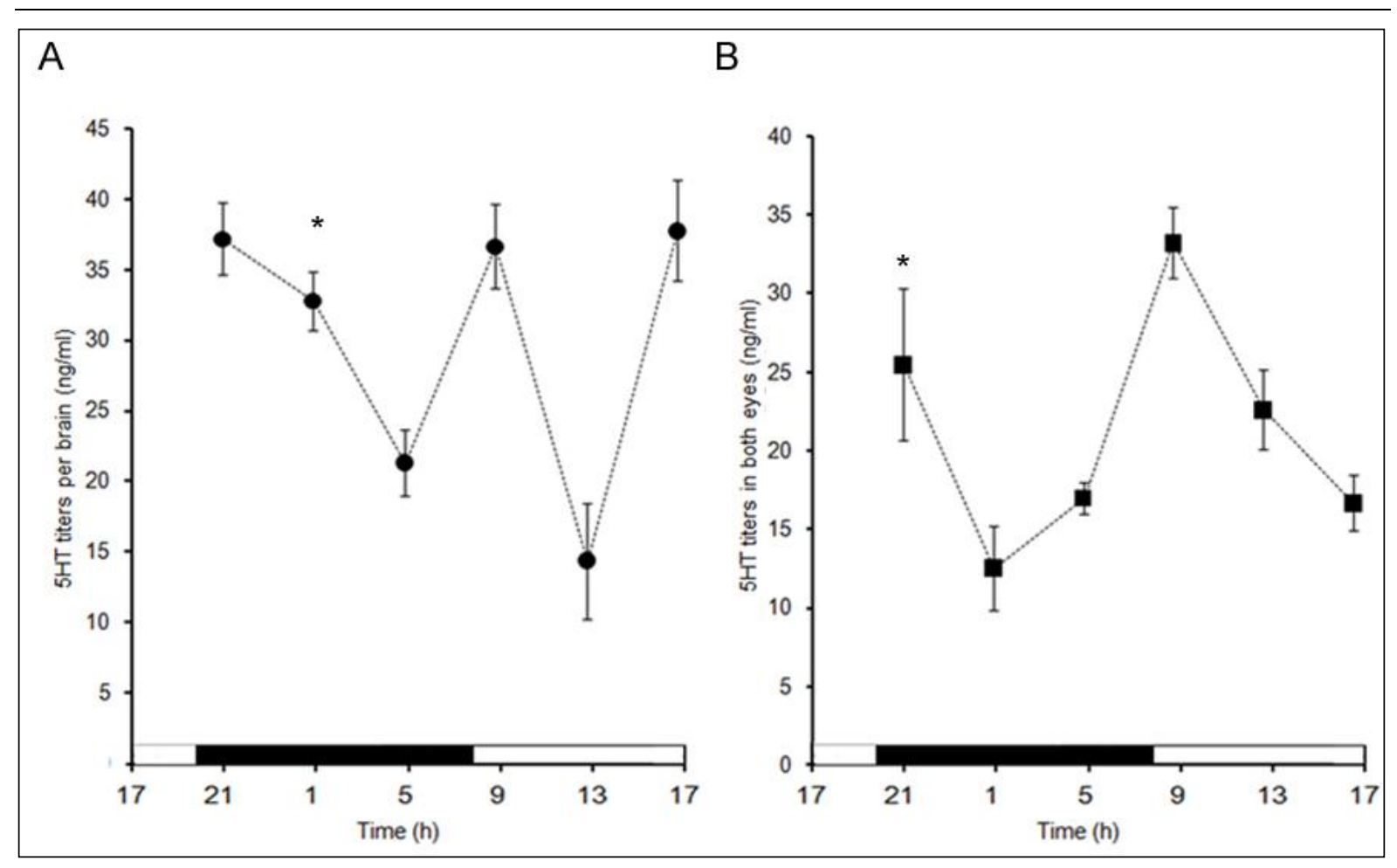

Figure 21. Diurnal changes of melatonin levels measured by ELISA from brains (A) and eyestalks (B) of the marbled crayfish Procambarus spec. Each point represents mean \pm SEM $(n=3-5$ per time point). Samples were obtained every 4 hours. The first time point was one hour after lights on. Lights onset occurred at 8 hrs. Black bars represent 12 hours of scotophase and white bars 12 hours photophase (asterisk shows significant difference $\mathrm{p}=0.05$ ).

group of cells was located at the level of the lobula, close to the margin of the sinusoidal gland. Some other cells were observed more anteriorly, dispersed in the lobula and lamina (with low numbers and at variable locations). In the central brain, two big somata were located whose axons projected distal posterior, running through the whole nerve cord. These cells are known as giant cells acting as command neurons for escape behavior (Teshiba et al., 2001). In addition, melatonin imunocytochemistry was performed, but was generally difficult to evaluate. Regardless of concentration and duration of incubation with the first antibody melatonin immunoreactivity resulted in variable staining from individual to individual. In most cases, melatonin-ir cell bodies grouped in the lobula-medulla terminalis area (Figure 22 B and C). 


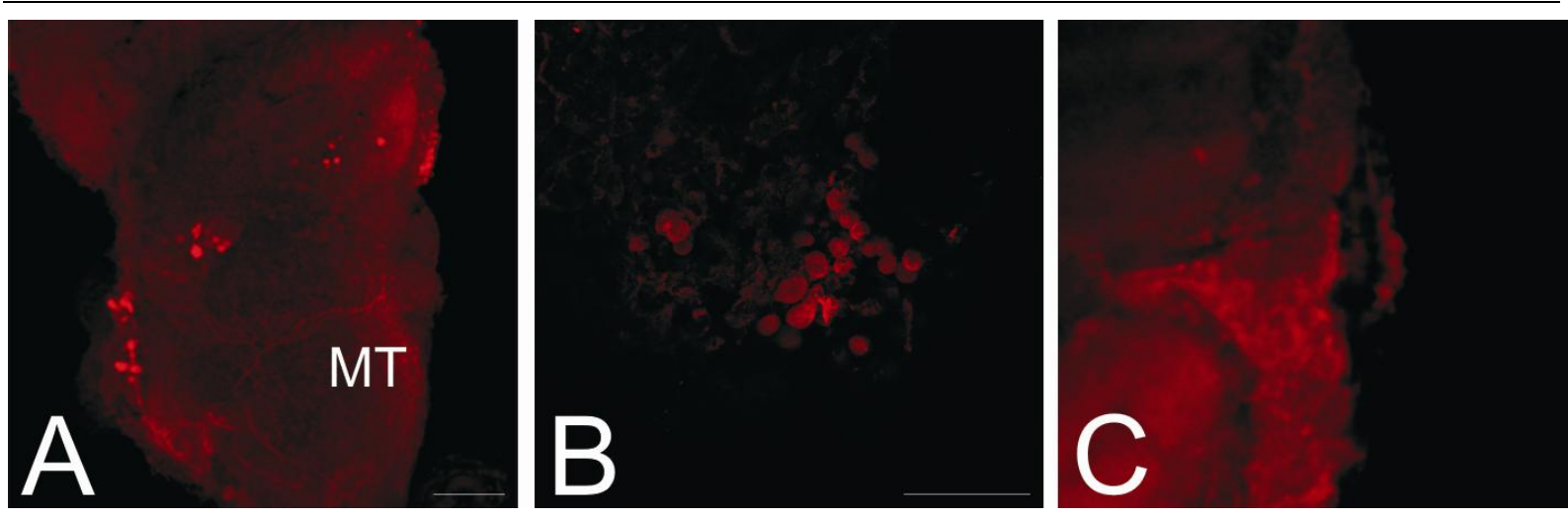

Figure 22. Serotonin and melatonin immunistainings in the eyestalk of the crayfish. Images are overlayed of maximal projection of a CLSM optical section series scanned at $2 \mu \mathrm{m}$ z-distance. (A) shows groups of serotoninergic cells observed in the medulla terminalis of the eyestalk. $\mathrm{B}$ and $\mathrm{C}$ show melatonin immunoreactivity in two differen regions of the lobula. 


\section{DISCUSSION}

\section{The marbled crayfish as a model for analysis of circadian rhythms in}

\section{crustacea}

Crayfish have been widely used for the study of many functions including motor pattern generation, agonistic and escape behavior, and various physiological mechanisms (Clarac and Pearlstein, 2007). Its readiness to reproduce in aquaria, its easiness to be manipulated and the accession to its nervous system has allowed for diverse physiological studies. Since the chronobiological approach, crayfish have also been extensively studied. Its diurnal variations of locomotor activity were reported the first time by Kalmus (1938). Since then, circadian variations of oxygen uptake, retinal electrical activity, hormonal activity, pigment migration, ventilator activity, and other circadian functions were reported. However, where endogenous circadian rhythmicity originates and what goups of cells are responsible for its contol in crustaceans is unknown.

In contrast to the scarce information concerning the location of circadian pacemakers, crustaceans have provided rich knowledge about substances (hormones and neurotransmitters) involved in the orchestration of circadian rhythms and other functions, such as 5-HT, melatonin, dopamine, octopamine, GABA, FMRF, CHH, PDH, MIH, ecdysteroids, juvenile hormone and molting hormone (Arechiga et al., 1993; Fanjul-Moles and Prieto-Sagredo, 2003). Most of the chemical messengers are of peptidic nature and released from the main neurosecretory organ in crustaceans, the X-Organ-SG (reviewed by Garcia and Arechiga, 1998). Most of these substances have also been studied in insects and some have been implicated in the function of the endogenous clock. Here I use the marbled crayfish Procambarus spec., a unique parthenogenetic decapod species, which has been introduced into german aquaria trade but whose geographical origin remains untraceable. 
Basic studies concerning the anatomy, mode of reproduction, phylogeny, ecology, and development (Vogt et al., 2004; Braband, 2006; Alwes and Scholtz, 2006; Vilpoux et al., 2006) of this species are already available. The marbled crayfish produces isogenic offspring by parthenogenetic reproduction and offers the chance to generate genetically altered lines of animals.

\section{Behavioral rhythms in the marbled crayfish Procambarus spec.}

\section{Diurnal and circadian cotrol of locomotor activity and agonistic behavior}

Crustaceans represent excellent models to study both circadian rhythms (Arechiga and Rodriguez-Sosa, 1998; Fanjul-Moles et al., 2004; Ramon et al., 2004) and agonistic behavior (reviews by: Kravitz, 2000; Edwards et al., 2003; Edwards and Herberholz, 2005). In this study, I introduce the marbled crayfish as a new species for neuroethological studies and demonstrate for the first time in a crustacean that agonistic behavior is controlled by endogenous circadian pacemakers.

As a prerequisite, I analyzed agonistic behavior and the formation of hierarchies in marbled crayfish, from which only females are known. Consequently, sexual competition can be excluded as a driving force for agonistic behavior in this species. As it has been described for male vs. male and female vs. female fights in other decapod crustaceans, marbled crayfish engage in agonistic interactions and establish dominance relationships even in featureless environments that contain no particular resource besides space (Bovbjerg, 1953; Huber and Kravitz, 1995; Issa et al., 1999; Herberholz et al., 2007). Like in other lobsters and crayfish, agonistic encounters of marbled crayfish consist of temporal sequences of threat displays, restrained fighting and (occasionally) brief periods of unrestrained combat which are 
characterized by stereotypic postures and behavioral patterns (described in detail in Huber and Kravitz, 1995). As a consequence of losing a fight marbled crayfish refuse to initiate further agonistic encounters and retract from approaches of the winner suggesting that a stable dominance relation has been established during the preceding agonistic interaction. An inhibition of aggression resulting from loss and a reinforcement of aggressive motivation by winning fights is suggested to underlie the establishment of dominance hierarchies in groups of crayfish (Issa et al., 1999). In previous studies on groups of Procambarus clarkii hierarchies were established during an initial period with high frequency of agonistic encounters and either one superdominant animal with several equally ranked subordinates or a hierarchy with differentiated ranks was characterized on the basis of an individual's wins and losses (Issa et al., 1999; Herberholz et al., 2007). In the three groups of six marbled crayfish analyzed in the present study, dominance hierarchies with clearly defined ranks emerged during the first three hours of their introduction to the observation tank and were refined during subsequent seven days of continuous monitoring of agonistic behavior. Though crayfish had different aggressive motivation at the beginning of the experiment (indicated by the numbers of encounter initiations) that was not always in line with their rank in the dominance hierarchy, both parameters adjusted during the seven days of co-habitation and interaction. During the second half of the observation period the most dominant marbled crayfish participated in about half of all encounters within the three groups analyzed and both initiated and won most of them. Based on the proportion of won encounters, there was a hierarchy of relative dominance relations among the subordinate crayfish with higher tendencies to initiate agonistic encounters by the higher ranked animals. All observations made in this study suggest that marbled crayfish are typical decapod crustaceans with respect to their behavioral patterns during and after agonistic interactions. 
A number of studies on different crustacean species revealed a circadian control of physiological mechanisms (sensitivity of sensory receptors, heart rate, ventilation, pigment movements, levels of blood sugar and other circulating metabolites) and behaviors (locomotion, plugging of burrows) by endogenous pacemakers (reviewed by: Arechiga et al., 1993; Arechiga and Rodriguez-Sosa, 2002; Fanjul-Moles et al., 2003; Fanjul-Moles, 2006). Here I extend the catalogue of circadian controlled behaviors by demonstrating for the first time in a crustacean species that agonistic behavior of marbled crayfish is under circadian control. Modulation of agonistic behavior by circadian rhythms has previously been reported from fish (Radilova et al., 1991), golden hamsters (Landau, 1975), rats (Haller et al., 2000), mice (Sofia and Salama, 1970) and primates (Martensz et al., 1987). In addition, self-directed aggressive behaviors of humans cluster around particular periods of the day (Caracciolo et al., 1996) as does the performance of violent acts of psychiatric inpatients against other patients and hospital staff (Manfredini et al., 2001). Whether agonistic behavior is regulated by circadian pacemakers has, to my knowledge, not been investigated in invertebrates. According to a more general observation, cockroaches engage in more agonistic encounters during the dark phase (Breed et al., 1975) but in order to detect endogenous behavioral rhythms agonistic interactions during periods of constant darkness have not been analyzed in any invertebrate species.

Agonistic behavior differs from previously investigated circadian phenomena by the fact that it results from interactions of two or more individuals. Under LD 12:12 conditions groups of six marbled crayfish displayed the highest frequencies of pair wise agonistic encounters following light-to-dark and dark-to-light transitions. The absolute numbers of agonistic encounters clearly decreased from the first to the third switch in illumination and seemed to oscillate on a medium level following subsequent light changes. After switching to constant darkness elevations of agonistic encounter frequencies were only recognized at times that 
coincided with previous light-to-dark changes. An enhanced agonistic activity coinciding with dark-to-light changes of previous LD rhythm was absent in constant darkness. Agonistic activity in constant darkness was more evenly distributed over the 24-hour period and differences between high activity following times of previous light changes and periods in between were far less pronounced than under LD conditions. The generally increased activity of crayfish during the dark phase of the photoperiod (see below) is unlikely to account for this, since the differences between light change-induced high activity phases and the periods until the next light change were quite similar during light and dark periods (Fig. 7A). A factor that more likely contributes to the temporal dispersion of group agonistic activity in constant darkness is the lack of the entraining signal. In contrast to the LD 12:12 condition, in which agonistic activity of all six crayfish is entrained to the (the same) light cycle, agonistic activity in constant darkness depends on endogenous pacemakers of six animals with different circadian periods (endogenous circadian periods of the most dominant crayfish of the groups were $\tau=23.0 ; 25.5$ and $26.3 \mathrm{hrs}$ ). This was also reflected in the range of circadian periods of enhanced agonistic activity. The sharper peak seen under LD conditions results from a high coincidence of changes in agonistic activity of all six crayfish (Fig. 7C). In contrast, circadian rhythmicity of enhanced activity under constant darkness was less synchronized in both, crayfish groups (Fig. 8B) and individuals (Fig. 9B). Such a loss of synchronization after transition from LD to constant darkness was not observed for locomotor activity of isolated crayfish (Fig. 6B, C) and may therefore result from the initiation of agonistic encounters by other crayfish of the group whose agonistic activity is regulated with a different endogenous circadian period. However, individual crayfish contributed quite differently to the agonistic activity of their group and a significant rhythm of encounter frequency in constant darkness was only displayed by the most dominant crayfish in each of the three groups of my study. In line with earlier studies on lobsters and other crayfish species (Atema, 1980; Issa et al., 1999), 
the more dominant marbled crayfish displayed a higher aggressive motivation reflected by the number of initiated encounters, while in the most subordinate individuals aggressive motivation was low and agonistic behavior essentially absent. Studies by (Herberholz et al., 2007) found that burrowing was enhanced in dominant and suppressed in subordinate crayfish Procambarus clarkii, while in contrast, locomotor activity was not affected by social rank. This suggests that the position in the dominance hierarchy suppresses some specific behavior related to intraspecific competition rather than generally reducing all activities in subordinates. Whether endogenous circadian periods of agonistic and other types of behavior of individual marbled crayfish may change with changes in dominance hierarchies has not yet been explored.

In addition to the overall agonistic behavior of crayfish groups, which depends on interactions of several individuals, I also explored circadian locomotor behavior of isolated marbled crayfish. Circadian rhythms of locomotor activity have been reported in different species of crustacea (Page and Larimer, 1972; Hammond and Fingerman, 1975; Fanjul-Moles et al., 1996; Miranda-Anaya, 2004). Nocturnally active crayfish typically display two peaks of activity in LD cycles, a short burst following lights on and a more extended period starting shortly before lights off. When placed in constant darkness, this bimodal pattern of locomotor activity usually changed to a unimodal pattern, with only the long burst of activity at lights off remaining (Page and Larimer, 1972; Fanjul-Moles et al., 1998; Miranda-Anaya, 2004) though one study found a persisting bimodal activity (Fuentes Pardo et al., 1996). The circadian rhythms of locomotor activity in marbled crayfish reported here coincide with previous observations in related species. While all marbled crayfish displayed a bimodal rhythm of locomotor activity in LD cycles with higher and more prolonged activity following light-todark transitions, most experimental animals switched to a unimodal rhythm during subsequently imposed periods of constant darkness. Most crayfish displayed endogenous 
activity rhythms with period durations close to $24 \mathrm{hrs}$, the majority with periods shorter than $24 \mathrm{hrs}$ (average in these animals was $\tau=23.22 \pm 0.91 \mathrm{hrs} \quad(\mathrm{n}=18)$. Even though marbled crayfish have been reported to generate isogenetic offspring (Martin et al., 2007) and all marbled crayfish used in my experiments originally derived from one specimen, endogenous rhythms varied and the most extreme rhythm observed had a period duration of $\tau=29.8 \mathrm{hrs}$.

Since circadian rhythmicity in crustaceans seems to be controlled by multiple independent pacemakers that need to interact and coordinate their functions by yet unknown neural or humoral pathways, one can only speculate about the mechanism that couple both, locomotor activity and agonistic behavior to endogenous rhythmic centers. It is definitely tempting to study the contribution of biogenic amines to this mechanism, since serotonin, dopamine and octopamine have been demonstrated to promote or suppress agonistic behavior (reviewed by Kravitz, 2000). However, serotonin is not necessary for agonistic behavior to occur but rather modulates aggressive motivation to initiate and continue agonistic interactions (Doernberg et al., 2001). Since serotonin has also been shown to contribute to circadian rhythmicity (FanjulMoles et al., 2003), serotonin itself or one of its metabolites $N$-acetylserotonin and melatonin may play a role in the coupling of endogenous circadian pacemakers to the neural circuits that generate locomotor and agonistic behavior in crustacea.

The marbled crayfish may serve as a favorable species to conduct these and other future studies. Parthenogenetic marbled crayfish are easy to breed and produce large numbers of isogenetic offspring (Martin et al., 2007), which may reduce variability of physiological parameters between individuals within the same treatment group. Since the circadian control of activity and even complex social behaviors such as agonistic interactions seem to be similar to that of Procambarus clarkii and other decapod crustaceans used in previous studies, marbled crayfish can be regarded as typical decapod crustaceans despite their unusual mode of reproduction. 


\section{Circadian pacemaker location in crustacea}

In insects, PDF has been identified as output signal of a defined and small population of circadian clock neurons situated in the optic lobes, and these neurons express all canonical clock proteins, at least in Drosophila (see Stanewsky, 2002 for review), but apparently also in other insects (Lupien et al., 2003). In order to identify possible circadian pacemaker candidates in the marbled crayfish and to reveal a possible homology of crustacean PDH-ir neurons to insect pacemaker neurons known as the PDFMe or LNv, I performed anti- $\beta$-PDH immunolabelling in central brains and eyestalks of the crayfish. Since insect PDFMe neurons are partly reactive to antisera against FMRFamide, additionally FMRF-ir neurons of the crayfish were explored.

Crustacean PDH was first isolated from the shrimp Pandalus borealis (Fernlund, 1976), and later from other crustaceans like the crabs Uca pugilator and Cancer magister (Rao et al., 1985; Kleinholz, 1986) and the crayfish Procambarus clarkii (McCallum et al., 1991). The crustacean PDH occurs in two classes with larger differences in amino acid sequences, namely the $\alpha-\mathrm{PDH}$ and the $\beta$-PDH (Rao and Riehm, 1993). In the context of this work, 'PDH' always refers to $\beta$-PDH. Neurons expressing PDH were found throughout the central nervous system (Bonomelli et al., 1988; Klein et al., 1994; Löhr et al., 1993; Mangerich and Keller, 1988; Staub and Fingerman, 1984) and in the stomatogastric system (Mortin and Marder, 1991) of several malacostracan crustacean species. Homologues of $\beta$-PDH are highly conserved among crustacean species, although two $\beta$-PDH isoforms in the same species have recently been identified in the crab Cancer productus (Hsu et al., 2008). However, both were labeled with $\beta-\mathrm{PDH}$ antiserum.

For decapod crustaceans, the anatomy of PDH-ir neurons in central brains and eyestalks was determined by immunohistochemistry in Orconectes limosus, Carcinus maenas, and Cancer productus (Mangerich and Keller, 1988; Hsu et al., 2008), and in Cancer productus, 
additionally by in situ hybridization with labeled $\beta$-PDH RNA (Hsu et al., 2008). Similar groups of neuron and their projection patterns in different brain structures were labeled in all species. My immunolabeling results with both the anti- $\beta$-PDH and the anti-Drosophila-PDF antibodies coincided largely with the previous reports with respect to cerebral PDH-ir neuron pericarya distribution and fiber arborization. These previous reports and my results showed distinct PDH-ir neuron groups in the eyestalks innervating all neuropils, and in the central brain innervating many neuropils. The morphology of decapod central brain PDH-ir neurons is shown in Mangerich and Keller (1988) for O. limosus and C. maenas, but a clear assignment of PDH-ir neurons to known neuron groups was not given there. However, the drawings indicate that the PDH-CBC6 and PDH-CBC16 I labelled in the marbled crayfish coincide with two neuron groups of $O$. limosus and $C$. maenas. Contrarily, marbled crayfish PDH-CBC17 does not match a posterior, bilaterally paired group of $\mathrm{PDH}$-ir neurons in $O$. limosus and C. maenas, where instead another group not found in the marbled crayfish, laid more laterally, thus implicating some species differences in crustacean PDH expression. A weak labeling slightly above background in the deutocerebral CBC10 of marbled crayfish was not interpreted as PDH-ir and similar cells were also not shown in O. limosus and C. maenas.

In the eyestalks I described four groups of PDH-ir neurons, the PDH-La, PDH-A, PDH-B, and PDH-C. Neurons corresponding to these groups had previously been described in $O$. limosus, C. maenas, and C. productus (Mangerich and Keller, 1988a; Hsu et al., 2008). In contrast, one group, the PDH-A on the medial-distal margin of the hemiellipsoid body, appeared exclusively marbled crayfish and not in the other crustacean species. The PDH-C with up to 20 neurons was the second largest PDH-ir neuron group in the eyestalk (and even in the whole brain) after the PDH-La. PDH-C group was situated close to the lobula and gave rise to most of the $\mathrm{PDH}$-ir projections in medulla and lobula and appeared to innervate also the lamina, medulla terminalis, and hemiellipsoid body. For reasons explained later, this 
group is assumed to be homologous to the insect PDFMe/LNv. A part of this group appears to innervate the sinusoidal gland to release PDH into the hemolymph, which was also suggested by Hsu et al. (2008). Due to the large soma size, these cells were clearly identified as members of the PDH-C1 subgroup. In fact most if not all PDH-ir fibers of the sinusoidal gland appear to stem from PDH-C1 and not from the PDH-B, which belong to the X-organ that actually supplies the sinusoidal gland with peptidergic innervations. It cannot be excluded that PDH-B neurons additionally innervate the sinusoidal gland, but this group consists of only few and small somata and neurites could not be unambiguously traced to the sinusoidal gland. A group similar to PDH-C owing to the location and projection areas, including projections to the sinusoidal gland, medulla, and lamina, was also described in an isopod species, the woodlouse Oniscus asellus (group PGR3 in Nussbaum and Dircksen, 1995).

The labeling with anti-FMRFamide antisera revealed a similar pattern of immunoreactive neurons as the PDH immunolabelings. In the eyestalks, all neuropils except the sinusoidal gland contained FMRF-ir fibers. In the central brain, FMRF-ir fibers were present in most neuropils including the olfactory and accessory lobes, which where nearly free of PDH-ir fiber projections.

The peptide FMRFamide was originally isolated from the bivalve mollusk Macrocallista nimbosa upon its cardioexcitatory activity (Price and Greenberg, 1977). Since then, more than 100 neuropeptides were isolated from central and peripheral nervous systems of invertebrates and vertebrates that generally share the C-terminal amidated RF (Arg-Phe- $\mathrm{NH}_{2}$ ) sequence (reviewed by Nässel and Winther, 2002; Orchard et al., 2001; Mercier et al., 2003; Orchard and Lange, 2006). These include the N-terminally extended FMRFamides and FL/IRFamides, the short and long extended neuropeptides F (sNPFs and INPFs, respectively), the myosuppressins (extended FLRFamides), and the sulfakinins (extended HMRFamides with a sulfated tyrosine residue). These peptides are commonly referred as FMRF-related peptides 
(FaRPs), although their families are structurally different and not further related to one another (hence, the term FMRFamide-like peptides, FLPs, is often used). Corresponding to their diversity in structure, their functions are similarly versatile including modulation of reproduction, circulation, ecdysis, development, salivary production, heart beat, osmoregulation, among otheres. As for most neuropeptides, functions arising through paracrine release from central neurons are largely unknown. Effects are mediated by modulation of synaptic transmission and certainly depend on the type and location of releasing neurons, release sites, receiver neurons and their receptors. In crustacea, 19 FaRPs were identified until 2003 (Mercier et al., 2003; Weiss et al., 2003). At least eight of them were aso associated with the eyestalk. In crustaceans as in other animals FaRPs were found to exert numerous physiological actions (Mercier et al., 2003). Despite the relevance of FaRPs in the function of nervous systems detailed anatomical studies of FaRP expressing neurons in crustacean central nervous systems are remarkably scarce, as it is also the case for PDH.

The FMRFamide antibodies used in my study are known to label a variety of FaRPs in invertebrates (Grimmelikhuijzen, 1983; Lundquist and Nässel, 1990). The single members of the family cannot be distinguished by the antisera, but it can not be fully excluded that single FaRP members could not be labeled. However, both antibodies used in my studies revealed practically the same staining patterns, thus supporting their specificity. In the eyestalks, five main groups of neurons were labeled, with two subgroups in the FMRF-C. The locations of FMRF-La1, FMRF-A, FMRF-B, and FMRF-C1 overlapped with that of PDH-La, PDH-A, PDH-B, and PDH-C. However, double labeling with anti-PDH and anti-FMRFamide revealed that colocalisation of both immunoreactivities only occurred in PDH-La and PDH-C1 somata. This does contradict some of the findings of Mangerich et al. (1987) in C. maenas and $O$. limosus, who demonstrated FMRF/PDH-ir colocalization in most of the eyestalk's neuropils including the X-organ neurons that correspond to marbled crayfish PDH-B and FMRF-B 
groups. However, colocalization was reported in pericarya of the lamina and in a neuron group corresponding to PDH-C. Methodologically, the occurrence of neurons expressing either PDH- or FMRFamide immunoreactivity exclusively is a good evidence that neither antibody cross-reacts with the other peptide to cause false positive staining.

In the optic neuropils lamina, medulla, and lobula, a layered staining pattern with the antiFMRFamide antisera was visible as for PDH. Layers were interconnected by a network of columnar fibers. This suggests a modulatory function to all the columnar neuronal units ('optic cartridges') for FaRPs as well as for PDH. In the lamina, labeled layers did not overlap at a first glance, where a middle FMRFamide-ir layer was flanked by two PDH-ir layers (see Fig. 14A-C). However, very weak FMRFamide immunoreactivity could be seen in the PDHir layers, thus indicating that FMRF-ir lamina neurons terminate in different target areas than FMRF-ir PDH-La. In medulla and lobula, I observed colocalized staining in prominent layers, but, as to be expected, not in all fibers. The results suggest simultaneous expression and perhaps simultaneous release of PDH and FaRP peptides in eyestalk neurons to exert so far unknown co-modulatory functions.

In the central brain, FMRF-CBC6 and FMRF-CBC16 shared locations with PDH-CBC6 and $\mathrm{PDH}-\mathrm{CBC} 16$, respectively, but colocalizing immunoreactivity was not detected. These locations coincided with the FMRFamide-ir neurons described by Mangerich and Keller (1988) in C. maenas and O. limosus. They also reported FMRFamide immunoreactivity in a group corresponding to FMRF-CBC9 including widespread but rather weak immunoreactivity throughout the olfactory and accessory lobes. This is one of the major differences between the otherwise rather similar pericarya locations and arborization patterns of FMRF- and PDH-ir neurons and suggests a prominent role of FaRPs in modulating olfactory information. Even more, the FMRF-CBC10 was found, to my knowledge, so far only in the marbled crayfish. The FMRF-CBC15 were also not described by Mangerich and Keller (1988), instead they 
reported FMRFamide immunoreactivity in a group corresponding to $\mathrm{CBC} 17$, where I instead found PDH immunoreactivity. In general, more cells and fibers in marbled crayfish were immunoreactive to anti-FMRF than to anti-PDH. The widespread localization of both peptides throughout the brain indicates an important role for both FaRPs and PDH in regulating neuronal activities in the crayfish.

\section{Are PDH-neurons of the eyestalk homologous to insect PDFMe/LNv?}

Initially, PDH was thought to be present only in crustaceans (Dircksen et al., 1987) until the $\beta$-PDH homolog PDF was isolated in the grasshopper Romalea microptera (Rao et al., 1987). In insects, PDF is termed "factor" instead of "hormone" since it has not been reported to be released to the circulatory system and has no pigment migrating activity. However, insect PDF causes pigment migration in bioassays using crustacean species (Rao et al., 1987). Later, PDF-expressing neurons were found with an antiserum against $\beta$-PDH in orthopteran insects and blowflies (Homberg et al., 1991; Nässel et al., 1991). The amino acid sequence of this octadecapeptide is well conserved in crustaceans and different PDHs show only minor changes in few amino acids that appear not to be structurally relevant (Riehm and Rao, 1982). So far, about a dozen different $\beta$-PDHs were isolated in a variety of crustacean species (Matsushima et al., 2004). It turned out that $\beta$-PDHs of crustacea are closely related to insect PDFs and even more, differences between crustacean PDHs and insect PDFs are not greater than differences among crustacean PDHs or insect PDFs.

The importance of PDF in insect circadian clock function has rapidly gained attention and now PDF is suggested to be part of the rhythm generation and/or output of pacemaker driving insect circadian locomotor activity, ecdysis, and probably other rhythms (Homberg, 1991; reviewed in Vansteensel et al., 2008). This view was supported by anatomical studies where PDF-expressing LNvs in Drosophila where shown to also express the canonical clock 
element PER (Helfrich-Förster, 1993; Helfrich-Förster, 1995; Kaneko et al., 1997) and other clock elements (reviewed by Stanewsky, 2002). Other functional studies have provided information sustaining the idea that PDF is an important clock output signal (Blau and Young, 1999; Fernandez et al., 2008; Fernandez et al., 2007; Park et al., 2000; Petri and Stengl, 1997; Petri et al., 1995; Reischig and Stengl, 2003b; Renn et al., 1999; Stengl and Homberg, 1994) involved in the control of insect behavioral rhythms (Murad et al., 2007).

Since insects and crustaceans are phylogenetically related and very likely represent sister groups within a taxon called Tetraconata or Pancrustacea (Dohle, 2001; Richter, 2002) and insect PDF and crustacean PDH are so conserved, I was interested in whether there are also functional similarities. In this respect I first wanted to find out whether insect and crustacean PDH/PDF neurons could be homologous to each other. At first it stands out that crustacean PDH-ir neurons are much more numerous than insect PDF-expressing neurons. One reason could be cross-reaction capabilities of respective antibodies in crustacea, but this is very unlikely since first, the antibodies used (generally the \#3B3 anti- $\beta$-PDH of Dircksen et al., 1987) are very specific and very well characterized by a variety of authors in different crustacean species (Dircksen et al., 1987; Bonomelli et al., 1988; Löhr et al., 1993; Mancini and Frontali, 1967; 1970; Mangerich and Keller, 1988; Mangerich et al., 1987; Nussbaum and Dircksen, 1995). Second, I achieved identical immunolabeling with two different antiPDH/PDF antibodies in the crayfish. Therefore, I assume all PDH-ir neurons of the crayfish and other crustaceans actually as truely PDH expressing.

In the central brains of insects, PDF neurons have been reported in a few cases (e.g., Drosophila, (Helfrich-Förster, 1993); tobacco hawkmoth Manduca sexta (Homberg, 1991), but generally they are absent there (see overviews of PDF neurons in a variety of insect species in (Homberg, 1991; Sehadová et al., 2003; Závodská et al., 2003). This could reflect a derived situation in insects, if one would assume that the character 'many PDH neurons 
throughout the brain' is the ancestral condition, as it appears the case for most other peptidergic neurons. The insect optic lobes generally contain three groups of PDF neurons: the dorsal and ventral PDFLa at the lamina and the PDFMe (or LNv in Drosophila) between medulla and lobula in an anterior position of the optic lobe. This raises the question about a possible homology between insect optic lobe and crustacean eyestalk PDF/PDH neurons. A prerequisite to compare insect optic lobes and crustacean eyestalks is the assumption of a homology relationship of both structures. This appears to be the case for laminae, medullae, and lobulae of both taxa (Rao and Riehm, 1988; Strausfeld, 2005). The medulla terminalis and the hemiellipsoid body of the crustacean eyestalk are structures that are rather homologous to lateral parts of the insect central protocerebrum (Strausfeld, 2005).

The most obvious similarity exists between the crayfish's PDH-La and the insect's PDFLa. As in the crayfish, these neurons count more than 100, e. g, in the cockroach $L$. maderae, and in both species, they are at least to a large part immunoreactive to antiFMRFamide antisera (Petri et al., 1995). In both cases, they appeared to arborise mainly in the lamina, although in the crayfish they occasionally expressed centripetal projections. It is nor clear whether centripetal PDFLa-projections exist in insects, but central projections of peptidergic lamina neurons at the locations of PDFLa are at least demonstrated for locustamyoinhibin-ir neurons in the locust (Schoofs et al., 1994). The fact that PDFLa are clustered in insects and dispersed at the base of the lamina in decapods is not assumed as an argument against a homology relationship, since a transition between these conditions appears easy to accomplish. Therefore, I suggest a homology relationship between insect PDFLa and crustacean PDH-La due to the homology criteria of similar position and neurochemical quality.

I assume a homology also between the crustacean PDH-C and insect PDFMe. First, these neurons have tangential arborisations in laminae, medullae, and lobulae of both taxa. Second, 
in both taxa the somata form subgroups that differ in size and are situated near medulla and lobula, although they appear to be shifted more proximally in crustacea. This appears not to contradict a homology relationship, since in locust embryos it was shown that the PDFMe develop near or probably from the central protocerebrum (Homberg and Prakash, 1996). Third, parts of the insect PDFMe are reactive to antisera against FMRFamide (Petri et al., 1995; Würden and Homberg, 1992). I have demonstrated the same for the PDH-C in the marbled crayfish and aso previously been described by Mangerich et al. (1987) in O. limosus and C. maenas. Fourth, with backfill experiments I could demonstrate that at least a portion of the crayfish's PDH-C neurons projects to the median protocerebrum. Also in insects, the PDFMe ramify in wide areas of lateral and median parts of the central brain, including contralateral regions. My reconstruction of $\mathrm{PDH}$-ir fiber projections in the crayfish also revealed fibers crossing the midline between both hemispheres and these appear partly to originate from the optic stalk and hence from the PDH-C, since PDH-A and PDH-B did not emerge in my backfill experiments. Therefore, criteria of similar position and neurochemical content suggest a homology of crayfish PDH-C and insect PDFMe and both may have emerged as descendants of a PDH expressing neuron group in the visual system of the last common ancestor of crustaceans and insects. However, with backfills I did not find PDH-ir fibers that directly connect the two optic stalks in the crayfish. That kind of connection is a common feature for insect PDFMe, where these neurons are assumed to provide pathways for mutual synchronization of the bilateral pacemakers (Reischig et al., 2004; Reischig and Stengl, 2002). Nevertheless, these connections are also absent in some insects species (crickets; Stengl, 1995) and missing connections might therefore not account as a strong criterion for exclusion of a homology relationship between crayfish PDH-C and insect PDFMe. It has been shown that a neuronal pacemaker synchronizing pathway between both eyestalk clocks exists in the crayfish (Arechiga and Rodriguez-Sosa, 2002; Larimer and 
Smith, 1980), but mutual pacemaker coupling could be accomplished by other direct or indirect neuronal connections.

To construct such a homology relationship is more difficult for the remaining eyestalk PDH-ir neurons, the PDH-A and PDH-B. The PDH-B is situated at the proximal margin of the hemiellipsoid body, a neurosecretory region referred to as the X-organ, which belongs to the lateral protocerebrum of the crayfish. I did not observe FMRFamide immunoreactivity in this group (although this was seen in O. limosus and C. maenas by Mangerich et al., 1987) and backfills delivered no hint for projections to the central brain. Therefore, I do not assume homology of these neurons with any of the insect optic lobe PDF neurons. The case is more complicated for the PDH-A. This group lies more distally and it is not clear whether it projects only to the medulla terminalis and/or hemiellipsoid body or additionally to the visual neuropils. Further, this group was not described by Mangerich et al. (1987). However, these neurons were also not FMRFamide-ir and showed no central projections. For now I do not regard them as homology partners for any of the insect PDF neurons.

\section{The marbled crayfish shows no AMe-like structure}

In insects, the AMe is a small neuropil situated next to the proximal medulla, which is thought to be involved in integrating timing information (Homberg et al., 1991; HelfrichFörster, 1998; Helfrich-Förster et al., 2007; Homberg et al., 2003; Reischig and Stengl, 1996; 2003a; 2003b). Before 1991, the AMe was best known from holometabolous insects, where, together with accessory laminae, it serves, as a visual center during larval development that often persists in adult insects (Ehnbom, 1948; Frisch et al., 1996; Hagberg, 1986; Frisch et al., 1996). Occasionally, AMe-like structures were described in hemimetabolous species. However, not until 1991 AMe became generally known as a part of the visual systems also of hemimetabolous insects due to their conspicuous innervation by PDF neurons (Homberg, 
1991). AMe are probably present in most pterygote insects sharing similar qualities (Reischig, 2005). Since the AMe appears to be a common component of the insect visual system and insect and crustacean visual systems appear to be homologous structures, I wanted to know whether the crayfish possesses an AMe, too. In insects, the AMe is conspicuous due to its dense nodular neuropil that distinguishes it directly from the large layered, retinotopically organized visual neuropils. I carefully examined crayfish eyestalks in methylene blue stained wax section series, but did not find a comparable structure within or among the visual components of the eyestalks. Also, the anti-PDH labelings on wax and vibratome sections did not reveal an AMe-like structure.

The insect AMe can be reliably labeled with antisera against allatotropin and serotonin in locusts and cockroaches (Petri et al., 1995; Würden and Homberg, 1995) and all other insects till now investigated herein including silverfishes and lepidopterans (Reischig, unpublished). I therefore performed immunohistochemistry with anti-allatotropin and anti-serotonin antisera, but again I did not find a hint to an AMe-like structure in terms of a conspicuous concentration of allatotropin- and/or serotonin-ir fibers. Allatotropin- and serotonin-ir somata, even with colocalising immunoreactivities, were observed in the vicinity to the PDH-C, but they neither were clustered as in insect AMe nor did they form a conspicuous nodular neuropil. Instead, they were dispersed throughout the optic stalk. Neither allatotropin nor serotonin immunoreactivity was present in the crayfish PDH-C (or any other PDH-ir neuron group of the eyestalk) which is also not the case in insects PDFMe.

One would suggest the sinusoidal gland as candidate for a homology partner for the insect AMe in crustacea, since it lies close to the medulla and is densely invaded by PDH-ir fibers (Mangerich et al., 1987; Nussbaum and Dircksen, 1995) as I could also verify in my experiments. However, the sinusoidal gland is not a neuropil but a neurohaemal organ that releases hormones from the terminals of nerve fibres into the hemolymph of the animal, 
similar to the corpora cardiaca of insects (Dircksen, 1992). Therefore and due to the position on the posterior edge of the eyestalk, a homology between the crustacean sinus gland and the insect AMe is unlikely. The insect AMe contains a very conspicuous amount of peptidergic fibers with about a dozen different neuropeptides (Ammermüller et al., 1994; Nässel and Homberg, 2006; Nässel et al., 2000; Petri et al., 1995; Schoofs et al., 1994; Würden and Homberg, 1995) but again, it is a typical neuropil where fibers interact between each other by forming synapses (Reischig and Stengl, 1996; Reischig and Stengl, 2003b). However and interestingly, the PDH-ir fibers of the sinusoidal gland appeared rather to arise from the PDH$\mathrm{C}$ than from the $\mathrm{PDH}-\mathrm{B}$, although the latter belong to the $\mathrm{X}$-organ that is connected to the sinusoidal gland. It was recently reported by different authors that indeed not all X-organ neurons project to the sinusoidal gland (Andrew et al., 1978; Arechiga et al., 1993).

In summary, a structure resembling the insect AMe was not detected in the marbled crayfish, suggesting that it may not exist in crustaceans. Until now, a structure like the AMe was never reported in crustaceans and also was not evident in previous reports employing anti-PDH immunocytochemistry. For these two explanations are possible: either the common ancestor of crustaceans and insects did not possess an AMe, meaning that it was newly developed in insect evolution or the AMe of a common ancestor was reduced at least in those crustacean groups that have so far been studied (mainly malacostracan species). Therefore, it would be interesting to study crustacean species from less well known and/or more basal groups. Within the crustacean, the branchiopods appear more closely related to insects than malacostraca including the decapods (Glenner et al., 2006) and may therefore be more suited to look for homologous structures. 


\section{Indolamine diurnal changes in the nervous system of the crayfish}

A last purpose of this work was to identify melatonin and two of its precursors in the metabolic pathway from tryptophan to melatonin and check whether some diurnal changes in the content of these substances in the nervous system of the adult marbled crayfish exist. The results obtained demonstrate the presence of melatonin, serotonin and NAS. Mean values (mean \pm S.E.M.) were of $21.05 \pm 0.93 \mathrm{ng} / \mathrm{ml}$ for 5 -HT in brains and $6.75 \pm 0.36$ for 5 -HT in eyestalks ng/ml, NAS in brains $5.65 \pm 0.29 \mathrm{ng} / \mathrm{ml}$, NAS in eyestalks $3.12 \pm 0.23 \mathrm{ng} / \mathrm{ml}$; melatonin in brains $30.82 \pm 1,61 \mathrm{pg} / \mathrm{ml}$ and melatonin in eyestalks $21.66 \pm 1.54 \mathrm{pg} / \mathrm{ml}$. Concentrations of all three substances were higher in brains as in the eyestalks by 1.5 to 3 fold. Aditionally, concentrations of melatonin were one thousand times smaller in relation to 5-HT and NAS titers. 5-HT levels in the marbled crayfish were found to peak at the beginning of the light phase, showing levels around $10 \mathrm{ng} / \mathrm{ml}$ with significant differences between maxima and minima and single cosinor analysis showed values of fit to a sinusoidal curve close to significance. These results coincide with previous records of 5-HT in other crustaceans, such as the crayfish Procambarus clarkii, in which diurnal and circadian rhythms of 5-HT in the nervous system of juvenile and adult stages have been reported (CastanonCervantes et al., 1999).

In my results, as in the report mentioned, the main serotonin peak in the eyestalks is associated with the onset of light. Similar increases were observed previously and a correlation between the elevated serotonin and the endogenous as well as exogenous peaks of locomotor activity has been suggested. Changes in serotonergic signaling have been suggested to control motor behavior (Alvarado-Alvarez et al., 2000; Arechiga et al., 1990; Fanjul-Moles et al., 2003; Heinrich et al., 1999). The mechanisms of serotonin's actions 
underlying behavioral changes in crustacean nervous system have been intensely studied (Alvarado-Alvarez et al., 2000; Arechiga et al., 1990; Fanjul-Moles and Prieto-Sagredo, 2003; Hazlett, 1969; Heinrich et al., 1999; Kravitz, 2000; Sandeman and Sandeman, 1987; Sneddon et al., 2000; Tierney et al., 2004; Wildt et al., 2004; Huber et al., 1997b; Saenz et al., 1997). 5HT has the capability of phase-shifting the circadian output of retinal and extraretineal photosensitive neurons located in the sixth abdominal ganglion (Arechiga et al., 1990; Rodriguez-Sosa et al., 2007). In addition, changes in locomotor rhythmicity can be observed after electrolytic lesion of brain serotoninergic projection neurons (Sandeman et al., 1995). As behavior is controlled by hormones targeting effector systems, influences of serotonin on neuroendocrine factors may be equally important. Changes of serotonin have been compared with the availability of peptide hormones such as red pigment dispersing hormone and hyperglycemic hormone (Arechiga and Fuentes Pardo, 1974; Escamilla-Chimal et al., 2002; Fingerman and Fingerman, 1977; Saenz et al., 1997). As peptide hormones are secreted and released by the XO-SG and some of them have been demonstrated to be under the influence of 5-HT, this system is reminiscent of the mammalian circadian neuroendocrine system (Haus et al., 1998).

NAS, the resulting product of 5-HT $N$-acetylation (and also melatonin demethylation), was detected in similar concentrations as 5-HT in the nervous system of the marbled crayfish. Highest NAS values were observed around both, the end and the beginning of dark phase. Surprisingly, NAS was not significantly modulated over the 24 hour cycle (in eyestalks close to significance, at $\mathrm{p}=0.061$ ). The available information on NAS in invertebrate tissues is relatively scarce. In vertebrates, NAS (syn. normelatonin) has received more attention because of its antioxidant properties in the nervous system (Hardeland, 2005; Hardeland et al., 1996; 2007b) and its function as a transcriptional inhibitor (Hardeland and Poeggeler, 2007; Lezoualc'h et al., 1998). The antioxidant properties reported for NAS coincide in many cases 
with those of melatonin. However, NAS seems to exert effects independent of melatonin, depending on cell types and mechanisms (Hardeland and Poeggeler, 2007; Lezoualc'h et al., 1998). Although serotonin receptor subtypes and their pharmacological properties have been poorly characterized in arthropods, the possibility of serotoninergic actions by NAS should not be neglected. In vertebrates, NAS interacts with several 5-HT receptor subtypes, a finding which receives particular importance from the much longer half-life of NAS compared to 5HT (Hardeland and Poeggeler, 2007). This difference results from the fact that $N$-acetylated indoles are not substrates of monoamine oxidases (in vertebrates, MAO A).

NAS, along with other 5-HT metabolites, has been shown to exhibit circadian rhythms in the retina of trout (Zaunreiter et al., 1998). In invertebrates, septiapterin reductase (Primus and Brown, 1994) is known to be sensitive to NAS and melatonin, but insensitive to 5-HT. This relationship is insofar important as the suppression of sepiapterin reductase leads to declines in the tetrahydropterin cofactors of tryptophan hydroxylase and thus reflects a negative feedback loop that limits serotonin formation. Declines in sepiapterin reductase may have additional consequences of biological relevance, since NO synthases likewise depend on tetrahydropterins, in particular tetrahydrobiopterin (Hardeland et al., 2007a).

The melatonin content of decapod nervous systems has been previously investigated (Agapito et al., 1995; Balzer et al., 1997; Tilden et al., 2001; 2003), but when comparing the results reported, diurnal or circadian changes in melatonin concentration turn out to be controversial. It was not the aim of this report to only investigate possible diurnal changes of melatonin, but additionally to relate such possible changes to the dynamics of the precursors, 5-HT and NAS. Information on diurnal changes of bioactive serotonin metabolites, in conjunction with immunocytochemical data, could help understanding the kinetics of potentially important chronobiotics and the sites of their synthesis, release and action. 
Melatonin levels determined here by ELISA resemble more the quantities reported by Tilden et al. (2001) from Cancer, but are lower than those by Agapito et al. (1995) and Balzer et al. (1997) from studies on Procambarus clarkii. In all these reports melatonin was measured by radioimmunoassay. Here I established a novel, sensitive system avoiding the use of radioactive reagents. The system has additional advantages, since a large number of samples can be measured simultaneously. Even more, using this ELISA system I was able to determine 5-HT, NAS and melatonin simultaneously from tissues of the same individual. Recent reports of melatonin measurements by radioimmunoassay stress the advantage of not transferring the sample many times during the process (Farca Luna, 2004; Gorbet and Steel, 2003). That advantage is also present in the ELISA, since samples are processed in the same well after homogenization.

The results obtained here showed significant differences between maximal and minimal values in most of the cases when compared by analysis of variance. Despite such differences, in none of the cases, a cosinor analysis was capable of demonstrating significance $(p=0.05)$, but some showed statistical trends in the range of $p=0.06-0.07$. This is the case for serotonin in the eyestalks $(p=0.067)$ and melatonin in brains $(p=0.061)$ whereas for NAS the uncertainty was slightly higher $(\mathrm{p}=0.083)$.

Cosinor analysis fits data to a sinusoidal curve and tests whether the amplitude of the curve differs from zero, i.e. whether a rhythm exists for an assumed $\tau$ (in this case $24 \mathrm{~h}$ ). High individual variability of the samples reflected in large standard error values was observed in many cases. This individual variability might reflect changes of the indolamines due to physiological factors, possibly related to development, age or social status. Moreover, shortterm fluctuations might contribute to the noisy appearance of a time series. This could apply particularly to serotonin, because of additional functions, perhaps also to NAS. Serotonin has been involved in the willingness of decapods to face opponent. Considering that animals have 
different hierarchies in the population, serotonin differences among individuals may differ as discussed previously. On the other hand, it has been observed that melatonin levels change from larvae to adult stages in Rhodnius prolixus (Farca Luna, 2004). In this study only adult marbled crayfish in intermoult stages were used, but since these animals keep molting in adult stages, indolamine changes related to molting cycles cannot be entirely ruled out. Although a large number of samples was assayed (more than 200 plus standards to create standard curves), it was only possible to evaluate 3 to 6 animals per time point over one day. Significance may be reached by increasing the number of animals and samples. Moreover, the applicability of the cosinor procedure could be questioned, because the time patterns obtained did not strictly exhibit sinusoidal properties. However, other non-sinusoidal least-square fitting techniques would require even larger data sets. Another indicator of non-sinusoidal patterns may be seen in the fact that statistical comparisons of single time points clearly revealed significant differences of biogenic messenger concentrations over the daily cycle. A further complication for the analysis of time patterns may have resulted from bimodality and eventual ultradian components.

In insects, specifically in Drosophila melanogaster, AA-NAT enzymes have been identified: AA-NAT1 and AA-NAT2 (AA-NAT1 with two different kinetic regimes) (Amherd et al., 2000; Hintermann et al., 1996). In none of the cases, AA-NAT has been tested for its contribution to melatonin formation. However, in arrhythmic PER deficiency mutants, melatonin was not detectable although normal levels of $N$-acetylserotonin were present (Callebert et al., 1991). This fact may be indicative of a role for melatonin in invertebrate circadian rhythmicity. Melatonin values in marbled crayfish are approximately 1000-fold smaller than those of serotonin and NAS. The theoretical explanation that melatonin is degraded faster than synthesized seems rather unlikely and would be at variance with anything known about melatonin metabolism in other organisms. The most probable 
interpretation would be to assume that serotonin $\mathrm{N}$-acetylation does not represent the ratelimiting step of melatonin formation and, thus, crayfish differ in this regard from the vertebrate pineal. This conclusion is not at all beyond reality, since the same conclusion had to be drawn in Drosophila, in which the NAS level is, as in this report, three orders of magnitude higher than that of melatonin (Callebert et al., 1991). This seems to result from the loss of a functional HIOMT gene in Drosophila, so that melatonin can be formed from NAS solely by other O-methyltransferases (Hardeland, pers. commun.). No contribution AA-NAT to the formation of melatonin has been reported in insects or crustaceans which may cause relatively higher NAS levels melatonin levels. This explanation is in contrast to the classical methabolic pathway present in most vertebrates, where AA-NAT is the limiting enzyme (Bembenek et al., 2005; De Angelis et al., 1998; Hardeland, 2008; Hardeland et al., 2006; Klein, 2006; Roseboom et al., 1998; Szewczuk et al., 2007) but agrees with previous studies of NAT activity in prawns. These report that NAT, due to its kinetics, is unlikely to be the rate limiting enzyme for melatonin synthesis (Withyachumnarnkul et al., 1992; 1995). Reliably reports about melatonin immunohistochemistry are rare. Successful immunostaining has been reported in the cnidarian Renilla kollikeri (Mechawar and Anctil, 1997). The low levels of melatonin detected by ELISA could explain the difficulty reported here to locate the indoleamine in tissue by immunoreactivity. Additionally, melatonin is a small molecule that highly lipophylic and sensitive to light, which may compromise its localization by antisera in fixed tissues. It has been stated that AA-NAT could be an enzyme present in vertebrates with homologs in bacteria, fungi, green algae and amphioxus, but not in arthropods (Coo and Klein, 2006). The presence of melatonin in insects and crustaceans suggests the presence of AA-NAT, although other enzymes could replace its role in melatonin formation (as stated before). The method presented here, allows to measure melatonin, and its precursors NAS and 5-HT simultaniously and is sensitive to the low concentrations of the chemical messengers in 
arthropod tissues. Therefore, the approach provides a new tool to analyze the significance of the daily fluctuations of the three indoleamines serotonin, $\mathrm{N}$-acetylserotonin and melatonin and may foster future studies of their relevance for the generation of circadian rhythms in arthropod tissues. 


\section{BIBLIOGRAPHY}

Agapito, M.B. Herrero, M.I. Pablos, J.L. Miguel, and J.M. Recio. 1995. Circadian rhythms of melatonin and serotonin-N-acetyltransferase activity in Procambarus clarkii. Comp Biochem Physiol. A 112:179-185.

Alvarado-Alvarez, R.H. Arechiga, and U. Garcia. 2000. Serotonin activates a $\mathrm{Ca}(2+)-$ dependent $\mathrm{K}(+)$ current in identified peptidergic neurons from the crayfish. $J$ Exp Biol. 203:715-23.

Alwes, F., and G. Scholtz. 2006. Stages and other aspects of the embryology of the parthenogenetic Marmorkrebs (Decapoda, Reptantia, Astacida). Dev Genes Evol. 216:169-84.

Amherd, R., E. Hintermann, D. Walz, M. Affolter, and U.A. Meyer. 2000. Purification, cloning, and characterization of a second arylalkylamine $\mathrm{N}$-acetyltransferase from Drosophila melanogaster. DNA Cell Biol. 19:697-705.

Ammermüller, J., M. Oltrogge, and U. Janssenbienhold. 1994. Neurotensin-like immunoreactivity in locust supraesophageal ganglion and optic lobes. Brain Research. 636:40-48.

Andrew, R.D., I. Orchard, and A.S. Saleuddin. 1978. Structural re-evaluation of the neurosecretory system in the crayfish eyestalk. Cell Tissue Res. 190:235-46.

Archer, J. 1988. The behavioural biology of aggression. Cambridge University Press, Cambridge. 257 p.

Arechiga, H., E. Banuelos, E. Frixione, A. Picones, and L. Rodriguez-Sosa. 1990. Modulation of crayfish retinal sensitivity by 5-hydroxytryptamine. J Exp Biol. 150:123-43.

Arechiga, H., B. Chavez, and R.M. Glantz. 1985. Dye coupling and gap junctions between crustacean neurosecretory cells. Brain Res. 326:183-7.

Arechiga, H., F. Fernandez-Quiroz, F. Fernandez de Miguel, and L. Rodriguez-Sosa. 1993. The circadian system of crustaceans. Chronobiol Int. 10:1-19.

Arechiga, H., and B. Fuentes Pardo. 1974. Hormonal influence on the nervous system of invertebrates. Bol Estud Med Biol. Suppl 1:261-85.

Arechiga, H., B. Fuentes-Pardo, and B. Barrera-Mera. 1974. Influence of retinal shielding pigments on light sensitivity in the crayfish. Acta Physiol Lat Am. 24:601-11.

Arechiga, H., and L. Rodriguez-Sosa. 1998. Circadian clock function in isolated eyestalk tissue of crayfish. Proc Biol Sci. 265:1819-23.

Arechiga, H., and L. Rodriguez-Sosa. 2002. Distributed circadian rhythmicity in the crustacean nervous system. In The crustacean nervous system. K. Wiese, editor. Springer, Berlin. 113-123. 
Arendt, J., and V. Marks. 1986. Jet lag and melatonin. Lancet. 2:698-9.

Atema, J.C., JS. 1980. Social behaviour. In The biology and management of lobsters. J. Cobb, Phillips, BF., editor. Academic Press, London. 409-450.

Balzer, I.R., B. Espinola, and B. Fuentes-Pardo. 1997. Daily variations of immunoreactive melatonin in the visual system of crayfish. Biol Cell. 89:539- 543.

Barrera-Mera, B., and G.D. Block. 1990. Protocerebral circadian pacemakers in crayfish: evidence for mutually coupled pacemakers. Brain Res. 522:241-5.

Barrera-Mera, B., J. Cibrian-Tovar, and D.E. Garcia-Diaz. 1980. The role of protocerebrum in the modulation of circadian rhythmicity in the crayfish visual system. Brain Res Bull. 5:66772 .

Bell-Pedersen, D., V.M. Cassone, D.J. Earnest, S.S. Golden, P.E. Hardin, T.L. Thomas, and M.J. Zoran. 2005. Circadian rhythms from multiple oscillators: Lessons from diverse organisms. Nature Reviews Genetics. 6:544-556.

Bembenek, J., H. Sehadova, N. Ichihara, and M. Takeda. 2005. Day/night fluctuations in melatonin content, arylalkylamine $\mathrm{N}$-acetyltransferase activity and NAT mRNA expression in the CNS, peripheral tissues and hemolymph of the cockroach, Periplaneta americana. Comp Biochem Physiol B Biochem Mol Biol. 140:27-36.

Berrill, M., and M. Arsenault. 1984. The breeding behaviour of a northern temperate orconectid crayfish, Orconectes rusticus. Animal Behaviour. 32:333-339.

Blau, J., and M.W. Young. 1999. Cycling vrille expression is required for a functional Drosophila clock. Cell. 99:661-671.

Bloch, G., S.M. Solomon, G.E. Robinson, and S.E. Fahrbach. 2003. Patterns of PERIOD and pigment-dispersing hormone immunoreactivity in the brain of the European honeybee (Apis mellifera): Age- and time-related plasticity. J Comp Neurol. 464:269-284.

Bonomelli, S.L., K.R. Rao, and J.P. Riehm. 1988. Development and application of an ELISA for crustacean beta-PDH. American Zoologist. 28:A117-A117.

Bovbjerg, R.V. 1953. Dominance order in the crayfish Orconectes virilis (Hagen). Physiol Zool. 26:173-178.

Braband A. , T.K., G. Scholtz,. 2006. The phylogenetic position of the East Asian freshwater crayfish Cambaroides within the Northern Hemisphere Astacoidea (Crustacea, Decapoda, Astacida) based on molecular data. Journal of Zoological Systematics \& Evolutionary Research. 44:17-24.

Breed, M.D., C.M. Hinkle, and W.J. Bell. 1975. Agonistic behavior in the German cockroach, Blattella germanica. Z Tierpsychol:24-32. 
Callebert, J., J.M. Jaunay, and J.M. Jallon. 1991. Control of Drosophila biorhythms. Adv Pineal Res. 5:81-84.

Caracciolo, S., R. Manfredini, M. Gallerani, and S. Tugnoli. 1996. Circadian rhythm of parasuicide in relation to violence of method and concomitant mental disorder. Acta Psychiatr Scand. 93:252-6.

Castanon-Cervantes, O., B. Battelle, and M.L. Fanjul-Moles. 1999. Rhythmic changes in the serotonin content of the brain and eyestalk of crayfish during development. J Exp Biol. 202 (Pt 20):2823-30.

Chen, S., A.Y. Lee, N.M. Bowens, R. Huber, and E.A. Kravitz. 2002. Fighting fruit flies: a model system for the study of aggression. Proc Natl Acad Sci U S A. 99:5664-8.

Clarac, F., and E. Pearlstein. 2007. Invertebrate preparations and their contribution to neurobiology in the second half of the 20th century. Brain Res Rev. 54:113-61.

Cromarty, S.I., J. Mello, and G. Kass-Simon. 2000. Molt-related and size-dependent differences in the escape response and post-threat behavior of the American lobster, Homarus americanus. Biol Bull. 199:265-77.

Cronin, T.W., and T.H. Goldsmith. 1982. Photosensitivity spectrum of crayfish rhodopsin measured using fluorescence of metarhodopsin. J Gen Physiol. 79:313-32.

De Angelis, J., J. Gastel, D.C. Klein, and P.A. Cole. 1998. Kinetic analysis of the catalytic mechanism of serotonin $\mathrm{N}$-acetyltransferase (EC 2.3.1.87). J Biol Chem. 273:3045-50.

de la Iglesia, H.O., E.M. Rodriguez, and R.E. Dezi. 1994. Burrow plugging in the crab Uca uruguayensis and its synchronization with photoperiod and tides. Physiol Behav. 55:913-9.

Dierick, H.A., and R.J. Greenspan. 2006. Molecular analysis of flies selected for aggressive behavior. Nat Genet. 38:1023-31.

Dircksen, H. 1992. Fine structure of the neurohemal sinus gland of the shore crab, Carcinus maenas, and immuno-electron-microscopic identification of neurosecretory endings according to their neuropeptide contents. Cell and Tissue Research. 269:249-266.

Dircksen, H., C.A. Zahnow, G. Gaus, R. Keller, K.R. Rao, and J.P. Riehm. 1987. The ultrastructure of nerve endings containing pigment-dispersing hormone (PDH) in crustacean glands: Identification by an antiserum against a synthetic PDH. Cell and Tissue Research. 250:377-387.

Doernberg, S.B., S.I. Cromarty, R. Heinrich, B.S. Beltz, and E.A. Kravitz. 2001. Agonistic behavior in naive juvenile lobsters depleted of serotonin 5,7-dihydroxytryptamine. J Comp Physiol [A]. 187:91-103.

Dohle, W. 2001. Are the insects terrestrial crustaceans? A discussion of some new facts and arguments and the proposal of the proper name 'Tetraconata' for the monophyletic unit Crustacea plus Hexapoda. Annales de la Societe Entomologique de France. 37:85-103. 
Duran-Lizarraga, M.E., J. Prieto-Sagredo, M.E. Gonsebatt, and M.L. Fanjul-Moles. 2001. Crayfish Procambarus clarkii shows circadian variations in different parameters of the GSH cycle. Photochem Photobiol. 74:350-5.

Edwards, D.H., and J. Herberholz. 2005. Crustacean models of aggression. In The Biology of Aggression,. R.J. Nelson, editor. Oxford University Press. 38-61.

Edwards, D.H., F.A. Issa, and J. Herberholz. 2003. The neural basis of dominance hierarchy formation in crayfish. Microsc Res Tech. 60:369-76.

Escamilla-Chimal, E.G., M. Hiriart, M.C. Sanchez-Soto, and M.L. Fanjul-Moles. 2002. Serotonin modulation of $\mathrm{CHH}$ secretion by isolated cells of the crayfish retina and optic lobe. Gen Comp Endocrinol. 125:283-90.

Fanjul-Moles, M.L. 2006. Biochemical and functional aspects of crustacean hyperglycemic hormone in decapod crustaceans: review and update. Comp Biochem Physiol C Toxicol Pharmacol. 142:390-400.

Fanjul-Moles, M.L., T. Bosques-Tistler, J. Prieto-Sagredo, O. Castanon-Cervantes, and L. Fernandez-Rivera-Rio. 1998. Effect of variation in photoperiod and light intensity on oxygen consumption, lactate concentration and behavior in crayfish Procambarus clarkii and Procambarus digueti. Comp Biochem Physiol A Mol Integr Physiol. 119:263-9.

Fanjul-Moles, M.L., M.E. Duran-Lizarraga, M.E. Gonsebatt, and J. Prieto-Sagredo. 2003. The effect of photoperiod and light irradiance on the antioxidant circadian system of two species of crayfish from different latitudes: Procambarus clarkii and P. digueti. Photochem Photobiol. 77:210-8.

Fanjul-Moles, M.L., E.G. Escamilla-Chimal, A. Gloria-Osorio, and G. Hernandez-Herrera. 2004. The crayfish Procambarus clarkii CRY shows daily and circadian variation. J Exp Biol. 207:1453-60.

Fanjul-Moles, M.L., M. Miranda-Anaya, and J. Prieto. 1996. Circadian locomotor activity rhythm during ontogeny in crayfish Procambarus clarkii. Chronobiol Int. 13:15-26.

Fanjul-Moles, M.L., and J. Prieto-Sagredo. 2003. The circadian system of crayfish: a developmental approach. Microsc Res Tech. 60:291-301.

Farca Luna, A.J. 2004. Distribution and rhythmicity of melatonin in the insect Rhodnius Prolixus. M. in Sc. Thesis. York University, Canada.

Fernandez, M.P., J. Berni, and M.F. Ceriani. 2008. Circadian remodeling of neuronal circuits involved in rhythmic behavior. PLoS Biol. 6:e69.

Fernandez, M.P., J. Chu, A. Villella, N. Atkinson, S.A. Kay, and M.F. Ceriani. 2007. Impaired clock output by altered connectivity in the circadian network. Proc Natl Acad Sci U S A. 104:5650-5. 
Fernlund, P. 1976. Structure of a light-adapting hormone from the shrimp, Pandalus borealis. Biochim Biophys Acta. 439:17-25.

Fingerman, M., and A.D. Lago. 1957. Endogenous twenty four hour rhythms of locomotor activity and oxygen consumption in the crawfish Orconectes clypeatus. Am Mid Nat. 58:383393.

Fingerman, S.W., and M. Fingerman. 1977. Circadian variation in the levels of red pigmentdispersing hormone and 5-hydroxytryptamine in the eyestalks of the fiddler crab, Uca pugilator. Comp Biochem Physiol C. 56:5-8.

Finocchiaro, L., J. Callebert, J.M. Launay, and J.M. Jallon. 1988. Melatonin biosynthesis in Drosophila: its nature and its effects. J Neurochem. 50:382-7.

Frisch, B., G. Fleissner, C. Brandes, and J.C. Hall. 1996. Staining in the brain of Pachymorpha sexguttata mediated by an antibody against a Drosophila clock-gene product: labelling of cells with possible importance for the beetle's circadian rhythms. Cell and Tissue Research. 286:411-429.

Fuentes Pardo, B., M. Lara-Aparicio, S. Lopez de Medrano, and J. Viccon-Pale. 1996. Motor circadian rhythm in crayfish. An experimental and theoretical study. Trends Comp Biochem Physiol. 2:113-127.

Ganguly, S., S.L. Coon, and D.C. Klein. 2002. Control of melatonin synthesis in the mammalian pineal gland: the critical role of serotonin acetylation. Cell Tissue Res. 309:12737.

Garcia, U., and H. Arechiga. 1998. Regulation of crustacean neurosecretory cell activity. Cell Mol Neurobiol. 18:81-99.

Glenner, H., P.F. Thomsen, M.B. Hebsgaard, M.V. Sorensen, and E. Willerslev. 2006. Evolution. The origin of insects. Science. 314:1883-1884.

Goessmann, C., C. Hemelrijk, and M. Huber. 2000. The formation and maintenance of crayfish hierarchies: behavioral and self-structuring properties. Behav Ecol Sociobiol. 48:418428.

Gorbet, D.J., and C.G. Steel. 2003. A miniature radioimmunoassay for melatonin for use with small samples from invertebrates. Gen Comp Endocrinol. 134:193-7.

Grimmelikhuijzen, C.J.P. 1983. FMRFamide immunoreactivity is generally occurring in the nervous systems of coelenterates. Histochemistry. 78:361-381.

Hafner, G.S., G. Hammond-Scoltis, and T. Tokarski. 1980. Diurnal changes of lysosomerelated bodies in the crayfish photoreceptor cells. Cell Tissue Res. 206:319-32.

Hagberg, M. 1986. Ultrastructure and central projections of extraocular photoreceptors in caddiesflies. Cell Tissue Research. 245:643-648. 
Haller, J., S. Millar, J. van de Schraaf, R.E. de Kloet, and M.R. Kruk. 2000. The active phaserelated increase in corticosterone and aggression are linked. J Neuroendocrinol. 12:431-6.

Hammond, R.D., and M. Fingerman. 1975. Entrainment analysis of the circadian locomotor activity rhythm in specimens of the crayfish, Faxonella clypeata, having activity peaks at different times of the solar day. Chronobiologia. 2:119-32.

Hardeland, R. 2005. Antioxidative protection by melatonin: multiplicity of mechanisms from radical detoxification to radical avoidance. Endocrine. 27:119-30.

Hardeland, R. 2008. Melatonin, hormone of darkness and more: occurrence, control mechanisms, actions and bioactive metabolites. Cell Mol Life Sci. 65:2001-18.

Hardeland R, Pandi-Perumal SR, and P. B. 2007. Melatonin in plants - Focus on a vertebrate night hormone with cytoprotective properties. Funct Plant Sci Biotechnol; . 1:32-45.

Hardeland, R., C. Backhaus, and A. Fadavi. 2007a. Reactions of the NO redox forms NO+, *NO and HNO (protonated NO-) with the melatonin metabolite N1-acetyl-5methoxykynuramine. J Pineal Res. 43:382-8.

Hardeland, R., G. Behrmann, B. Fuhrberg, B. Poeggeler, S. Burkhardt, H. Uria, and B. Obst. 1996. Evolutionary aspects of indoleamines as radical scavengers. Presence and photocatalytic turnover of indoleamines in a unicell, Gonyaulax polyedra. Adv Exp Med Biol. 398:279-84.

Hardeland, R., Pandi-Perumal SR, and P. B. 2007b. Melatonin in plants - Focus on a vertebrate night hormone with cytoprotective properties. Funct Plant Sci Biotechnol;. 1:3245 .

Hardeland, R., S.R. Pandi-Perumal, and D.P. Cardinali. 2006. Melatonin. Int J Biochem Cell Biol. 38:313-6.

Hardeland, R., and B. Poeggeler. 2003. Non-vertebrate melatonin. J Pineal Res. 34:233-41.

Hardeland, R., and B. Poeggeler. 2007. Actions of Melatonin, Its Structural and Functional Analogs in the Central Nervous System and the Significance of Metabolism. Central Nervous System Agents in Medicinal Chemistry. 7: 289-303.

Hardeland, R., R.J. Reiter, B. Poeggeler, and D.X. Tan. 1993. The significance of the metabolism of the neurohormone melatonin: antioxidative protection and formation of bioactive substances. Neurosci Biobehav Rev. 17:347-57.

Hazlett, B.A. 1969. "Individual" recognition and agonistic behaviour in Pagurus bernhardus. Nature. 222:268-9.

Heinrich, R., P. Bräunig, I. Walter, H. Schneider, and E.A. Kravitz. 2000. Aminergic neuron systems of lobsters: morphology and electrophysiology of octopamine-containing neurosecretory cells. J Comp Physiol [A]. 186:617-29. 
Heinrich, R., S.I. Cromarty, M. Hörner, D.H. Edwards, and E.A. Kravitz. 1999. Autoinhibition of serotonin cells: an intrinsic regulatory mechanism sensitive to the pattern of usage of the cells. Proc Natl Acad Sci U S A. 96:2473-8.

Helfrich-Förster, C. 2005. Organization of endogenous clocks in insects. Biochem Soc Trans. 33:957-61.

Helfrich-Förster, C. 1993. Neurons in the brain of Drosophila melanogaster immunostained by an antiserum against the pigment-dispersing-hormone (PDH) contain also the periodprotein (per). In: Elsner and M. Heisenberg (eds): Gene-Brain-Behavior. Stuttgart, New York: Thieme Verlag. p. 543.

Helfrich-Förster, C. 1995. The period clock gene is expressed in central nervous system neurons which also produce a neuropeptide that reveals the projections of circadian pacemaker cells within the brain of Drosophila melanogaster. Proci Nat Acad Sci USA. 92:612-616.

Helfrich-Förster, C. 1998. Robust circadian rhythmicity of Drosophila melanogaster requires the presence of lateral neurons: a brain-behavioral study of disconnected mutants. J Comp Physiol A. 182:435-453.

Helfrich-Förster, C., O.T. Shafer, C. Wülbeck, E. Grieshaber, D. Rieger, and P. Taghert. 2007. Development and morphology of the clock-gene-expressing lateral neurons of Drosophila melanogaster. J Comp Neurol. 500:47-70.

Helfrich-Förster, C., M. Stengl, and U. Homberg. 1998. Organization of the circadian system in insects. Chronobiol Int. 15:567-94.

Herberholz, J., F.A. Issa, and D.H. Edwards. 2001. Patterns of neural circuit activation and behavior during dominance hierarchy formation in freely behaving crayfish. $J$ Neurosci. 21:2759-67.

Herberholz, J., C. McCurdy, and D.H. Edwards. 2007. Direct benefits of social dominance in juvenile crayfish. Biol Bull. 213:21-7.

Hernandez-Falcon, J., and F. Ramon. 1998. The circadian rhythm of cardiac frequency in crayfish: a multioscillator system? Biological Rhythm Research. 29:464-470.

Hintermann, E., N.C. Grieder, R. Amherd, D. Brodbeck, and U.A. Meyer. 1996. Cloning of an arylalkylamine $\mathrm{N}$-acetyltransferase (aaNAT1) from Drosophila melanogaster expressed in the nervous system and the gut. Proc Natl Acad Sci U S A. 93:12315-20.

Homberg, U. 1991. Neuroarchitecture of the central complex in the brain of the locust Schistocerca gregaria and S. americana as revealed by serotonin immunocytochemistry. $J$ Comp Neurol. 303:245-254.

Homberg, U., N.T. Davis, and J.G. Hildebrand. 1991a. Peptide-immunocytochemistry of neurosecretory cells in the brain and retrocerebral complex of the sphinx moth Manduca sexta. J Comp Neurol. 303:35-52. 
Homberg, U., S. Hofer, K. Pfeiffer, and S. Gebhardt. 2003. Organization and neural connections of the anterior optic tubercle in the brain of the locust, Schistocerca gregaria. $J$ Comp Neurol. 462:415-430.

Homberg, U., and N. Prakash. 1996. Development of pigment-dispersing hormone-like immunoreactivity in the brain of the locust Schistocerca gregaria: comparison with immunostaining for urotensin I and Mas-allatotropin. Cell and Tissue Research. 285:127-139.

Homberg, U., S. Würden, H. Dircksen, and K.R. Rao. 1991. Comparative anatomy of pigment-dispersing hormone-immunoreactive neurons in the brain of orthopteroid insects. Cell and Tissue Research. 266:343-357.

Hsu, Y.W., E.A. Stemmler, D.I. Messinger, P.S. Dickinson, A.E. Christie, and H.O. de la Iglesia. 2008. Cloning and differential expression of two beta-pigment-dispersing hormone (beta-PDH) isoforms in the crab Cancer productus: evidence for authentic beta-PDH as a local neurotransmitter and beta-PDH II as a humoral factor. J Comp Neurol. 508:197-211.

Huber, R., and E.A. Kravitz. 1995. A quantitative analysis of agonistic behavior in juvenile American lobsters (Homarus americanus L.). Brain Behav Evol. 46:72-83.

Huber, R., M. Orzeszyna, N. Pokorny, and E.A. Kravitz. 1997a. Biogenic amines and aggression: experimental approaches in crustaceans. Brain Behav Evol. 50 Suppl 1:60-8.

Huber, R., K. Smith, A. Delago, K. Isaksson, and E.A. Kravitz. 1997b. Serotonin and aggressive motivation in crustaceans: altering the decision to retreat. Proc Natl Acad Sci U S A. 94:5939-42.

Issa, F.A., D.J. Adamson, and D.H. Edwards. 1999. Dominance hierarchy formation in juvenile crayfish Procambarus clarkii. J Exp Biol. 202 Pt 24:3497-506.

Itoh, M.T., A. Hattori, T. Nomura, Y. Sumi, and T. Suzuki. 1995a. Melatonin and arylalkylamine $\mathrm{N}$-acetyltransferase activity in the silkworm, Bombyx mori. Mol Cell Endocrinol. 115:59-64.

Itoh, M.T., A. Hattori, Y. Sumi, and T. Suzuki. 1995b. Day-night changes in melatonin levels in different organs of the cricket (Gryllus bimaculatus). J Pineal Res. 18:165-9.

Iwasaki, M., A. Delago, H. Nishino, and H. Aonuma. 2006. Effects of previous experience on the agonistic behaviour of male crickets, Gryllus bimaculatus. Zoolog Sci. 23:863-72.

Kaneko, M., C. Helfrich-Förster, and J.C. Hall. 1997. Spatial and temporal expression of the period and timeless genes in the developing nervous system of Drosophila: newly identified pacemaker candidates and novel features of clock gene product cycling. J Neurosci. 17:67456760.

Karavanich, C., and J. Atema. 1998. Individual recognition and memory in lobster dominance. Anim Behav. 56:1553-1560. 
Klein, D.C. 2006. Evolution of the vertebrate pineal gland: the AANAT hypothesis. Chronobiol Int. 23:5-20.

Klein, D.C. 2007. Arylalkylamine N-acetyltransferase: "the Timezyme". J Biol Chem. 282:4233-7.

Klein, J.M., C.J. Mohrherr, F. Sleutels, J.P. Riehm, and K. Rao. 1994. Molecular cloning of two pigment-dispersing hormone (PDH) precursors in the blue crab Callinectes sapidus reveals a novel member of the PDH neuropeptide family. Biochemical and Biophysical Research Communications. 205:410-416.

Kravitz, E.A. 2000. Serotonin and aggression: insights gained from a lobster model system and speculations on the role of amine neurons in a complex behavior. J Comp Physiol [A]. 186:221-38.

Kumar, V. 1997. Photoperiodism in higher vertebrates: an adaptive strategy in temporal environment. Indian J Exp Biol. 35:427-37.

Landau, I.T. 1975. Light-dark rhythms in aggressive behavior of the male golden hamster. Physiol Behav. 14:767-74.

Larimer, J.L., and J.T.F. Smith. 1980. Circadian rhythm of retinal sensitivity in the crayfish: modulation by the cerebral and optic ganglia. J Comp Physiol. 136:313-326.

Laubichler, W., and M. Ruby. 1986. [Diurnal relations of criminal behavior]. Arch Kriminol. 177:176-84.

Lerner, A.B., J.D. Case, and Y. Takahashi. 1960. Isolation of melatonin and 5methoxyindole-3-acetic acid from bovine pineal glands. J Biol Chem. 235:1992-7.

Lezoualc'h, F., Y. Sagara, F. Holsboer, and C. Behl. 1998. High Constitutive NF-kappa B Activity Mediates Resistance to Oxidative Stress in Neuronal Cells. J. Neurosci. 18:32243232.

Linn, C.E., K.R. Poole, W.L. Roelofs, and W.-Q. Wu. 1995. Circadian changes in melatonin in the nervous system and hemolymph of the cabbage looper moth, Trichoplusia ni. J Comp Physiol A. 176:761-771.

Löhr, J., J. Klein, S.G. Webster, and H. Dircksen. 1993. Quantification, immunoaffinity purification and sequence analysis of a pigment-dispersing hormone of the shore crab, Carcinus maenas (L.). Comp Biochem Physiol B. 104:699-706.

Lundquist, T., and D.R. Nassel. 1990. Substance P-, FMRFamide-, and gastrin/cholecystokinin-like immunoreactive neurons in the thoraco-abdominal ganglia of the flies Drosophila and Calliphora. J Comp Neurol. 294:161-178.

Lupien, M., S. Marshall, W. Leser, G.S. Pollack, and H.W. Honegger. 2003. Antibodies against the PER protein of Drosophila label neurons in the optic lobe, central brain, and 
thoracic ganglia of the crickets Teleogryllus commodus and Teleogryllus oceanicus. Cell and Tissue Research. 312:377-391.

Mancini, G., and N. Frontali. 1967. Fine structure of the mushroom body neuropile of the brain of the roach, Periplaneta americana. Z Zellforsch. 83:334-343.

Mancini, G., and N. Frontali. 1970. On the ultrastructural localization of catecholamines in the beta lobes (Corpora pedunculata) of Periplaneta americana. Z Zellforsch. 103:341-350.

Manfredini, R., A. Vanni, L. Peron, O. La Cecilia, M.H. Smolensky, and L. Grassi. 2001. Day-night variation in aggressive behavior among psychiatric inpatients. Chronobiol Int. 18:503-11.

Mangerich, S., and R. Keller. 1988. Localization of pigment-dispersing hormone (PDH) immunoreactivity in the central nervous system of Carcinus maenas and Orconectes limosus (Crustacea), with reference to FMRFamide immunoreactivity in O. limosus. Cell and Tissue Research. 253:199-208.

Mangerich, S., R. Keller, H. Dircksen, K.R. Rao, and J.P. Riehm. 1987. Immunocytochemical localization of pigment-dispersing hormone (PDH) and its coexistence with FMRFamideimmunoreactive material in the eyestalks of the decapod crustaceans Carcinus maenas and Orconectes limosus. Cell and Tissue Research. 250:365-375.

Martensz, N.D., S.V. Vellucci, L.M. Fuller, B.J. Everitt, E.B. Keverne, and J. Herbert. 1987. Relation between aggressive behaviour and circadian rhythms in cortisol and testosterone in social groups of talapoin monkeys. J Endocrinol. 115:107-20.

Martin, P., K. Kohlmann, and G. Scholtz. 2007. The parthenogenetic Marmorkrebs (marbled crayfish) produces genetically uniform offspring. Naturwissenschaften. 94:843-6.

Matsushima, A., S. Sato, Y. Chuman, Y. Takeda, S. Yokotani, T. Nose, Y. Tominaga, M. Shimohigashi, and Y. Shimohigashi. 2004. cDNA cloning of the housefly pigment-dispersing factor (PDF) precursor protein and its peptide comparison among the insect circadian neuropeptides. J Pept Sci. 10:82-91.

McCallum, M.L., K.R. Rao, J.P. Riehm, C.J. Mohrherr, and W.T. Morgan. 1991. Primary structure and relative potency of an analog of beta-PDH (pigment-dispersing hormone) from the crayfish Procambarus clarkii. Pigment Cell Res. 4:201-8.

Mechawar, N., and M. Anctil. 1997. Melatonin in a primitive metazoan: seasonal changes of levels and immunohistochemical visualization in neurons. J Comp Neurol. 387:243-54.

Mercier, A.J., R. Friedrich, and M. Boldt. 2003. Physiological functions of FMRFamide-like peptides (FLPs) in crustaceans. Microsc Res Tech. 60:313-324.

Meyer-Rochow, V.B., and O. Vakkuri. 2002. Head and abdominal melatonin of summer and winter bees. J Pineal Res. 32:275-6. 
Miranda-Anaya, M. 2004. Circadian Locomotor Activity in Freshwater Decapods:An Ecological Approach. Biological Rhythm Research. 35:69-78.

Miranda-Anaya, M., and M.L. Fanjul-Moles. 1997. Nonparametric effects of monochromatic light on the activity rhythm of juvenile crayfish. Chronobiol Int. 14:25-34.

Morita, M., F. Hall, J.B. Best, and W. Gern. 1987. Photoperiodic modulation of cephalic melatonin in planarians. J Exp Zool. 241:383-8.

Mortin, L.I., and E. Marder. 1991. Differential distribution of beta-pigment-dispersing hormone (beta-PDH)-like immunoreactivity in the stomatogastric nervous system of five species of decapod crustaceans. Cell Tissue Res. 265:19-33.

Murad, A., M. Emery-Le, and P. Emery. 2007. A subset of dorsal neurons modulates circadian behavior and light responses in Drosophila. Neuron. 53:689-701.

Nässel, D.R. 1991. Neurotransmitters and neuromodulators in the insect visual system. Prog Neurobiol. 37:179-254.

Nässel, D.R., and U. Homberg. 2006. Neuropeptides in interneurons of the insect brain. Cell and Tissue Research. 326:1-24

Nässel, D.R., M.G. Persson, and J.E. Muren. 2000. Baratin, a nonamidated neurostimulating neuropeptide, isolated from cockroach brain: distribution and actions in the cockroach and locust nervous systems. J Comp Neurol. 422:267-286.

Nässel, D.R., S. Shiga, E.M. Wikstrand, and K.R. Rao. 1991. Pigment-dispersing hormoneimmunoreactive neurons in the blowfly and cockroach visual system. Cell and Tissue Research. 266:511-523.

Nässel, D.R., and A.M. Winther. 2002. Neuronal co-localization of different isoforms of tachykinin-related peptides (LemTRPs) in the cockroach brain. Cell Tissue Res. 308:225-239.

Nilsen, S.P., Y.B. Chan, R. Huber, and E.A. Kravitz. 2004. Gender-selective patterns of aggressive behavior in Drosophila melanogaster. Proc Natl Acad Sci U S A. 101:12342-7.

Nussbaum, T., and H. Dircksen. 1995. Neuronal pathways of classical crustacean neurohormones in the central nervous system of the woodlouse, Oniscus asellus (L). Philosophical Transactions of the Royal Society of London Series B. 347:139-154.

Orchard, I., and A.B. Lange. 2006. Insect myosuppressins/FMRFamides and FL/IRFamides/NPFs. In Handbook of bioloically active peptides. A.J. Kastin, editor. Academic Press Inc., Burlington. 193-199.

Orchard, I., A.B. Lange, and W.G. Bendena. 2001. FMRFamide-related peptides: a multifunctional family of structurally related neuropeptides in insects. Adv Insect Physiol. 28:267-329. 
Page, T.L., and J.L. Larimer. 1972. Entrainment of the circadian locomotor activity rhythm in crayfish. The role of the eyes and caudal photoreceptor. J Comp Physiol. 78:107-120.

Page, T.L., and J.L. Larimer. 1976. Extraretinal photoreception in entrainment of crustacean circadian rhythms. Photophysiology. 23:245-51.

Palmer, J.D. 1971. Comparative studies of circadian locomotory rhythms in four species of terrestrial crabs. Am Mid Nat. 85:97-107.

Pandi-Perumal, S.R., V. Srinivasan, G.J. Maestroni, D.P. Cardinali, B. Poeggeler, and R. Hardeland. 2006. Melatonin: Nature's most versatile biological signal? Febs J. 273:2813-38.

Park, J.H., C. Helfrich-Förster, G. Lee, L. Liu, M. Rosbash, and J.C. Hall. 2000. Differential regulation of circadian pacemaker output by separate clock genes in Drosophila. Proc Natl Acad Sci USA. 97:3608-3613.

Petri, B., and M. Stengl. 1997. Pigment-dispersing hormone shifts the phase of the circadian pacemaker of the cockroach Leucophaea maderae. J Neurosci. 17:4087-4093.

Petri, B., M. Stengl, S. Würden, and U. Homberg. 1995. Immunocytochemical characterization of the accessory medulla in the cockroach Leucophaea maderae. Cell and Tissue Research. 282:3-19.

Polanska, M.A., A. Yasuda, and S. Harzsch. 2007. Immunolocalisation of crustaceanSIFamide in the median brain and eyestalk neuropils of the marbled crayfish. Cell Tissue Res. 330:331-344.

Pollard, T., and J.L. Larimer. 1977. Circadian rhythmicity of heart rate in the crayfish, Procambarus clarkii. Comp Biochem Physiol. 57A:221-226.

Price, D.A., and M.J. Greenberg. 1977. Purification and characterization of a cardioexcitatory neuropeptide from the central ganglia of a bivalve mollusc. Prep Biochem. 7:261-81.

Primus, J.P., and G.M. Brown. 1994. Sepiapterin reductase and the biosynthesis of tetrahydrobiopterin in Drosophila melanogaster. Insect Biochem Mol Biol. 24:907-18.

Puche, J., and B. Barrera-Mera. 1993. Effects of asphyxia on the visual activity of the crayfish with neural deafferentation of the eyestalks. Rev Esp Fisiol. 49:121-4.

Pyza, E., and B. Cymborowski. 2001. Circadian rhythms in behaviour and in the visual system of the blow fly, Calliphora vicinia. Journal of Insect Physiology. 47:897-904.

Radilova, J., N. Kovacevic, L. Rakic, and T. Radil. 1991. Circadian differences in aggressive behavior of sea fish Serranus scriba. Homeost Health Dis. 33:155-6.

Ramon, F., J. Hernandez-Falcon, B. Nguyen, and T.H. Bullock. 2004. Slow wave sleep in crayfish. Proc Natl Acad Sci U S A. 101:11857-61. 
Ranta, E., and K. Lindström. 1993. Body size and shelter possession in mature signal crayfish, Pacifastacus leniusculus. Annales Zoologici Fennici. 30:125-132.

Rao, K.R., C.J. Mohrherr, J.P. Riehm, C.A. Zahnow, S. Norton, L. Johnson, and G.E. Tarr. 1987. Primary structure of an analog of crustacean pigment-dispersing hormone from the lubber grasshopper Romalea microptera. J Biol Chem. 262:2672-2675.

Rao, K.R., and J.P. Riehm. 1988. Pigment-dispersing hormones: a novel family of neuropeptides from arthropods. Peptides. 9 Suppl 1:153-9.

Rao, K.R., and J.P. Riehm. 1989. The pigment-dispersing hormone family: chemistry, structure-activity relations, and distribution. Biol Bull. 177:225-229.

Rao, K.R., and J.P. Riehm. 1993. Pigment-dispersing hormones. Ann N Y Acad Sci. 680:7888 .

Rao, K.R., J.P. Riehm, C.A. Zahnow, L.H. Kleinholz, G.E. Tarr, L. Johnson, S. Norton, M. Landau, O.J. Semmes, R.M. Sattelberg, W.H. Jorenby, and M.F. Hintz. 1985. Characterization of a pigment-dispersing hormone in eyestalks of the fiddler crab Uca pugilator. Proc Natl Acad Sci U S A. 82:5319-5322.

Reddy, D.C., M. Raghupathi, K.R. Purushotham, and B.P. Naidu. 1981. Daily rhythms in levels of blood glucose \& hepatopancreatic glycogen in the fresh water field crab Oziotelphusa senex senex (Fabricius). Indian J Exp Biol. 19:403-4.

Reddy, P.S. 1991. Suppression of the diurnal rhythm of oxygen uptake by eyestalk ablation in the crab Oziotelphusa senex senex Fabricius. Arch Int Physiol Biochim Biophys. 99:393-5.

Reischig, T. 2005. Search for the neurotransmitters and transmitter receptors in the pigmentdispersing factor (PDF)-immunoreactive neurons of the cockroach Leucophaea maderae. In Proceedings of the $6^{\text {th }}$ meeting of the German Neuroscience Society/30 ${ }^{\text {th }}$ Göttingen neurobiology conference. K. Krieglstein, editor, Göttingen. 265A.

Reischig, T., B. Petri, and M. Stengl. 2004. Pigment-dispersing hormone (PDH)immunoreactive neurons form a direct coupling pathway between the bilaterally symmetric circadian pacemakers of the cockroach Leucophaea maderae. Cell and Tissue Research. 318:553-564.

Reischig, T., and M. Stengl. 1996. Morphology and pigment-dispersing hormone immunocytochemistry of the accessory medulla, the presumptive circadian pacemaker of the cockroach Leucophaea maderae: a light- and electron- microscopic study. Cell and Tissue Research. 285:305-319.

Reischig, T., and M. Stengl. 2002. Optic lobe commissures in a three-dimensional brain model of the cockroach Leucophaea maderae: a search for the circadian coupling pathways. $J$ Comp Neurol. 443:388-400. 
Reischig, T., and M. Stengl. 2003a. Ectopic transplantation of the accessory medulla restores circadian locomotor rhythms in arrhythmic cockroaches (Leucophaea maderae). J Exp Biol. 206:1877-86.

Reischig, T., and M. Stengl. 2003b. Ultrastructure of pigment-dispersing hormoneimmunoreactive neurons in a three-dimensional model of the accessory medulla of the cockroach (Leucophaea maderae). Cell and Tissue Research. 314:421-435.

Reiter, R.J. 1992. The ageing pineal gland and its physiological consequences. Bioessays. 14:169-75.

Reiter, R.J. 1993. The melatonin rhythm: both a clock and a calendar. Experientia. 49:654-64.

Reiter, R.J., M.K. Vaughn, D.E. Blask, and L.Y. Johnson. 1974. Melatonin: its inhibition of pineal antigonadotrophic activity in male hamsters. Science. 185:1169-71.

Renn, S.C., J.H. Park, M. Rosbash, J.C. Hall, and P.H. Taghert. 1999. A pdf neuropeptide gene mutation and ablation of PDF neurons each cause severe abnormalities of behavioural circadian rhythms in Drosophila. Cell. 99:791-802.

Reppert, S.M. 1997. Melatonin receptors: molecular biology of a new family of G proteincoupled receptors. J Biol Rhythms. 12:528-31.

Richter, S. 2002. The Tetraconata concept: hexapod-crustacean relationships and the phylogeny of Crustacea. Organisms, Diversity \& Evolution. 2:217-237.

Rodriguez-Sosa, L., G. Calderon-Rosete, and G. Flores. 2008. Circadian and ultradian rhythms in the crayfish caudal photoreceptor. Synapse. 62:643-52.

Rodriguez-Sosa, L., G. Calderon-Rosete, G. Flores, and M.G. Porras. 2007. Serotonin-caused phase shift of circadian rhythmicity in a photosensitive neuron. Synapse. 61:801-8.

Romeis, B. 1989. Mikroskopische Technik. Verlag Urban und Schwarzenberg, Munich.

Roseboom, P.H., M.A. Namboodiri, D.B. Zimonjic, N.C. Popescu, I.R. Rodriguez, J.A. Gastel, and D.C. Klein. 1998. Natural melatonin 'knockdown' in C57BL/6J mice: rare mechanism truncates serotonin N-acetyltransferase. Brain Res Mol Brain Res. 63:189-97.

Russell, J.W., and G. Singer. 1983. Relations between muricide, circadian rhythm and consummatory behavior. Physiol Behav. 30:23-7.

Rutishauser, R.L., A.C. Basu, S.I. Cromarty, and E.A. Kravitz. 2004. Long-term consequences of agonistic interactions between socially naive juvenile American lobsters (Homarus americanus). Biol Bull. 207:183-7.

Saenz, F., U. Garcia, and U. Arechiga. 1997. Modulation of electrical activity by 5hydroxytryptamine in crayfish neurosecretory cells. J Exp Biol. 200:3079-90. 
Sandeman, D., B. Beltz, and R. Sandeman. 1995. Crayfish brain interneurons that converge with serotonin giant cells in accessory lobe glomeruli. J Comp Neurol. 352:263-79.

Sandeman, R.E., and D.C. Sandeman. 1987. Serotonin-like immunoreactivity of giant olfactory interneurons in the crayfish brain. Brain Res. 403:371-4.

Sato, S., Y. Chuman, A. Matsushima, Y. Tominaga, Y. Shimohigashi, and M. Shimohigashi. 2002. A circadian neuropeptide, pigment-dispersing factor-PDF, in the last-summer cicada Meimuna opalifera: cDNA cloning and immunocytochemistry. Zoological Science. 19:821828.

Sauman, I., and S.M. Reppert. 1996. Circadian clock neurons in the silkmoth Antheraea pernyi: novel mechanisms of Period protein regulation. Neuron. 17:889-900.

Schallek, W. 1942. Some mechanisms controlling locomotor activity in the crayfish. $J$ Exp Zool. 91:155-166.

Scholtz, G., A. Braband, L. Tolley, A. Reimann, B. Mittmann, C. Lukhaup, F. Steuerwald, and G. Vogt. 2003. Ecology: Parthenogenesis in an outsider crayfish. Nature. 421:806.

Schoofs, L., D. Veelaert, G.M. Holman, T.K. Hayes, and A. De Loof. 1994. Partial identification, synthesis and immunolocalization of locustamyoinhibin, the third myoinhibiting neuropeptide isolated from Locusta migratoria. Regulatory Peptides. 52:139156.

Sehadová, H., I. Sauman, and F. Sehnal. 2003. Immunocytochemical distribution of pigmentdispersing hormone in the cephalic ganglia of polyneopteran insects. Cell and Tissue Research. 312:113-125.

Settembrini, B.P., and M.J. Villar. 2005. FMRFamide-like immunocytochemistry in the brain and subesophageal ganglion of Triatoma infestans (Insecta: Heteroptera). Coexpression with beta-pigment-dispersing hormone and small cardioactive peptide B. Cell and Tissue Research. 321:299-310.

Siepka, S.M., S.H. Yoo, J. Park, C. Lee, and J.S. Takahashi. 2007. Genetics and neurobiology of circadian clocks in mammals. Cold Spring Harb.Symp.Quant.Biol. 72:251-259.

Sneddon, L.U., A.C. Taylor, F.A. Huntingford, and D.G. Watson. 2000. Agonistic behaviour and biogenic amines in shore crabs Carcinus maenas. J Exp Biol. 203:537-45.

Soehler, S., S. Neupert, R. Predel, and M. Stengl. 2008. Examination of the role of FMRFamide-related peptides in the circadian clock of the cockroach Leucophaea maderae. Cell Tissue Res. 332:257-269.

Sofia, R.D., and A.I. Salama. 1970. Circadian rhythm for experimentally-induced aggressive behavior in mice. Life Sci. 9:331-8.

Sokolove, P.G., and W.N. Bushell. 1978. The chi square periodogram: its utility for analysis of circadian rhythms. J Theor Biol. 72:131-60. 
Stach, T. 2002. Minireview: On the homology of the protocoel in Cephalochordata and 'lower' Deuterostomia. Acta Zoologica. 83:25-31.

Stanewsky, R. 2002. Clock mechanisms in Drosophila. Cell and Tissue Research. 309:11-26.

Staub, G.C., and M. Fingerman. 1984. A mechanism of action for the inhibition of black pigment dispersion in the fiddler crab, Uca pugilator, by naphthalene. Comp Biochem Physiol C. 79:447-53.

Stengl, M. 1995. Pigment-dispersing hormone-immunoreactive fibres persist in crickets which remain rhythmic after bilateral transection of the optic stalks. J Comp Physiol A. 176:217-228.

Stengl, M., and U. Homberg. 1994. Pigment-dispersing hormone-immunoreactive neurons in the cockroach Leucophaea maderae share properties with circadian pacemaker neurons. $J$ Comp Physiol A. 175:203-213.

Sternberger, L.A. 1979. Immunocytochemistry. Wiley \& Sons, New York.

Stevenson, P.A., V. Dyakonova, J. Rillich, and K. Schildberger. 2005. Octopamine and experience-dependent modulation of aggression in crickets. J Neurosci. 25:1431-41.

Stocker, A.M., and M. Huber. 2001. Fighting strategies in crayfish Orconectes rusticus (Decapoda, Cambaridae) Differ with hunger state and the presence of food cues. Ethology. 107:727-736.

Strausfeld, N.J. 2005. The evolution of crustacean and insect optic lobes and the origins of chiasmata. Arthropod Structure \& Development. 34:235-256.

Strausfeld, N.J., and D.R. Nässel. 1981. Neuroarchitectures serving compound eyes of Crustacea and insects. In Handbook of sensory physiology VII 6B. Springer Verlag, New York, Heidelberg, Berlin. 1-132.

Szewczuk, L.M., S.A. Saldanha, S. Ganguly, E.M. Bowers, M. Javoroncov, B. Karanam, J.C. Culhane, M.A. Holbert, D.C. Klein, R. Abagyan, and P.A. Cole. 2007. De novo discovery of serotonin N-acetyltransferase inhibitors. J Med Chem. 50:5330-8.

Taghert, P.H., R.S. Hewes, J.H. Park, M.A. O'Brien, M. Han, and M.E. Peck. 2001. Multiple amidated neuropeptides are required for normal circadian locomotor rhythms in Drosophila. $J$ Neurosci. 21:6673-6686.

Taghert, P.H., and O.T. Shafer. 2006. Mechanisms of clock output in the Drosophila circadian pacemaker system. J Biol Rhythms. 21:445-457.

Tamarkin, L., W.K. Westrom, A.I. Hamill, and B.D. Goldman. 1976. Effect of melatonin on the reproductive systems of male and female Syrian hamsters: a diurnal rhythm in sensitivity to melatonin. Endocrinology. 99:1534-41. 
Tamm, G.R., and J.S. Cobb. 1978. Behavior and the Crustacean Molt Cycle: Changes in Aggression of Homarus americanus. Science. 200:79-81.

Tierney, A.J., M.A. Greenlaw, K. Dams-O'Connor, S.D. Aig, and A.M. Perna. 2004. Behavioral effects of serotonin and serotonin agonists in two crayfish species, Procambarus clarkii and Orconectes rusticus. Comp Biochem Physiol A Mol Integr Physiol. 139:495-502.

Tilden, A., L. McGann, J. Schwartz, A. Bowe, and C. Salazar. 2001. Effect of melatonin on hemolymph glucose and lactate levels in the fiddler crab Uca pugilator. J Exp Zool. 290:37983.

Tilden, A.R., W.J. Anderson, and V.H. Hutchison. 1994. Melatonin in two species of damselfly, Ischnura verticalis and Enallagma civile. Journal of Insect Physiology. 40:775780 .

Tilden, A.R., R. Brauch, R. Ball, A.M. Janze, A.H. Ghaffari, C.T. Sweeney, J.C. Yurek, and R.L. Cooper. 2003. Modulatory effects of melatonin on behavior, hemolymph metabolites, and neurotransmitter release in crayfish. Brain Res. 992:252-62.

Tricoire, H., A. Locatelli, P. Chemineau, and B. Malpaux. 2002. Melatonin enters the cerebrospinal fluid through the pineal recess. Endocrinology. 143:84-90.

Vansteensel, M.J., S. Michel, and J.H. Meijer. 2008. Organization of cell and tissue circadian pacemakers: A comparison among species. Brain Res Rev. 58:18-47.

Verde, M.A., C. Barriga-Montoya, and B. Fuentes-Pardo. 2007. Pigment dispersing hormone generates a circadian response to light in the crayfish, Procambarus clarkii. Comp Biochem Physiol A Mol Integr Physiol. 147:983-92.

Vilpoux, K., R. Sandeman, and S. Harzsch. 2006. Early embryonic development of the central nervous system in the Australian crayfish and the Marbled crayfish (Marmorkrebs). Dev Genes Evol. 216:209-23.

Vivien-Roels, B., and P. Pévet. 1986. Is melatonin an evolutionary conservative molecule involved in the transduction of photoperiodic information in all living organisms? Advances in pineal research. 1:61-68.

Vivien-Roels, B., and P. Pévet. 1993. Melatonin: Presence and formation in invertebrates. Experientia. 13.:642- 647.

Vogt, G., L. Tolley, and G. Scholtz. 2004. Life stages and reproductive components of the Marmorkrebs (marbled crayfish), the first parthenogenetic decapod crustacean. J Morphol. 261:286-311.

Webb, H.M., and F.A. Brown, Jr. 1965. Interactions of diurnal and tidal rhythms in the fiddler crab, Uca pugnax. Biol Bull. 129:582-91. 
Weiss, T., S. Kreissl, and W. Rathmayer. 2003. Localization of a FMRFamide-related peptide in efferent neurons and analysis of neuromuscular effects of DRNFLRFamide (DF2) in the crustacean Idotea emarginata. Eur J Neurosci. 17:239-248.

Wildt, M., E.M. Goergen, J.L. Benton, D.C. Sandeman, and B.S. Beltz. 2004. Regulation of serotonin levels by multiple light-entrainable endogenous rhythms. J Exp Biol. 207:3765-74.

Withyachumnarnkul, B., A. Pongsa-Asawapaiboon, S. Ajpru, P. Siamwalla, W. Trakulrungsi, and C. Samritthong. 1992. Continuous light increases $\mathrm{N}$-acetyltransferase activity in the optic lobe of the giant freshwater prawn Macrobrachium rosenbergii de Man (Crustacea: Decapoda). Life Sci. 51:1479-84.

Withyachumnarnkul, B., P. Pongtippatee, and S. Ajpru. 1995. N-acetyltransferase, hydroxyindole-O-methyltransferase and melatonin in the optic lobes of the giant tiger shrimp Penaeus monodon. J Pineal Res. 18:217-21.

Würden, S., and U. Homberg. 1992. Colocalization of peptide immunoreactivities in the lamina and accessory medulla of the locust Schistocerca gregaria. In: Elsner N, Richter D (eds) Rhythmogenesis in neurons and networks. Thieme, Stuttgart New York, p 307

Würden, S., and U. Homberg. 1995. Immunocytochemical mapping of serotonin and neuropeptides in the accessory medulla of the locust, Schistocerca gregaria. J Comp Neurol. 362:305-319.

Yang, J.S., Z.M. Dai, F. Yang, and W.J. Yang. 2006. Molecular cloning of Clock cDNA from the prawn, Macrobrachium rosenbergii. Brain Res. 1067:13-24.

Zaunreiter, M., R. Brandstatter, and A. Goldschmid. 1998. Evidence for an endogenous clock in the retina of rainbow trout: I. Retinomotor movements, dopamine and melatonin. Neuroreport. 9:1205-9.

Závodská, R., I. Sauman, and F. Sehnal. 2003. Distribution of PER protein, pigmentdispersing hormone, prothoracicotropic hormone, and eclosion hormone in the cephalic nervous system of insects. J Biol Rhythms. 18:106-122.

Zulandt Schneider, R., R. Huber, and P. Moore. 2001. Individual and status recognition in the crayfish, Orconectes rusticus: the effects of urine release on fights dynamics. Behaviour. 138:137-153. 


\section{Curriculum Vitae of Abud Jose Farca Luna}

\section{Personal Information.}

Name. Abud Jose Farca Luna

Date and Place of Birth $13^{\text {th }}$ July, 1976, Mexico City

Nationality Mexican

Civil Status Married

Address. Kurze Geismar Str 33. Goettingen, 37073.

Low Saxony, Germany. +495519953730

Office Dept. Neurobiologie Institut für Zoologie und Anthropologie.

Georg August Universität Göttingen. Berliner Strasse 28,

Göttingen, 37073. Germany

+4905513991183. Fax +490551395408

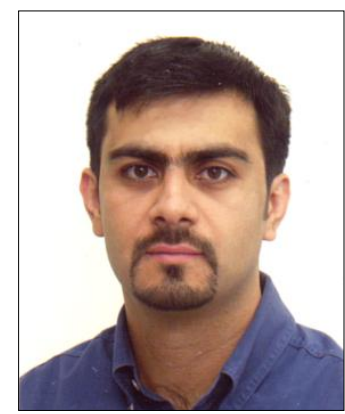

\section{Education}

$\mathrm{Ph}$ D. (Biology) Thesis. Department of Neurobiology, Institut fuer Zoologie und Anthropologie. Georg August Universitaet Goettingen. Germany. Current since April 2005. Zentrum für Biologie des Verhaltens. "Possible influences of circadian melatonin on the function of neurosecretory neurons, and serotonin-modulated behaviour in Crayfish". (DAAD).

M. in Sc. (Biology) Thesis. Invertebrate Endocrinology Lab. Department of Biology. York University. Toronto. Canada. 2002-2005 Supervisor Dr. Steel. "Melatonin and the circadian organization of the insect Rhodnius prolixus." (Conacyt)

Bachelor Thesis. Comparative Neurophysiology Lab. Science Faculty. Universidad Nacional Autonoma de México. México 1998-2000. Superivisor Dr. Fanjul Moles (Fundacion Telmex)'Effects of photoperiod and irradiance in the cardiac and respiratory frequency of the crayfish Procambarus clarkii. (Probetel, Fundacion Telmex)

\section{Achievements}

Scholarship for Ph D. DAAD. Germany. From October 2004 to December 2008.

Scholarship for M. in Sc.in Canada by Conacyt. Mexico, January, 2002 - December, 2004.

Canada-Mexico Graduate Study Grant Program DFAIT Canada, 2003

Entrance Scholarship. York University. Canada. November $26^{\text {th }}, 2001$

Scholarship for Bachelor Thesis. Fundación Telmex. Mexico 2000-2001

National Academic Exchange. Universidad Veracruzana - UNAM (Mexico). February to July 2000.

Scholarship for Academic Achivements. Fundacion Telmex. Mexico. 1997-2000

Scholarship for Social Service. SEDESOL. Mexico. 1997.

\section{Publicaions}

Circadian regulation of agonistic behaviour in groups of parthenogenetic marbled crayfish, Procambarus spec. Journal of Biological Rhythms. In press. February 2009

Homology of pigment-dispersing hormone (PDH)-immunoreactive neurons of the marbled crayfish to insect circadian pacemaker neurons. (in preparation)

Farca-Luna A., Prieto-Sagredo J., Fanjul-Moles M.L. 2002 "Effect of photoperiod and irradiance of 24 h cycles on the heart rate and ventilation of the crayfish Procambarus clarkil'. Freshwater Crayfish 14. The conference procedings.

\section{Teaching}

Academic Advisor. Studium International, George August Universitaet Goettingen (Germany) - German Buro for Academic Exchange (DAAD) - Universidad Autonoma de Nuevo Leon (Mexico). 2006-2007.

Bachelor Student Supervision. Department of Neurobiology, Institut fuer Zoologie und Anthropologie. Georg August Universitaet Goettingen. Germany. Supervision of Bachelor thesis of an exchange student in the topic "Circadian aggressive behavior in crayfish". 2006-2007. 
Teacher Assistant. Zoology Lab Course Faculty of Biology. Georg August Universitaet Goettingen. Germany. Winter, 2006, Winter, 2007.

TA. Lab Course Natural Science. Department of Biology. York University. Toronto, Canada. Fall 2003

TA. Lab Course Animal Physiology Lab. Department of Biology. York University. Toronto, Canada. Winter 2003

Organization of the minisymposium: "The clocks that role us: circadian clocks in mammals" 24th February 2006 Centrum for Systems in Neuroscience (ZNV). Max Plank Institute for Experimental Medicine, Primate Zentrum Goettingen and Georg August Universitaet-Goettingen.

\section{Meetings}

Farca Luna A., Hurtado Zavala J. and Heinrich R. 2008. Circadian agonistic behavior in the marbled crayfish Procambarus sp. FENS 2008. Geneve . Poster presentation.

Farca-Luna, T. Reischig and R. Heinrich. 2007. "Possible influences of circadian melatonin on the function of neurosecretory neurons and serotonin modulated behaviour in crayfish". 7th Goettingen Meeting of the German Neuroscience Society. (March 29-April 1, 2007). Poster Presentation.

Farca-Luna, T. Reischig and R. Heinrich.2006 "Possible influences of circadian melatonin on the function of neurosecretory neurons and serotonin modulated behaviour in crayfish". Euclock Summer School Chronobiology. Trest Chateau, Chec Republic. Poster and Oral Presentation.

DAAD Fellows Meeting. 2005. Attendance to the meeting of scholarship holders from the German Buro for Academic Exchange.

Farca-Luna and C. Steel. 2005. "Distribution and Rhythmicity of Melatonin in the Insect Rhodnius Prolixus". 10. European Pineal \& Biological Rhythms Society Congress. Frankfurt am Main, Germany. Oral Presentation.

Farca-Luna; J. Prieto-Sagredo and Fanjul Moles M. L. 2001. "Crayfish Procambarus clarkii shows two different circadian oscillators controling the heart and scaphognathite beat rate". $31^{\text {st }}$ Annual Meeting. Society for Neuroscience. San Diego, CA, USA. Poster Presentation

Farca-Luna; J. Prieto-Sagredo and Fanjul Moles M. L. 2001 "Effects of photoperiod and irradiance on the cardiac and respiratory frequency of the crayfish Procambarus clarkii " XLII National Meeting for Physiological Science. Universidad Autónoma de Nuevo Leon. Mexico. Mexican Society of Physiological Science.

Farca-Luna; J. Prieto-Sagredo and Fanjul Moles M. L. 1999. "Effects of different LD cycles on the scaphognathite beating of the crayfish Procambarus clarkii during the nectimer". XLII National Meeting for Physiological Science. Universidad Autónoma de Zacatecas. Mexico. Mexican Society of Physiological Science.

Attendance to XLI National Meeting for Physiological Science. Universidad Autónoma de San Luis Potosí. Mexico, 1998. Mexican Society of Physiological Science.

Farca-Luna A. Galindo-Miranda N. E. and J. Soria 1998 "Determinations of economically important species of whiteflies in greenhouses in Morelos, Mexico.” XXXIII National Meeting of Entomology Acapulco, Gro. Mexico. Sociedad Mexicana de Entomología. Oral Presentation and First Place Prize in Students Category.

XV Students Meeting for the Experimental Method. "Quantification of Phalacrocorax olivacious in Tuxtepec, Oaxaca". CCH-UNAM. Mexico 1995.

\section{Relevant Courses}

Circadian Activity Analysis. 14 April, 2008. MPI BPC. Goettingen.

Pens Hertie Winter School. 6-13 January 2008. The design of neuronal networks, lessons from invertebrates. Obergurgl. Austria.

Euclock Summer School in Chronobiology. Trest Chateau, Czech Republic Poster and Oral Presentation. 2006

DZG/GfE Workshop. Orthologous genes- Homologous structures (Sequence Workshop) 16-17 March. JohannFriedrich-Blumenbach-Institut fur Zoologie und Anthropologie. Entwicklungsbiologie. Dr. Bucher.

Course "Radiation Safety". Department of Ocupational Health and Safety. York University. Toronto, Canada. January $24^{\text {th }}, 2002$.

Course "Actualization in Pharmacobiology" XLII National Meeting for Physiological Science. Universidad Autónoma de Nuevo Leon and National Society of Physiological Science. Monterrey, Mexico. 2001.

Voluntieer in the monitoring of damage in coral reefs of Veracruz Mexico by AGRA. Universidad Veracruzana. Mexico. 2000 . 


\section{Memberships}

Federation of the European Neuroscience Society (Fens alumni)

Mexican Society of Physiological Science (SMCF student member)

\section{Languages}

Spanish (mother tongue)

English (fluent) TOEFLComputer-based test. 2001.

German (fluent) TestDaF Goettingen Germany. March 2005.

French Reading Comprehension. Certified by CELE, UNAM. Mexico.1998. 